\title{
Incontinence in individuals with genetic syndromes associated with intellectual disability
}

Citation for published version (APA):

Niemczyk, J. (2018). Incontinence in individuals with genetic syndromes associated with intellectual disability. [Doctoral Thesis, Maastricht University]. Datawyse / Universitaire Pers Maastricht. https://doi.org/10.26481/dis.20181023jn

Document status and date:

Published: 01/01/2018

DOI:

10.26481/dis.20181023jn

Document Version:

Publisher's PDF, also known as Version of record

\section{Please check the document version of this publication:}

- A submitted manuscript is the version of the article upon submission and before peer-review. There can be important differences between the submitted version and the official published version of record.

People interested in the research are advised to contact the author for the final version of the publication, or visit the DOI to the publisher's website.

- The final author version and the galley proof are versions of the publication after peer review.

- The final published version features the final layout of the paper including the volume, issue and page numbers.

Link to publication

\footnotetext{
General rights rights.

- You may freely distribute the URL identifying the publication in the public portal. please follow below link for the End User Agreement:

www.umlib.nl/taverne-license

Take down policy

If you believe that this document breaches copyright please contact us at:

repository@maastrichtuniversity.nl

providing details and we will investigate your claim.
}

Copyright and moral rights for the publications made accessible in the public portal are retained by the authors and/or other copyright owners and it is a condition of accessing publications that users recognise and abide by the legal requirements associated with these

- Users may download and print one copy of any publication from the public portal for the purpose of private study or research.

- You may not further distribute the material or use it for any profit-making activity or commercial gain

If the publication is distributed under the terms of Article $25 \mathrm{fa}$ of the Dutch Copyright Act, indicated by the "Taverne" license above, 


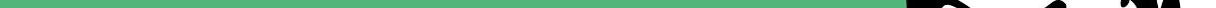


The studies presented in this thesis were performed within the collaboration of the Saarland University Hospital, Homburg, Germany and the Governor Kremers Centre, Maastricht University, The Netherlands.

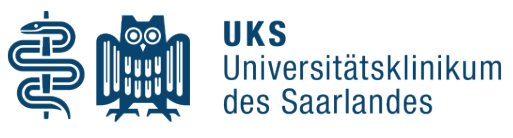

\section{Maastricht UMC+}

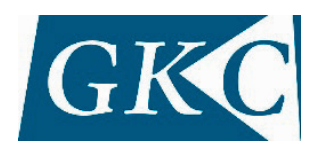




\title{
Incontinence in individuals with genetic syndromes associated with intellectual disability
}

\author{
DISSERTATION \\ to obtain the degree of Doctor at Maastricht University, \\ on the authority of the Rector Magnificus Prof. dr. Rianne M. Letschert \\ in accordance with the decision of the Board of Deans, \\ to be defended in public on \\ Tuesday, 23 October 2018, at 16.00 hours
}

by

Justine Niemczyk 


\section{Supervisors}

Prof. dr. L. M. G. Curfs

Prof. dr. A. von Gontard (Saarland University Hospital)

\section{Assessment Committee}

Prof. dr. H. Steinbusch (chair)

Prof. dr. G. van Koeveringe

Dr. S. Rahnama' i (RWTH Aachen)

Prof. dr. Ph. van Kerrebroeck

Prof. dr. D. Baeyens (University Leuven) 


\section{Content}

List of Abbreviations

List of Tables

List of Figures

Chapter 1 General Introduction

Chapter 2 Prevalence of incontinence and associated factors in four genetic syndromes

2.1 Incontinence in persons with Down Syndrome

2.2 Incontinence in persons with Noonan Syndrome

2.3 Incontinence in persons with Angelman Syndrome

2.4 Incontinence and psychological symptoms in individuals with Mowat-Wilson Syndrome

Chapter 3 Detailed assessment of incontinence in boys with Fragile-X-Syndrome in a home setting

Chapter 4 General Discussion

Summary

Samenvatting

Valorization

Acknowledgements

Curriculum vitae

Publications 


\section{List of Abbreviations}

ACC

AD

ADHD

ANS

APA

APP

AS

ASD

$\mathrm{CBCL}$

CNS

CPM

DBC

DS

DSM-5

DUI

DV

DVSS

EDNRB

EEG

ENS

$\mathrm{FI}$

FI-C

FI-NR

FXS

GI

HSCR

ICCS

ICIQ-CLUTS

ID

LUTS
Anterior cingulate cortex

Alzheimer's disease

Attention-deficit/Hyperactivity disorder

Autonomic nervous system

American Psychiatric Association

Amyloid precursor protein

Angelman Syndrome

Autism spectrum disorder

Child Behavior Checklist

Central nervous system

Coloured Progressive Matrices

Developmental Behavior Checklist

Down Syndrome

Diagnostic and Statistical Manual of Mental Disorders Fifth Edition

Daytime urinary incontinence

Dysfunctional voiding

Dysfunctional Voiding Score System

Endothelin receptor type $B$

Electroencephalogram

Enteric nervous system

Fecal incontinence

Fecal incontinence with constipation

Non-retentive fecal incontinence

Fragile-X-Syndrome

Gastro-intestinal

Hirschsprung disease

International Children's Continence Society

International-Consultation-on-Incontinence-Questionnaire Pediatric Lower Urinary Tract Symptom

Intellectual disability

Lower urinary tract symptoms 
MVV

MWS

NE

NS

OCD

ODD

PAG

PMC

PQ-EnU

PVR

PWS

RET

ROME-III/-IV

SCQ

SOD-1

SPM

UI

UPD

UTI

VP

WHO

WS

ZFHX1B
Maximum voided volume

Mowat-Wilson Syndrome

Nocturnal enuresis

Noonan Syndrome

Obsessive-compulsive disorder

Oppositional Defiant Disorder

Periaqueductal gray

Pontine micturition center

Parental Questionnaire: Enuresis/Urinary Incontinence

Post-void residual urine

Prader-Willi-Syndrome

Ret proto-oncogene

Criteria for Childhood functional gastrointestinal disorders

Social Communication Questionnaire

Superoxide dismutase-1

Standard Progressive Matrices

Urge incontinence

Uniparental disomy

Urinary tract infections

Voiding postponement

World Health Organization

Williams syndrome

Zinc finger homeobox $1 \mathrm{~B}$ 


\section{List of Tables}

Table 1: Studies on incontinence in genetic syndromes associated with ID 16

Table 2: Descriptive data and gender comparisons in Down syndrome 32

Table 3: Incontinence, LUTS and DBC-P/A data over the age groups in Down syndrome 33

Table 4: Associations of incontinence and behavioral symptoms in the clinical range: children/adolescents and adults with Down syndrome 34

Table 5: Descriptive data, prevalence of incontinence and DBC data in the total sample and age groups in Noonan syndrome

Table 6: Noonan syndrome: mean age, LUTS-score and psychological problems in continent children and adolescents (5-17 years), those with NE and those with DUI

Table 7: Angelman syndrome: descriptive data and gender comparisons, medication 56

Table 8: Incontinence, LUTS and DBC-P/A data over the age groups in Angelman syndrome

Table 9: Associations of incontinence and behavioral symptoms in the clinical range: children and teens and adults with Angelman syndrome

Table 10: Incontinence and DBC-P/A data over the genotypes of Angelman syndrome

Table 11: Incontinence and DBC-P/A data for patients with Angelman syndrome and epilepsy

Table 12: Descriptive data, somatic conditions and subgroups of incontinence of the total sample with Mowat-Wilson syndrome

Table 13: Incontinence, constipation and clinical DBC over the age groups in MowatWilson syndrome

Table 14: Adaptive toileting skills and symptoms of incontinence over the age groups in Mowat-Wilson syndrome

Table 15: Descriptive data: age, IQ, medical data, behavioral symptoms, psychological disorders (DSM-5) in boys with Fragile-X-syndrome and controls

Table 16: Incontinence, LUTS and urological findings in boys with Fragile-X-syndrome and controls

Table 17: Comparison of continent and incontinent boys with Fragile-X-syndrome

\section{List of Figures}

Figure 1: Rates of incontinence from studies presented in chapters 2.1 - 2.4 and chapter 3 by syndrome and age group 100 
Chapter

General Introduction 

Bladder and bowel control are crucial milestones in the life of every individual. The majority of children achieve continence between the age of 2 to 4 years of age. If this developmental process is disturbed, e.g. by medical conditions or impairments of the child, a delayed continence may cause distress, family problems, psychological symptoms and have an impact on social functioning and quality of life, not only in the person him/herself but in parents or caregivers. Although children with intellectual disability (ID) are at higher risk of not achieving continence, research in this field has been neglected, so far. The present thesis has the aim to examine specific manifestations of incontinence in ID focusing on five different genetic syndromes, including different phenotypes.

\section{Incontinence}

Incontinence means an involuntary excretion of urine or feces and is an umbrella term for different conditions involving the genitourinary and gastrointestinal tract, as well as specific brain regions and the central nervous system. According to the terminology of the International Children's Continence Society (ICCS), intermittent incontinence comprises nocturnal enuresis (wetting during sleep), daytime urinary incontinence (wetting during daytime) and fecal incontinence (soiling) and must be distinguished from continuous incontinence (constant leakage) which is mostly associated with organic malformations (Austin et al., 2016).

Nocturnal enuresis (NE) can be either primary (no dry period longer than six months) or secondary (dry period over six months before), and either monosymptomatic (no further incontinence or lower urinary tract symptoms (LUTS)) or non-monosymptomatic (cooccurring incontinence or LUTS). NE is diagnosed from the age of five years onwards when wetting occurs at least once per month (over three months) after excluding organic causes (Austin et al., 2016). In typically developing 7-year old children, NE is present in about $10 \%$ (male/female ratio 2:1), reducing with a spontaneous remission rate of 15\%/year to 1-2\% in adolescents and 0.5\% in adults (Butler, Golding, \& Northstone, 2005; Hirasing, Van Leerdam, Bolk-Bennink, \& Janknegt, 1997; Wright, 2015).

Daytime urinary incontinence (DUI) is diagnosed in individuals older than 5 years when wetting occurs at least once per month after ruling out organic causes (Austin et al., 2016). DUI affects about 6-8\% of 7-year-old children (Wright, 2015) and comprises a heterogeneity of subtypes. Most common in childhood is urge incontinence (or overactive bladder) with symptoms of urgency, voiding frequency and loss of small urine amounts. Further subtypes are voiding postponement (habitually postponing micturition, low frequency, holding manoeuvers) and dysfunctional voiding (contracting sphincter while voiding, interrupted flow) (Austin et al., 2016). DUI rates decrease over age similarly as in NE, with $0.5-3 \%$ of adolescents and young adults affected (Buckley \& Lapitan, 2010; Swithinbank, Brookes, Shepherd, \& Abrams, 1998). In older women, rates of DUI increase 
up to $36 \%$ due to stress incontinence (urine leakage due to higher intra-abdominal pressure while coughing, sneezing, effort or physical exertion) (Buckley \& Lapitan, 2010).

Fecal incontinence (FI) or encopresis is diagnosed in children four years or older when soiling occurs at least once per month after excluding organic causes (American Psychiatric Association (APA), 2013). As Fl is often accompanied by constipation, the ROME-III (and ROME-IV) criteria distinguish functional constipation (with/without fecal incontinence) and non-retentive fecal incontinence (Hyams et al., 2016; Rasquin et al., 2006). FI rates vary between 1-7\% in 5-7-year old children and decrease with age (1-1.5\% in 10-12 year olds) (van Der Wal, Benninga, \& Hirasing, 2005; Wright, 2015).

\section{Assessment of incontinence}

There are different methods to measure incontinence in a population. According to the guidelines of the ICCS, the ROME-III and ROME-IV criteria, a complete assessment of urinary and fecal incontinence includes a thorough history, a 48 hour daytime frequency and volume chart, a full pediatric and neurological examination, ultrasound of the renal system, bladder, rectum and post-void residual urine (PVR), and uroflowmetry (Austin et al., 2016; Hoebeke, Bower, Combs, De Jong, \& Yang, 2010; Hyams et al., 2016; Rasquin et al., 2006). All these examinations are non-invasive and should always be conducted in incontinent children to diagnose specific subtypes and introduce adequate treatment. These tools can also be used in incontinence assessment in children with genetic syndromes (von Gontard, 2013).

To receive data of incontinence from a larger study group, incontinence questionnaires are reliable instruments to gain information in clinical assessment or in research. To date, there are no standardized instruments available for incontinence in persons with ID or genetic syndromes. Therefore, studies on incontinence in these groups have applied questionnaires that are used in typically developing children, as the Dysfunctional Voiding Score System (DVSS) (Farhat et al., 2000), the International-Consultation-on-IncontinenceQuestionnaire - Pediatric Lower Urinary Tract Symptom (ICIQ-CLUTS) (De Gennaro et al., 2010) or the Parental Questionnaire: Enuresis/Urinary Incontinence (PQ-EnU) (von Gontard \& Lehmkuhl, 2009; von Gontard, 2012b). The DVSS is a short self-report questionnaire with 10 items referring to voiding dysfunctions, e.g. wetting, bowel movements or LUTS, that build a total score (Farhat et al., 2000). The ICIQ-CLUTS exists as parental and child version with 12 questions on LUTS that build a total score with good psychometric properties (De Gennaro et al., 2010). The "Parental Questionnaire: Enuresis/Urinary Incontinence" is a parental questionnaire, which is used in clinical settings to complete anamnesis (von Gontard \& Lehmkuhl, 2009; von Gontard, 2012b). The current version includes the diagnostic criteria for NE and DUI according to ICCS and was validated recently (Niemczyk, Schäfer, Becker, Equit, \& von Gontard, 2018). Further, the questionnaire can be completed by the "Encopresis Questionnaire - Screening Version" (von Gontard, 
2010; von Gontard, 2012a) with diagnostic criteria for FI and constipation according to the ROME-III criteria.

\section{Incontinence in intellectual disability}

Most typically developing individuals develop continence before the age of 4 years (Berk \& Friman, 1990; Heron, Joinson, Croudace, \& von Gontard, 2008). The remaining small group of individuals has either a delayed development of voluntary bladder and bowel function or has chronic or relapsing incontinence which is reflected by the decreasing prevalence rates over age.

Intellectual disability (ID) is defined as deficits in intellectual functioning (e.g. reasoning, learning) and in adaptive behavior covering communication, social skills, personal independence and school/work functioning, occurring during the developmental period (APA, 2013). According to the ICD-10, ID is subdivided into four different levels: mild ID (IQ 50-69), moderate ID (IQ 35-49), severe (IQ 20-34) and profound (IQ<20) (World Health Organization (WHO), 1993). The overall prevalence of ID in the population is estimated $1 \%$ which was confirmed by a recent meta-analysis (Maulik, Mascarenhas, Mathers, Dua, \& Saxena, 2011).

In individuals with ID, prevalence of incontinence is 2 to 4 times higher than in typically developing persons. In a population-based sample of 3206 seven-year-old children with ID prevalence of NE was $26.6 \%$ (vs. 9.8\% in the total sample) (Jarvelin, VikevainenTervonen, Moilanen, \& Huttunen, 1988). Von Wendt et al. examined a whole cohort of 132 individuals with ID at the age of 7 years and again at the age of 20 years regarding bladder and bowel control (von Wendt, Simila, Niskanen, \& Jarvelin, 1990). At 7 years, rates for NE, DUI and FI were 38\%, 39\% and 30.5\%, respectively. At the age of 20 years, still 20\%, 20\%, and 19\% had NE, DUI and FI. The rates varied also between individuals with different levels of ID: $3-17 \%$ of seven-year-olds with mild ID and $86-100 \%$ with profound ID had incontinence. At age 20, incontinence was 0-6\% in the mild ID group, but still 57-79\% in the profound ID group (von Wendt et al., 1990). Other studies also found high incontinence rates among adults with ID (26-56\%) (de Waal, Tinselboer, Evenhuis, \& Penning, 2009; van Timmeren, van der Putten, van Schrojenstein Lantman-de Valk, van der Schans, \& Waninge, 2016) and associations with adaptive skills (Belva, Matson, Barker, Shoemaker, \& Mahan, 2011).

There are only few studies that examined incontinence in individuals with ID and included sonography or uroflowmetry. A Taiwanese research group examined voiding dysfunction in 51 children with ID (mean age 7.7 years) and 36 controls without ID (mean age 6.4 years) (Yang, Meng, \& Chou, 2010). The ID group had more incomplete bladder emptying or interrupted flows (35.2\%), incontinence and smaller bladder capacities than the controls (8.3\%). Further, more symptoms occurred in patients with severe ID compared to mild ID (Yang et al., 2010). 
Van Laecke et al. examined 111 children (mean age 9.1 years), of whom 22 had motor disability, 16 had ID and 73 had ID+motor disability (van Laecke, Raes, Vande Walle, \& Hoebeke, 2009). Incontinence rates were similar in all three groups (64\% motor, 63\% ID, $59 \%$ both), whereas the rates of NE were highest in the ID group (25\%). 33.3\% had FI and $27 \%$ had constipation. Further findings showed that only $10 \%$ had an adequate fluid intake and $11 \%$ had an age-adequate maximum voided volume (van Laecke et al., 2009). De Waal et al. performed abdominal ultrasound in 346 adults (18-82 years) with moderate and severe ID and found an elevated post-void residual urine (PVR) in $8.7 \%$ and incontinence in $26.3 \%$ (de Waal et al., 2009). Elevated PVR was associated with profound ID, age, chronic illness, incontinence, laxative use and immobility (de Waal et al., 2009).

Although research in the field of incontinence and ID is scarce, the results show that incontinence is more prevalent among persons with ID and persists more often into adulthood than in typically developing persons. In addition, incontinence is associated with many other symptoms e.g. LUTS or incomplete bladder emptying which can impede or complicate treatment.

\section{Incontinence in genetic syndromes associated with intellectual disability}

Although etiology of ID includes prenatal, perinatal and postnatal causes, in most cases a genetic etiology can be detected. Therefore, it is important to concentrate on specific genetic syndromes when examining incontinence in ID. Genetic causes (including specific syndromes and chromosomal aberrations) account for $25 \%$ of cases in persons with mild ID and in even for 43-48\% in persons with severe ID (Lundvall, Rajaei, Erlandson, \& Kyllerman, 2012; Strømme \& Hagberg, 2000). As techniques in genetic testing are advancing, more chromosomal micro-aberrations and copy number variations will be detected in future including more possible genetic causes of ID.

Incontinence has not been examined systematically in genetic syndromes, yet. First research results exist in eight genetic syndromes that are associated with ID (Angelman, Down, Fragile-X, Prader-Willi, Williams, Rett, Velocardiofacial syndrome and Tuberous Sclerosis). Table 1 gives an overview of incontinence rates found in samples with genetic syndromes, differentiated by the methodology that was used.

Incontinence prevalence varies between different syndromes, especially between those associated with mild/moderate and those with severe/profound ID. For example, incontinence rates are lower in publications on Prader-Willi syndrome (Equit, Piro-Hussong, Niemczyk, Curfs, \& von Gontard, 2013; von Gontard, Didden, Sinnema, \& Curfs, 2010) or Velocardiofacial syndrome (Antshel et al., 2010) than in studies on Angelman (Buntinx et al., 1995; Didden, Korzilius, Smits, \& Curfs, 2004; Laan, Den Boer, Hennekam, Renier, \& Brouwer, 1996; Radstaake et al., 2013) or Rett syndrome (Giesbers et al., 2012).

Further, incontinence differs within age groups of a syndrome. In publications that included different age groups, incontinence rates were usually higher in childhood than 
in adolescents or adults, as was shown for Williams syndrome (von Gontard et al., 2016), Down syndrome (De Carvalho Mrad et al., 2014), Angelman syndrome (Buntinx et al., 1995; Radstaake et al., 2013), Prader-Willi and Fragile-X syndrome (Equit et al., 2013). But to date, there exists only one longitudinal study (on Velocardiofacial syndrome) that showed a significant reduction of enuresis after three years (Antshel et al., 2010), as well.

The research on incontinence in genetic syndromes is scarce, differing in methodology, sample sizes and sample populations. Only one study assessed incontinence according to the "gold standard" including a history, bladder diary, physical examination, uroflowmetry and ultrasound (Sammour, Gomes, Duarte, Trigo-Rocha, \& Srougi, 2006). Many other assessments used questionnaires, which is an efficient way to gain first information in a larger sample, but always bear the disadvantage of relying on parental/caregiver opinions.

Another important aspect to consider is the assessment of the behavioral phenotype. In the typically developing population, incontinence is highly associated with psychological symptoms, which are found more often in incontinent than in continent children (Joinson, Heron, \& von Gontard, 2006; Joinson, Heron, Butler, \& von Gontard, 2006; Joinson, Heron, Emond, \& Butler, 2007). Psychiatric comorbidity (e.g. ADHD) can reduce treatment compliance and outcome (Crimmins, Rathbun, \& Husmann, 2003). Associations between the behavioral phenotype and incontinence also exist in genetic syndromes, as was shown for Fragile-X or Down syndrome (Equit et al., 2013; Mantry et al., 2008) and should therefore be always included to the assessment. 


\section{Chapter 1}

Table 1: Studies on incontinence in genetic syndromes associated with ID

\begin{tabular}{|c|c|c|c|c|c|}
\hline Authors & $\begin{array}{l}\text { Syndrome } \\
\text { (n) }\end{array}$ & $\begin{array}{l}\text { Age range } \\
\text { (Mean age) }\end{array}$ & Prevalence & Associations & Instrument \\
\hline \multicolumn{6}{|c|}{ Incontinence examination } \\
\hline $\begin{array}{l}\text { Kitamura et al. } \\
\text { (2014) }\end{array}$ & DS (55) & $5-15\left(9.0^{1}\right)$ & \multicolumn{2}{|l|}{$\begin{array}{l}\text { Urinary incontinence } 47 \% \text {, - } \\
\text { abnormal voiding pattern } \\
66 \% \text {, PVR } 7 \%\end{array}$} & $\begin{array}{l}\text { ultrasound, } \\
\text { uroflowmetry }\end{array}$ \\
\hline $\begin{array}{l}\text { Sammour et al. } \\
\text { (2006) }\end{array}$ & WS (28) & $3-19(9.7)$ & $\begin{array}{l}\text { NE 50\%, DUI 43\% (Urge } \\
\text { incontinence) }\end{array}$ & $\begin{array}{l}\text { voiding } \\
\text { symptoms* quality of life }\end{array}$ & $\begin{array}{l}\text { history, physical } \\
\text { examination, } \\
\text { ultrasound, } \\
\text { uroflowmetry, Q }\end{array}$ \\
\hline $\begin{array}{l}\text { Schulman et al. } \\
\text { (1996) }\end{array}$ & WS (41) & $1-43(9.4)$ & $\begin{array}{l}\text { Urinary symptoms } 32 \% \\
\text { (UTI, frequency, } \\
\text { incontinence); NE } 70 \% \text {, } \\
\text { DUI } 70 \%^{2}\end{array}$ & - & $\begin{array}{l}\text { Physical } \\
\text { examination, } \\
\text { ultrasound }\end{array}$ \\
\hline \multicolumn{6}{|c|}{ Incontinence questionnaire } \\
\hline $\begin{array}{l}\text { de Carvalho Mrad } \\
\text { et al. (2014) }\end{array}$ & DS (102) & $4-57(19.3)$ & LUTS $24 \%$ & LUTS*age, *gender & DVSS \\
\hline $\begin{array}{l}\text { Powers et al. } \\
\text { (2015) }\end{array}$ & DS (77) & $0-27(10.3)$ & $\begin{array}{l}\text { Incontinence } 46 \%, \mathrm{UTI} \\
21 \%\end{array}$ & - & Q \\
\hline $\begin{array}{l}\text { von Gontard et al. } \\
(2016)\end{array}$ & WS (231) & $4-59(19.4)$ & $\begin{array}{l}\text { NE } 18 \% \text {, DUI } 6 \% \text {, FI } 8 \% \text {, } \\
\text { LUTS } 4 \%\end{array}$ & $\begin{array}{l}\text { DUI*behavioral } \\
\text { symptoms }\end{array}$ & $\begin{array}{l}\text { PQ-EnU; ICIQ- } \\
\text { CLUTS }\end{array}$ \\
\hline $\begin{array}{l}\text { von Gontard et al. } \\
\text { (2010) }\end{array}$ & PWS (118) & $5-45(15.1)$ & NE 14\%, DUI 4\%, FI 3\% & - & PQ-EnU \\
\hline Equit et al. (2013) & $\begin{array}{l}\text { PWS (191) } \\
\text { FXS (166) }\end{array}$ & $\begin{array}{l}4-52(20.0) \\
4-52(15.4)\end{array}$ & $\begin{array}{l}\text { PWS: NE 22\%, DUI 12\%, FI } \\
13 \% \\
\text { FXS: NE 29\%, DUI 30\%, FI } \\
29 \%\end{array}$ & $\begin{array}{l}\text { I FXS: } \\
\text { Incontinence*behavior }\end{array}$ & $P Q-E n U$ \\
\hline $\begin{array}{l}\text { Radstaake et al. } \\
\text { (2013) }\end{array}$ & AS (71) & $6-45(20.5)$ & NE 89\%, DUI 54\%, FI 61\% & $\begin{array}{l}\text { NE*epilepsy; DUI*age, } \\
\text { *adaptive functioning }\end{array}$ & PQ-EnU \\
\hline $\begin{array}{l}\text { Giesbers et al. } \\
(2012)\end{array}$ & RS (63) & $5-47(19.3)$ & NE 98\%, DUI 97\%, FI 72\% & $\begin{array}{l}\text { urinary tract infection } \\
(\mathrm{UTI})^{*} \text { epilepsy, } \\
\text { *scoliosis }\end{array}$ & $P Q-E n U$ \\
\hline \multicolumn{6}{|c|}{ Diagnostic Interview/DSM-IV diagnoses } \\
\hline $\begin{array}{l}\text { Antshel et al. } \\
(2010)\end{array}$ & VCFS (70) & $11.8 ; 15.0$ & $\begin{array}{l}\text { NE 15\%, FI 4\%; } 3 \text { years } \\
\text { later: NE } 9 \% \mathrm{FI} 0 \%\end{array}$ & $\begin{array}{l}\text { significant reduction of } \\
\text { NE with age }\end{array}$ & $\begin{array}{l}\text { DI; DSM-IV } \\
\text { diagnoses; } \\
\text { longitudinal }\end{array}$ \\
\hline Gabis et al. (2011) & ) FXS (22) & $4-29(14.2)$ & NE 41\%, FI 36\% & - & $\begin{array}{l}\text { DI; DSM-IV } \\
\text { diagnoses }\end{array}$ \\
\hline $\begin{array}{l}\text { Backes et al. } \\
(2000)\end{array}$ & $\begin{array}{l}\text { FXS (49) } \\
\text { TSC (16) }\end{array}$ & $\begin{array}{l}5-16(8.5) \\
5-17(9.4)\end{array}$ & $\begin{array}{l}\text { FXS: NE } 27 \% \text {, FI } 20 \% \\
\text { TSC: NE } 13 \%, \text { FI } 6 \%\end{array}$ & - & $\begin{array}{l}\text { DI; DSM-IV } \\
\text { diagnoses }\end{array}$ \\
\hline $\begin{array}{l}\text { Pegoraro et al. } \\
\text { (2014) }\end{array}$ & $\begin{array}{l}\text { WS (10) } \\
\text { PWS (11) } \\
\text { FXS (13) }\end{array}$ & $\begin{array}{l}6-16(11.7) \\
6-16(11.1) \\
6-16(12.0)\end{array}$ & $\begin{array}{l}\text { WS: NE } 30 \% \\
\text { PWS: NE } 18 \% \\
\text { FXS: NE } 30 \%\end{array}$ & $\begin{array}{l}\text { No significant difference } \\
\text { in NE between } \\
\text { syndromes }\end{array}$ & $\begin{array}{l}\text { CR; DSM-IV } \\
\text { diagnoses }\end{array}$ \\
\hline
\end{tabular}




\begin{tabular}{|c|c|c|c|c|c|}
\hline Authors & $\begin{array}{l}\text { Syndrome } \\
\text { (n) }\end{array}$ & $\begin{array}{l}\text { Age range } \\
\text { (Mean age) }\end{array}$ & Prevalence & Associations & Instrument \\
\hline \multicolumn{6}{|c|}{ Other questionnaires/interviews/examinations (not incontinence-specific) } \\
\hline Lin et al. (2015) & DS (208) & $>15$ & Incontinence $11 \%$ & $\begin{array}{l}\text { Incontinence as onset } \\
\text { aging condition }\end{array}$ & Q \\
\hline $\begin{array}{l}\text { Chicoine \& Sulo } \\
\text { (2015) }\end{array}$ & DS (66) & 36.6 & NE $24 \%$, DUI $27 \%$ & - & Q \\
\hline $\begin{array}{l}\text { Brushini et al. } \\
\text { (2003) }\end{array}$ & DS (15) & $7-10$ & \multicolumn{2}{|l|}{ Urinary incontinence $73 \%$ - } & I \\
\hline $\begin{array}{l}\text { Mantry et al. } \\
(2008)\end{array}$ & DS (186) & $16-74(41.1)$ & \multicolumn{3}{|c|}{$\begin{array}{l}\text { Urinary incontinence 23\%, Urinary Health Check } \\
\begin{array}{ll}\text { FI } 17 \% & \text { incontinence* psychiatric } \\
& \text { disorder }\end{array}\end{array}$} \\
\hline $\begin{array}{l}\text { Annaz et al. } \\
\text { (2011) }\end{array}$ & WS (64) & $6-12(8.3)$ & NE 51\% & - & $\mathrm{CSHQ}$ \\
\hline $\begin{array}{l}\text { Didden et al. } \\
(2004)\end{array}$ & AS (109) & $2-44(15.2)$ & NE 93\% & - & Q \\
\hline Bruni et al. (2004) & AS (49) & $2-26(10.1)$ & NE $35 \%$ & - & Q \\
\hline Laan et al. (1996) & AS (28) & $20-53(32.0)$ & DUI 43\% & - & $\begin{array}{l}\text { history, } \\
\text { physical } \\
\text { examination }\end{array}$ \\
\hline \multicolumn{6}{|c|}{ Retrospective analyses } \\
\hline $\begin{array}{l}\text { Morris et al. } \\
(1988)\end{array}$ & WS (42) & $1-34$ & NE 52\% & - & $\begin{array}{l}\text { medical } \\
\text { records } \\
\text { review }\end{array}$ \\
\hline $\begin{array}{l}\text { Buntinx et al. } \\
\text { (1995) }\end{array}$ & AS (47) & $\begin{array}{l}2-16 \\
>16\end{array}$ & $\begin{array}{l}\text { DUI } 63 \% \\
\text { DUI } 13 \%\end{array}$ & - & $\begin{array}{l}\text { retrospective } \\
\text { review }\end{array}$ \\
\hline
\end{tabular}

AS = Angelman syndrome; DS = Down syndrome; FXS = Fragile-X-syndrome; PWS = Prader-Willi syndrome; RS = Rett syndrome; TSC = Tuberous Sclerosis; VCFS = Velocardiofacial syndrome; $W S=$ Williams syndrome LUTS = Lower Urinary Tract Symptoms; PVR = post-void residual urine; UTI = Urinary tract infection $\mathrm{CSHQ}=$ Child Sleep Habit Questionnaire; DVSS = Dysfunctional Voiding Score System; CR = Clinical Rating; DI = Diagnostic Interview; I = Non-standardized Interview; ICIQ-CLUTS = International-Consultation-on-Incontinence-Questionnaire - Pediatric Lower Urinary Tract Symptom (De Gennaro et al., 2010); PQ-EnU = Parental Questionnaire: Enuresis/Urinary Incontinence (von Gontard, 2009); Q = Self-Administered Questionnaire

${ }^{1}$ Median age

${ }^{2} \mathrm{NE}$ and DUI rates were assessed only in $n=10$

\section{Outline of the thesis and research questions}

The aim of this thesis is to assess incontinence and psychopathology in a standardized way in five different genetic syndromes that are associated with ID. The assessed syndromes should include different levels of ID, therefore Noonan (average IQ - mild ID), Down (mild - moderate ID), Fragile-X (moderate ID), Angelman and Mowat-Wilson (both severe - profound ID) syndromes were chosen.

In the first part (Chapter 2), incontinence and behavioral symptoms were assessed by parental questionnaires in four different genetic syndromes (Down, Noonan, Angelman 
and Mowat-Wilson syndrome). To describe incontinence, a combined version of the "Parental Questionnaire: Enuresis/Urinary Incontinence" (von Gontard \& Lehmkuhl, 2009; von Gontard, 2012b), which was already used in assessing incontinence in genetic syndromes before (Equit et al., 2013; Giesbers et al., 2012; Radstaake et al., 2013; von Gontard et al., 2010), the "Encopresis Questionnaire - Screening Version" (von Gontard, 2010; von Gontard, 2012a) and the ICIQ-CLUTS (De Gennaro et al., 2010) was applied to the study populations.

In addition, behavioral and psychological symptoms were measured by the Developmental Behavior Checklist (DBC) (Einfeld \& Tonge, 1995; Mohr, Tonge, Einfeld \& Taffe, 2011), a standardized instrument especially for persons with ID with separate norms for mild, moderate and severe ID (Einfeld \& Tonge, 1995). The combination of the incontinence questionnaire and the DBC allows the description of the behavioral phenotype of each syndrome and the association of behavior and incontinence symptoms.

The following research questions are addressed in Chapter 2:

1. What is the prevalence of incontinence overall, incontinence subtypes (NE, DUI, FI), constipation and LUTS in Down syndrome? Are there prevalence differences in gender or age groups? Are incontinence, LUTS or constipation associated with behavioral symptoms?

2. What is the prevalence of incontinence overall, incontinence subtypes (NE, DUI, FI) and LUTS in Noonan syndrome? Are there prevalence differences in age groups? Is incontinence associated with behavioral symptoms?

3. What is the prevalence of incontinence overall, incontinence subtypes (NE, DUI, FI), constipation, and LUTS in Angelman syndrome? Are there prevalence differences in gender, age group or genotype? Are incontinence, LUTS or constipation associated with behavioral symptoms or epilepsy?

4. What is the prevalence of incontinence overall, incontinence subtypes (NE, DUI, FI), constipation and LUTS in Mowat-Wilson syndrome? Are there prevalence differences in gender or age groups? How good are adaptive toileting skills developed in MowatWilson syndrome? Are there associations between behavioral symptoms and incontinence?

In the second part of the thesis (Chapter 3 ) incontinence is examined in children and adolescents with Fragile-X syndrome and a control group of typically developing children and adolescents not just by questionnaires, but also by a full medical, urological and psychiatric assessment.

The following research questions are addressed in Chapter 3:

5. What is the prevalence of incontinence in Fragile-X syndrome compared to a typically developing control group? Which specific subtypes of NE, DUI and FI can be diagnosed in Fragile-X syndrome? Are there differences in examination findings (ultrasound, uroflow), voiding and drinking habits and psychiatric diagnoses between children with 
Fragile-X syndrome and typically developing children? Are there differences in examination findings (ultrasound, uroflow), voiding and drinking habits and psychiatric diagnoses between Fragile- $X$ syndrome children with and without incontinence?

\section{Incontinence in persons with Down Syndrome}

Down Syndrome (DS) is the most common genetic cause of ID caused by trisomy of chromosome 21 and is accompanied by many different medical conditions, e.g. heart defects (Charleton, Dennis, \& Marder, 2010; Roizen, \& Patterson, 2003). Incontinence in DS was described in $46-73 \%$ of children and $11-27 \%$ of adults with DS (Brushini, Faria, Garcez, \& Srougi, 2003; Chicoine \& Sulo, 2015; Kitamura et al., 2014; Lin et al., 2015; Mantry et al., 2008; Powers et al., 2015). No study has differentiated between the subtypes NE, DUI and $\mathrm{FI}$ and no study has assessed associated psychological factors in incontinence in DS, so far. Therefore, the aim of the study was to analyze subtypes of functional incontinence and psychological symptoms in different age groups of individuals with DS with parental questionnaires on incontinence and psychopathology. The results of 317 individuals with DS (4-51 years, mean age 19.2 years) are presented in Chapter 2.1.

\section{Incontinence in persons with Noonan Syndrome}

Noonan Syndrome (NS) is an autosomal dominant, neurodevelopmental disorder with a high phenotypic variability due to mutations in several genes of the RAS-MAPK signaling pathways on the chromosomal band 12q24.1 (Roberts, Allanson, Tartaglia, \& Gelb, 2013). ID is described in 20-30\%, under-average IQ (70-84) in about 40\% (Lee, Portnoy, Hill, Gillberg, \& Patton, 2005). As incontinence in NS has not been assessed before, the aim of the study was to discover prevalence rates of NE, DUI and FI in a sample on 29 individuals with NS (5-48 years, mean age 15.3 years). Further, differences in age groups (children, adolescents, young adults, adults) and the association with psychological symptoms were examined. Psychological symptoms and incontinence were assessed by parental questionnaires. The results are outlined in Chapter 2.2.

\section{Incontinence in persons with Angelman Syndrome}

Angelman Syndrome (AS) is caused by a microdeletion or uniparental disomy (UPD) of chromosome 15q11-13, which leads to severe ID, typical dysmorphic signs and several medical conditions, e.g. epilepsy (Thibert, Larson, Hsieh, Raby, \& Thiele, 2013). Incontinence rates range between 13\% and 93\% (Buntinx et al., 1995; Didden et al., 2004; Laan et al., 1996; Radstaake et al., 2013), which were assessed with different methods and in different populations. The study results presented in Chapter 2.3 assessed incontinence and psychological symptoms by parental questionnaires in 144 persons with AS (4-31 years, mean age 15.1 years). In addition, associations between incontinence and psychopathology, seizures and genotype were examined. 
Incontinence and psychological symptoms in individuals with Mowat-Wilson syndrome

Mowat-Wilson Syndrome (MWS) is caused by a deletion or mutation of the ZEB2 gene on chromosome 2q22 leading to severe ID and other anomalies, e.g. seizures or Hirschsprung disease (HSCR) (Mowat \& Wilson, 2010). Incontinence has only been examined in case reports, so far (Adam et al., 2006). In Chapter 2.4, results of a first systematic examination on incontinence and associated psychological factors in MWS are presented. In total, parental questionnaires of 48 individuals with MWS (4-33 years, mean age 13.0 years) were evaluated.

Detailed assessment of incontinence in boys with Fragile-X-Syndrome in a home setting

Fragile-X-Syndrome (FXS) is caused by a mutation of the FMR1 gene located on Xq27.3 leading to ID and dysmorphic features especially in males (Brown, 2002; Gallagher \& Hallahan, 2012). Incontinence is present in about 20-30\% of individuals with FXS, with children being more affected than adults. Also, DUI and psychological symptoms are associated (Backes et al., 2000; Equit et al., 2013; Gabis, Baruch, Jokel, \& Raz, 2011; Pegoraro, Steiner, Celeri, Banzato, \& Dalgalarrondo, 2014). As incontinence has only been assessed by parental questionnaires or psychiatric interviews so far, this study examined incontinence and psychiatric comorbidity with a full somatic, urological and psychiatric assessment in 22 boys with FXS (4-17 years, mean age 11.0 years) and 22 typically developing boys (4-17 years, mean age 11.1 years). The results are presented in Chapter 3.

The results of the studies are discussed in Chapter 4 addressing study populations, methodological considerations and clinical implications. In addition, an outlook into future research on incontinence in genetic syndromes will be provided. 


\section{References}

Adam, M. P., Schelley, S., Gallagher, R., Brady, A. N., Barr, K., Blumberg, B., . . Hudgins, L. (2006). Clinical features and management issues in Mowat-Wilson syndrome. American Journal of Medical Genetics, Part A, 140(24), 2730-2741.

American Psychiatric Association (APA). (2013). Diagnostic and statistical manual of mental disorders - Fifth edition (DSM 5). Washington, D.C.: APA.

Antshel, K. M., Shprintzen, R., Fremont, W., Higgins, A. M., Faraone, S. V., \& Kates, W. R. (2010). Cognitive and psychiatric predictors to psychosis in velocardiofacial syndrome: A 3-year follow-up study. Journal of the American Academy of Child and Adolescent Psychiatry, 49(4), 333-344.

Annaz, D., Hill, C. M., Ashworth, A., Holley, S., \& Karmiloff-Smith, A. (2011). Characterisation of sleep problems in children with Williams syndrome. Research in developmental disabilities, 32(1), 164-169.

Austin, P.F., Bauer, S.B., Bower, W., Chase, J., Franco, I., Hoebeke, P., ... , Yang, S. S. (2016). The Standardization of Terminology of Lower Urinary Tract Function in Children and Adolescents: Update Report from the Standardization Committee of the International Children's Continence Society. Neurourology \& Urodynamics, 35(4), 471-481.

Backes, M., Genç, B., Schreck, J., Doerfler, W., Lehmkuhl, G., \& von Gontard, A. (2000). Cognitive and behavioral profile of fragile X boys: Correlations to molecular data. American Journal of Medical Genetics, 95(2), 150156.

Belva, B., Matson, J. L., Barker, A., Shoemaker, M. E., \& Mahan, S. (2011). The relationship between adaptive behavior and specific toileting problems according to the profile on toileting issues (POTI). Journal of Developmental and Physical Disabilities, 23(6), 535-542.

Berk, L. B., \& Friman, P. C. (1990). Epidemiologic aspects of toilet training. Clinical Pediatrics, 29(5), $278-282$.

Brown, T. (2002). The molecular biology of the fragile X mutation In R. J. Hagerman, \& P. J. Hagerman (Eds.), Fragile $X$ syndrome: Diagnosis, treatment, and research. Baltimore: Johns Hopkins University Press.

Bruni, O., Ferri, R., D'Agostino, G., Miano, S., Roccella, M., \& Elia, M. (2004). Sleep disturbances in Angelman syndrome: a questionnaire study. Brain and Development, 26(4), 233-240.

Brushini, H., Faria, N., Garcez, E., \& Srougi, M. (2003). Development of bladder control in mentally handicapped children. International Braz J Urol, 29(5), 455-458.

Buckley, B. S., \& Lapitan, M. C. M. (2010). Prevalence of urinary incontinence in men, women, and childrencurrent evidence: Findings of the fourth international consultation on incontinence. Urology, 76(2), 265270.

Buntinx, I. M., Hennekam, R. C., Brouwer, O. F., Stroink, H., Beuten, J., Mangelschots, K., \& Fryns, J. P. (1995). Clinical profile of angelman syndrome at different ages. American Journal of Medical Genetics, 56(2), 176183.

Butler, R. J., Golding, J., \& Northstone, K. (2005). Nocturnal enuresis at 7.5 years old: Prevalence and analysis of clinical signs. BJU International, 96(3), 404-410.

Charleton, P. M., Dennis, J., \& Marder, E. (2010). Medical management of children with Down syndrome. Paediatrics and Child Health, 20(7), 331-337.

Chicoine, B., \& Sulo, S. (2015). Rate of urinary retention in adults with Down syndrome: A prospective study. Journal of the American Board of Family Medicine, 28(1), 115-117.

Crimmins, C. R., Rathbun, S. R., \& Husmann, D. A. (2003). Management of urinary incontinence and nocturnal enuresis in attention-deficit hyperactivity disorder. The Journal of Urology, 170(4, Part 1), 1347-1350.

de Carvalho Mrad, F. C., De Bessa, J., De Rezende Duarte, A. M. B., Vieira, A. A. P., Araujo, F. C. C., De Camargo, M. L. S., . . Netto, J. M. B. (2014). Prevalence of lower urinary tract symptoms in individuals with down syndrome. Journal of Pediatric Urology, 10(5), 844-849.

de Gennaro, M., Niero, M., Capitanucci, M. L., von Gontard, A., Woodward, M., Tubaro, A., \& Abrams, P. (2010). Validity of the international consultation on incontinence questionnaire-pediatric lower urinary tract symptoms: A screening questionnaire for children. Journal of Urology, 184(4 SUPPL.), 1662-1667. 
de Waal, K. H., Tinselboer, B. M., Evenhuis, H. M., \& Penning, C. (2009). Unnoticed post-void residual urine volume in people with moderate to severe intellectual disabilities: Prevalence and risk factors. Journal of Intellectual Disability Research, 53(9), 772-779.

Didden, R., Korzilius, H., Smits, M. G., \& Curfs, L. M. G. (2004). Sleep problems in individuals with Angelman syndrome. American Journal on Mental Retardation, 109(4), 275-284.

Einfeld, S., \& Tonge, B. (1995). Manual for the Developmental behavior checklist - primary carer version (DBC-P) \& teacher version (DBC-T)(2nd ed.). Clayton, Melbourne: Monash University Centre for Developmental Psychiatry and Psychology.

Equit, M., Piro-Hussong, A., Niemczyk, J., Curfs, L., \& von Gontard, A. (2013). Elimination disorders in persons with prader-willi and fragile-X syndromes. Neurourology and Urodynamics, 32(7), 986-992.

Farhat, W., Bägli, D. J., Capolicchio, G., O'Reilly, S., Merguerian, P. A., Khoury, A., \& McLorie, G. A. (2000). The dysfunctional voiding scoring system: Quantitative standardization of dysfunctional voiding symptoms in children. Journal of Urology, 164(3 II), 1011-1015.

Gabis, L. V., Baruch, Y. K., Jokel, A., \& Raz, R. (2011). Psychiatric and autistic comorbidity in fragile X syndrome across ages. Journal of Child Neurology, 26(8), 940-948.

Gallagher, A., \& Hallahan, B. (2012). Fragile X-associated disorders: A clinical overview. Journal of Neurology, 259(3), 401-413.

Giesbers, S., Didden, R., Radstaake, M., Korzilius, H., von Gontard, A., Lang, R., . . Curfs, L. M. (2012). Incontinence in individuals with Rett syndrome: A comparative study. Journal of Developmental and Physical Disabilities, 24(3), 287-300.

Heron, J., Joinson, C., Croudace, T., \& von Gontard, A. (2008). Trajectories of daytime wetting and soiling in a united kingdom 4 to 9-year-old population birth cohort study. Journal of Urology, 179(5), 1970-1975.

Hirasing, R. A., Van Leerdam, F. J. M., Bolk-Bennink, L., \& Janknegt, R. A. (1997). Enuresis nocturna in adults. Scandinavian Journal of Urology and Nephrology, 31(6), 533-536.

Hoebeke, P., Bower, W., Combs, A., De Jong, T., \& Yang, S. (2010). Diagnostic evaluation of children with daytime incontinence. The Journal of Urology, 183(2), 699-703.

Hyams, J. S., Di Lorenzo, C., Saps, M., Shulman, R. J., Staiano, A., \& Van Tilburg, M. (2016). Childhood functional gastrointestinal disorders: Child/adolescent. Gastroenterology, 150(6), 1456-1468e2.

Jarvelin, M. R., Vikevainen-Tervonen, L., Moilanen, I., \& Huttunen, N. (1988). Enuresis in seven-year-old children. Acta Paediatrica Scandinavica, 77(1), 148-153.

Joinson, C., Heron, J., Butler, U., \& von Gontard, A. (2006). Psychological differences between children with and without soiling problems. Pediatrics, 117(5), 1575-1584.

Joinson, C., Heron, J., Emond, A., \& Butler, R. (2007). Psychological problems in children with bedwetting and combined (day and night) wetting: A UK population-based study. Journal of Pediatric Psychology, 32(5), 605-616.

Joinson, C., Heron, J., \& von Gontard, A. (2006). Psychological problems in children with daytime wetting. Pediatrics, 118(5), 1985-1993.

Kitamura, A., Kondoh, T., Noguchi, M., Hatada, T., Tohbu, S., Mori, K., . . Moriuchi, H. (2014). Assessment of lower urinary tract function in children with Down syndrome. Pediatrics International, 56(6), 902-908.

Laan, L. A. E. M., Den Boer, A. T., Hennekam, R. C. M., Renier, W. O., \& Brouwer, O. F. (1996). Angelman syndrome in adulthood. American Journal of Medical Genetics, 66(3), 356-360.

Lee, D. A., Portnoy, S., Hill, P., Gillberg, C., \& Patton, M. A. (2005). Psychological profile of children with Noonan syndrome. Developmental Medicine and Child Neurology, 47(1), 35-38.

Lin, J., Lin, L., Hsu, S., Chen, W., Lin, F., Wu, J., \& Chu, C. (2015). Are early onset aging conditions correlated to daily activity functions in youth and adults with down syndrome? Research in Developmental Disabilities, 36, 532-536.

Lundvall, M., Rajaei, S., Erlandson, A., \& Kyllerman, M. (2012). Aetiology of severe mental retardation and further genetic analysis by high-resolution microarray in a population-based series of 6- to 17-year-old children. Acta Paediatrica, International Journal of Paediatrics, 101(1), 85-91. 
Mantry, D., Cooper, S., Smiley, E., Morrison, J., Allan, L., Williamson, A., . . Jackson, A. (2008). The prevalence and incidence of mental ill-health in adults with Down syndrome. Journal of Intellectual Disability Research, 52(2), 141-155.

Maulik, P. K., Mascarenhas, M. N., Mathers, C. D., Dua, T., \& Saxena, S. (2011). Prevalence of intellectual disability: a meta-analysis of population-based studies. Research in developmental disabilities, 32(2), 419-436.

Mohr, C., Tonge, B., Einfeld, S., \& Taffe, J. (2011). Manual for the Developmental behavior checklist for adults (DBC-A). Clayton, Melbourne: Monash University Centre for Developmental Psychiatry and Psychology.

Morris, C. A., Demsey, S. A., Leonard, C. O., Dilts, C., \& Blackburn, B. L. (1988). Natural history of Williams syndrome: physical characteristics. The Journal of pediatrics, 113(2), 318-326.

Mowat, D., \& Wilson, M. (2010). Mowat-wilson syndrome. Management of genetic syndromes: Third edition (pp. 517-527)

Niemczyk, J., Schäfer, S., Becker, N., Equit, M., \& von Gontard, A. (2018). Psychometric properties of the "parental questionnaire: Enuresis/urinary incontinence"(PQ-EnU). Neurourology and urodynamics. 1-11. doi:10.1002/nau.23564

Pegoraro, L. F. L., Steiner, C. E., Celeri, E. H. R. V., Banzato, C. E. M., \& Dalgalarrondo, P. (2014). Cognitive and behavioral heterogeneity in genetic syndromes. Jornal De Pediatria, 90(2), 155-160.

Powers, M. K., Brown, E. T., Hogan, R. M., Martin, A. D., Ortenberg, J., \& Roth, C. C. (2015). Trends in toilet training and voiding habits among children with Down syndrome. Journal of Urology, 194(3), 783-787.

Radstaake, M., Didden, R., Giesbers, S., Korzilius, H., Peters-Scheffer, N., Lang, R., . . Curfs, L. M. G. (2013). Incontinence in individuals with Angelman syndrome: A comparative study. Research in Developmental Disabilities, 34(11), 4184-4193.

Rasquin, A., Di Lorenzo, C., Forbes, D., Guiraldes, E., Hyams, J. S., Staiano, A., \& Walker, L. S. (2006). Childhood functional gastrointestinal disorders: Child/Adolescent. Gastroenterology, 130(5), 1527-1537.

Roberts, A. E., Allanson, J. E., Tartaglia, M., \& Gelb, B. D. (2013). Noonan syndrome. The Lancet, 381(9863), 333342.

Roizen, N. J., \& Patterson, D. (2003). Down's syndrome. The Lancet, 361(9365), 1281-1289.

Sammour, Z. M., Gomes, C. M., Duarte, R. J., Trigo-Rocha, F. E., \& Srougi, M. (2006). Voiding dysfunction and the Williams-Beuren syndrome: A clinical and urodynamic investigation. Journal of Urology, 175(4), 1472 1476.

Schulman, S. L., Zderic, S., \& Kaplan, P. (1996). Increased prevalence of urinary symptoms and voiding dysfunction in Williams syndrome. The Journal of pediatrics, 129(3), 466-469.

Strømme, P., \& Hagberg, G. (2000). Aetiology in severe and mild mental retardation: A population-based study of norwegian children. Developmental Medicine and Child Neurology, 42(2), 76-86.

Swithinbank, L. V., Brookes, S. T., Shepherd, A. M., \& Abrams, P. (1998). The natural history of urinary symptoms during adolescence. British Journal of Urology, Supplement, 81(3), 90-93.

Thibert, R. L., Larson, A. M., Hsieh, D. T., Raby, A. R., \& Thiele, E. A. (2013). Neurologic manifestations of Angelman syndrome. Pediatric Neurology, 48(4), 271-279.

van Der Wal, M. F., Benninga, M. A., \& Hirasing, R. A. (2005). The prevalence of encopresis in a multicultural population. Journal of Pediatric Gastroenterology and Nutrition, 40(3), 345-348.

van Laecke, E., Raes, A., Vande Walle, J., \& Hoebeke, P. (2009). Adequate fluid intake, urinary incontinence, and physical and/or intellectual disability. Journal of Urology, 182(4 SUPPL.), 2079-2084.

van Timmeren, E. A., van der Putten, A. A. J., van Schrojenstein Lantman-de Valk, H. M. J., van der Schans, C. P., \& Waninge, A. (2016). Prevalence of reported physical health problems in people with severe or profound intellectual and motor disabilities: A cross-sectional study of medical records and care plans. Journal of Intellectual Disability Research, 60(11), 1109-1118.

von Gontard, A. (2010). Enkopresis - Leitfaden Kinder- und Jugendpsychotherapie (Band 15). Goettingen: Hogrefe.

von Gontard, A. (2012a). Encopresis. In J. M. Rey (Ed.), IACAPAP e-textbook of child and adolescent mental health. Geneva: International Association for Child and Adolescent Psychiatry and Allied Professions. http://iacapap.org/wp-content/uploads/C.5-ENCOPRESIS-0072012.pdf. Accessed 11.03.16. 
von Gontard, A. (2012b). Enuresis. In J. M. Rey (Ed.), IACAPAP e-textbook of child and adolescent mental health. Geneva: International Association for Child and Adolescent Psychiatry and Allied Professions. http://iacapap.org/wp-content/uploads/C.4-ENURESIS-072012.pdf. Accessed 11.03.16.

von Gontard, A. (2013). Urinary incontinence in children with special needs. Nature Reviews Urology, 10(11), 667-674.

von Gontard, A., Didden, R., Sinnema, M., \& Curfs, L. (2010). Urinary incontinence in persons with Prader-Willi syndrome. BJU International, 106(11), 1758-1762.

von Gontard, A., \& Lehmkuhl, G. (2009). Enuresis - Leitfaden Kinder- und Jugendpsychotherapie (Band 4) (2th ed.). Goettingen: Hogrefe.

von Gontard, A., Niemczyk, J., Borggrefe-Moussavian, S., Wagner, C., Curfs, L., \& Equit, M. (2016). Incontinence in children, adolescents and adults with Williams syndrome. Neurourology and Urodynamics, 35(8), $1000-$ 1005.

von Wendt, L., Simila, S., Niskanen, P., \& Jarvelin, M. (1990). Development of bowel and bladder control in the mentally retarded. Developmental Medicine and Child Neurology, 32(6), 515-518.

World Health Organization (WHO) (1993). The ICD-10 classification of mental and behavioral disorders: Diagnostic criteria for research. Geneva: World Health Organization.

Wright, A. (2015). The epidemiology of childhood incontinence. In I. Franco, P. F. Austin, S. Bauer, A., von Gontard \& Y. Homsy (Eds.), Pediatric incontinence - Evaluation and clinical management (1st ed., pp. 37-60). Chichester, UK: Wiley Blackwell.

Yang, P. Y., Meng, N. H., \& Chou, E. C. L. (2010). Voiding dysfunctions in children with mental retardation. Neurourology and Urodynamics, 29(7), 1272-1275. 
Chapter

Prevalence of incontinence and associated factors in four genetic syndromes 

Chapter 2.1

Incontinence in persons with Down Syndrome

Niemczyk, J., von Gontard, A., Equit, M., Medoff, D., Wagner, C., Curfs, L. (2016). Neurourology \& Urodynamics, 36(6), 1550-1556. 


\section{Abstract}

The aim was to assess the rates of incontinence and associated psychological problems in children, adolescents and adults with Down syndrome, a genetic syndrome caused by partial or complete triplication (trisomy) of chromosome 21 and characterized by typical facial features, a physical growth delay and mild or moderate intellectual disability.

Three hundred and seventeen persons with Down syndrome (4-51 years) were recruited through a German parent support group (59.6\% male, mean age 19.2 years). The Parental Questionnaire: Enuresis/Urinary Incontinence, the Incontinence QuestionnairePediatric Lower Urinary Tract Symptoms, as well as the Developmental Behavior Checklist (DBC) for parents or for adults were filled out by parents or care-givers.

$17.2 \%$ of the sample had nocturnal enuresis, $15.9 \%$ had daytime urinary incontinence and $14.2 \%$ had fecal incontinence. Incontinence was present in $64.0 \%$ of young children (4-12 years), $10.3 \%$ of teens (13-17y), $12.8 \%$ of young adults (18-30y) and in $22.4 \%$ of older adults (>30y). $13.6 \%$ of children and $8.4 \%$ of adults had a DBC score in the clinical range. $19.5 \%$ of children and $27.8 \%$ of adults with incontinence had behavioral problems. There was a significant association between nocturnal enuresis, daytime urinary incontinence and clinical DBC scores in adults.

Incontinence in Down syndrome is mainly present in young children and increases in older adults. Behavioral comorbidity is associated with incontinence only in adults with Down syndrome. Screening and treatment of incontinence in individuals with Down syndrome is recommended. 


\section{Introduction}

Down Syndrome (DS) is caused by trisomy of chromosome 21 with a prevalence of 1:1000 live births (Charleton, Dennis, \& Marder, 2010). Typical medical conditions include congenital heart defects, short stature, gastrointestinal conditions and many other problems (Charleton et al., 2010). Intelligence in DS is in the range of mild intellectual disability $(I Q=50-69)$ with a decline over age (Brown, Greer, Aylward, \& Hunt, 1990). About 20\% of children with DS show psychological problems, predominantly externalizing (ADHD, conduct and oppositional defiant disorders) or autism spectrum disorders (Dykens, 2007). In adolescents, internalizing disorders (anxiety, depression) are more prevalent, whereas in adults the risk of depression, psychosis, Alzheimer's disease (AD) and dementia increases (Dykens, 2007).

Functional incontinence includes daytime urinary incontinence (DUI), nocturnal enuresis (NE) as well as fecal incontinence (FI). According to the International Children's Continence Society (ICCS) and the Diagnostic and Statistical Manual of Mental Disorders - Fifth Edition (DSM-5), NE and DUI are diagnosed from the age of 5 years onwards (with wetting at least $1 x /$ month) after excluding organic causes (American Psychiatric Association (APA), 2013; Austin et al., 2016). Fl is diagnosed from the age of 4 years onwards (occurring at least $1 \mathrm{x} /$ month) after exclusion of organic causes. Fl with functional constipation and non-retentive FI can be differentiated (APA, 2013; Rasquin et al., 2006). Prevalences in typically developing children are about 5-10\% for NE, 6\% for DUI and 1-8\% for $\mathrm{Fl}$, with decreasing rates into adolescence and adulthood (Franco, Austin, Bauer, von Gontard, \& Homsy, 2015). In persons with intellectual disability (ID), incontinence is more prevalent (30-39\% in 7-yearolds, $19-20 \%$ in 20-year-olds) and associated with the degree of intellectual disability (ID) (Von Wendt, Simila, Niskanen, \& Jarvelin, 1990).

In children with DS, incontinence rates range between 46-73\% (Brushini, Faria, Garcez, \& Srougi, 2003; Kitamura et al., 2014; Powers et al., 2015). Rates are higher in children with lower IQ (Brushini et al., 2003) and with lower urinary tract symptoms (LUTS) (De Carvalho Mrad et al., 2014). Children with DS are also at risk for constipation (50\%), LUTS (27\%), pathological uroflows (66\%) and a delayed toilet training $(81.2 \%$ after 5 years of age) (De Carvalho Mrad et al., 2014; Kitamura et al., 2014; Powers et al., 2015). Incontinence rates in adults over an age of 15 years (Lin et al., 2015) decrease to $43 \%$ at a mean age of 42 years (Mantry et al., 2008). 9\% of adults with DS had urinary retention, associated with further LUTS (Chicoine \& Sulo, 2015).

The aim of the study was to analyze subtypes of functional incontinence (NE, DUI, FI) and psychological symptoms in different age groups of individuals with DS. Associations between incontinence, constipation, LUTS and psychological symptoms were examined. It was hypothesized that incontinence rates are highest in childhood and decrease with age and that incontinence, LUTS, constipation are associated with psychological problems. 


\section{Materials and Methods}

In cooperation with the German Down Syndrome support group "Arbeitskreis Down-Syndrom e. V." questionnaire packages were sent to 700 members over 5 months (June October 2013). The study was also announced in the German magazine "Leben mit DownSyndrom" (=Life with Down Syndrome). Interested families could request the questionnaires by email, which was done by 44 families.

The packages included the "Parental Questionnaire: Enuresis/Urinary Incontinence" (von Gontard, 2012b), "Encopresis Questionnaire - Screening Version" (von Gontard, 2012a), the German version of the "International-Consultation-on-Incontinence-Questionnaire - Pediatric Lower Urinary Tract Symptom" (ICIQ-CLUTS) (De Gennaro et al., 2010) and the Developmental Behavior Checklist (DBC) (Einfeld, Tonge, \& Steinhausen, 2007). Following informed consent, parents or caregivers were asked to complete the questionnaires, including either the parental version of the DBC (DBC-P) for children or adolescents, or the adult version (DBC-A) for adults. The study was approved by the local ethics committee.

The DBC is a questionnaire to assess psychopathology in persons with ID and consists of 96 items (106 in the adult version) rated with "0 - not true as far as you know", "1 somewhat or sometimes true" and "2 - very true or often true". Norms for persons with mild ID were used in this sample. Objectivity, reliability and validity are given (Steinhausen \& Metzke, 2011). The DBC-P includes the scales "Total Behavior Problem Score", "Disruptive/Antisocial", "Self-Absorbed", "Communication Disturbance", "Anxiety" and "Social Relating". The DBC-A has an additional scale termed "Anxiety/Depression". As a group of persons with Down syndrome was assessed, who are mainly associated with mild ID, the DBC (with norms for mild ID) is a much more suitable instrument for assessing psychological problems than questionnaires for typically developing persons.

The "Parental Questionnaire: Enuresis/Urinary Incontinence" comprises 41 items and has been validated with satisfying psychometric properties (Niemczyk et al., 2016). The 10 questions of the ICIQ-CLUTS (with four answer options each rated with points of 0 to 3) build a LUTS-score with clinically relevant scores over 13. In a group on incontinence and continent children, validity and reliability were confirmed (De Gennaro et al., 2010). According to the ICCS, NE and DUI were diagnosed in persons older than 5 years when wetting occurs at least once per month. According to DSM-5, FI was diagnosed from the age of 4 years when soiling occurs at least once per month.

Statistical analyses were performed by IBM SPSS Statistics 23. Descriptive statistics, nonparametric tests ( $\chi 2$-tests, Fisher's Exact tests) for categorical data and parametric tests (univariate ANOVA, Student t-tests, Welch tests) for interval data were used. Results were considered significant at a p-value $<0.05$. 


\section{Results}

Of the 744 sent questionnaire packages, 22 were returned due to unknown address. 335 packages were received. 3 questionnaires were incomplete and excluded. 15 cases were excluded because of an age younger than 4 years. The remaining sample consisted of 317 persons with a mean age of 19.2 years ( $S D=8.7$; range $4-51$ years). $59.6 \%$ were male. $63.8 \%$ had further somatic conditions, $52.6 \%$ were on medication. $63.8 \%$ had a physical disability or chronic illness, 3.2\% reported genitourinary tract anomalies, e.g. renal agenesis. In 4 cases (1.3\%), Hirschsprung's disease (HSCR) was described. Medication was assessed in an open question. All persons reported neither medication used for treatment of incontinence (desmopressin, anti-cholinergics) nor the use of diuretics. The use of laxatives was reported in 4 cases.

Table 2 shows incontinence rates, LUTS scores and clinical DBC scores in the total sample and by gender. In three cases, gender data was missing. $25.5 \%$ of the total sample had at least one subtype of incontinence, with prevalences for NE, DUI and FI of $17.2 \%$, $15.9 \%$ and $14.2 \%$, respectively. Constipation was found in $15.8 \%$. Only $0.6 \%$ had a clinically relevant LUTS-score. $13.6 \%$ of children and adolescents $(<18 \mathrm{y})$ and $8.4 \%$ of adults $(\geq 18 y)$ had clinically relevant DBC scores. Males were significantly more affected by DUI and psychological symptoms in adulthood (table 1 ). 
Table 2: Descriptive data and gender comparisons in Down syndrome

\begin{tabular}{|c|c|c|c|c|}
\hline & $\begin{array}{l}\text { Total } \\
\left(\mathrm{N}=317^{\mathrm{a}}\right)\end{array}$ & $\begin{array}{l}\text { Male } \\
(\mathrm{N}=187)\end{array}$ & $\begin{array}{l}\text { Female } \\
(\mathrm{N}=127)\end{array}$ & Significance $^{b}(p)$ \\
\hline Mean age in years (SD) & $19.2(8.7)$ & $18.6(8.88)$ & $20.1(8.42)$ & \\
\hline Incontinence overall \% (n) & $25.5(72 / 282)$ & $27.2(46 / 169)$ & $23.4(26 / 111)$ & .477 \\
\hline NE \% (n) & $17.2(52 / 303)$ & $19.7(35 / 178)$ & $13.9(17 / 122)$ & .198 \\
\hline DUI \% (n) & $15.9(48 / 301)$ & $19.4(35 / 180)$ & $10.9(13 / 119)$ & $.049 *$ \\
\hline $\mathrm{FI} \%(n)$ & $14.2(42 / 296)$ & $17.5(31 / 177)$ & $9.5(11 / 116)$ & .055 \\
\hline Constipation \% (n) & $15.8(46 / 292)$ & $14.5(25 / 173)$ & $18.1(21 / 116)$ & .405 \\
\hline LUTS $\geq 13 \%(n)$ & $0.6(2 / 317)$ & $0.5(1 / 187)$ & $0.8(1 / 127)$ & .782 \\
\hline LUTS mean score (SD) & $3.2(2.72)$ & $3.3(2.79)$ & $3.0(8.74)$ & .473 \\
\hline DBC-Pc (score $>46) \%(n)$ & $13.6(14 / 103)$ & $12.3(8 / 65)$ & $16.2(6 / 37)$ & .581 \\
\hline$D B C-P^{c}$ Total mean T-value (SD) & $46.1(8.42)$ & $46.8(8.22)$ & $45.1(8.74)$ & .343 \\
\hline DBC-A ${ }^{d}($ score $>51) \%(n)$ & $8.4(11 / 131)$ & $12.3(9 / 73)$ & $3.5(2 / 57)$ & $.111^{\mathrm{e}}$ \\
\hline DBC-Ad Total mean T-value (SD) & $39.0(10.19)$ & $41.4(10.48)$ & $35.8(9.06)$ & $.002 * *$ \\
\hline
\end{tabular}

${ }^{a}$ gender data is missing in 3 cases

${ }^{\mathrm{b}} \chi^{2}$-tests for non-parametric data and Student t-tests for interval data (in italics); results are considered significant when $\mathrm{p}<.05^{*}, \mathrm{p}<0.01^{* *}$ or $\mathrm{p}<.001^{* * *}$

c $D B C-P$ data refer to $n=103$ persons between $4-17$ years

${ }^{d}$ DBC-A data refer to $\mathrm{n}=131$ persons 18 years or older

e Fisher's Exact Test

The sample was subdivided into 4 age groups: children (4-12 years), adolescents (13-17 years), young adults (18-30 years) and adults (>30 years) (table 3 ). In 35 cases age data was missing. There was a significant effect of the age group on incontinence overall and on all subtypes (NE, DUI, FI). Constipation rates did not differ between the age groups. The LUTS mean score was highest in children. There was a significant difference for urgency and straining, of which children where most affected. Postponement symptoms did not change over age. There was a significant difference in the mean T-values, but not in the rate of DBC-scores in the clinical range between the groups. In the DBC subscales, there were significant differences within the age groups in all subscales except for "Social Relating". 
Table 3: Incontinence, LUTS and DBC-P/A data over the age groups in Down syndrome

\begin{tabular}{|c|c|c|c|c|c|c|}
\hline & $\begin{array}{l}\text { Total } \\
\left(\mathrm{N}=317^{\mathrm{a}}\right)\end{array}$ & $\begin{array}{l}\text { Children } \\
\text { (4-12 years) } \\
(\mathrm{N}=78)\end{array}$ & $\begin{array}{l}\text { Teens } \\
\text { (13-17 years) } \\
(\mathrm{N}=44)\end{array}$ & $\begin{array}{l}\text { Young adults } \\
(18-30 \text { years }) \\
(\mathrm{N}=139)\end{array}$ & $\begin{array}{l}\text { Adults } \\
\text { (>30 years) } \\
(\mathrm{N}=21)\end{array}$ & $\begin{array}{l}\text { Significance } \\
\text { (p) }\end{array}$ \\
\hline Any incontinence \% (n) & $\begin{array}{l}25.5 \\
(72 / 282)\end{array}$ & $64.0(48 / 75)$ & $10.3(4 / 39)$ & $12.8(16 / 125)$ & $22.2(4 / 18)$ & $<.001^{* * *}$ \\
\hline $\begin{array}{l}\text { Nocturnal enuresis } \\
\text { (NE) \% (n) }\end{array}$ & $\begin{array}{l}17.2 \\
(52 / 303)\end{array}$ & $49.4(38 / 77)$ & $2.5(1 / 40)$ & $5.0(1 / 20)$ & $8.9(12 / 135)$ & $<.001^{* * *}$ \\
\hline $\begin{array}{l}\text { Daytime urinary incon- } \\
\text { tinence (DUI) \% (n) }\end{array}$ & $\begin{array}{l}-15.9 \\
(48 / 301)\end{array}$ & $47.3(35 / 74)$ & $4.7(2 / 43)$ & $10.0(2 / 20)$ & $6.7(9 / 134)$ & $<.001^{* * *}$ \\
\hline $\begin{array}{l}\text { Fecal incontinence }(\mathrm{FI}) \\
\%(\mathrm{n})\end{array}$ & $\begin{array}{l}14.2 \\
(42 / 296)\end{array}$ & $40.8(31 / 76)$ & $2.4(1 / 42)$ & $15.8(3 / 19)$ & $5.4(7 / 130)$ & $<.001^{* * *}$ \\
\hline Constipation \% (n) & $\begin{array}{l}15.8 \\
(46 / 292)\end{array}$ & $22.5(16 / 71)$ & $12.5(5 / 49)$ & $13.7(18 / 131)$ & $16.7(3 / 15)$ & .377 \\
\hline LUTS-score $\geq 13 \%$ (n) & $0.6(2 / 317)$ & $2.6(2 / 78)$ & $0.0(0 / 44)$ & $0.0(0 / 139)$ & $0.0(0 / 21)$ & $.243^{f}$ \\
\hline LUTS mean score (SD) & $3.2(2.72)$ & $5.5(3.10)$ & $2.5(1.81)$ & $2.4(2.13)$ & $2.6(2.27)$ & $<.001 * * * g$ \\
\hline Urgency $\%$ (n) & $\begin{array}{l}11.9 \\
(30 / 252)\end{array}$ & $24.5(12 / 49)$ & $15.0(6 / 40)$ & $5.3(1 / 19)$ & $8.7(10 / 115)$ & $.033^{*}$ \\
\hline Postponement $\%$ (n) & $2.0(5 / 249)$ & $4.2(2 / 48)$ & $2.5(1 / 40)$ & $5.3(1 / 19)$ & $0.9(1 / 113)$ & $.216^{f}$ \\
\hline Straining $\%$ (n) & $\begin{array}{l}12.9 \\
(31 / 240)\end{array}$ & $22.4(11 / 49)$ & $16.2(6 / 37)$ & $0.0(0 / 19)$ & $9.3(10 / 107)$ & $.037^{* f}$ \\
\hline $\begin{array}{l}\text { Clinical DBC-P/A score } \\
\%(n)\end{array}$ & $13.6 / 8.4$ & $12.5(8 / 64)$ & $15.4(6 / 39)$ & $9.5(11 / 116)$ & $0.0(0 / 15)$ & .396 \\
\hline $\begin{array}{l}D B C-P / A \text { Total mean } T \text { - } \\
\text { value }(S D)^{d}\end{array}$ & & $46.5(8.01)$ & $45.4(9.11)$ & $39.7(10.16)$ & $33.5(8.96)$ & $<.001^{* * *}$ \\
\hline \multicolumn{7}{|l|}{$\begin{array}{l}\text { Subscales mean T-values } \\
(S D) \text { : }\end{array}$} \\
\hline Disruptive/Antisocial & & $43.7(8.30)$ & $42.3(9.97)$ & $31.4(5.78)$ & $37.7(8.24)$ & $<.001^{* * *}$ \\
\hline Self-Absorbed & & $48.3(8.83)$ & $44.6(7.92)$ & $38.2(7.42)$ & $45.5(7.87)$ & $.001^{* * *}$ \\
\hline $\begin{array}{l}\text { Communication Dis- } \\
\text { turbance }\end{array}$ & & $48.0(7.31)$ & $50.3(8.70)$ & $40.0(7.68)$ & $46.0(8.60)$ & $<.001^{* * *}$ \\
\hline Anxiety & & $47.0(9.98)$ & $45.7(9.76)$ & $38.6(8.60)$ & $41.5(8.81)$ & $<.001^{* * *}$ \\
\hline Social Relating & & $44.4(8.71)$ & 46.3 (7.99) & $41.8(10.67)$ & $44.2(10.14)$ & .419 \\
\hline
\end{tabular}

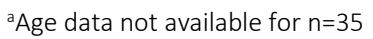

b Items 7, 8 and 9 of the ICIQ-CLUTS scored as 'most of the time' or 'all of the time'

${ }^{c}$ Clinical score when DBC-P score > 46 and DBC-A score > 51; DBC-P data refer to $n=103$ persons between 4-17 years; DBC-A data refer to $\mathrm{n}=131$ persons 18 years or older

d DBC-P mean T-values for children and teens, DBC-A mean T-values for young adults and adults

e Pearson's Chi ${ }^{2}$ test conducted for nonparametric data and one-way ANOVA for parametric data (in italics)

${ }^{f}$ Fisher's Exact test

$\mathrm{g}$ Welch test was conducted due to violation of variance homogeneity
} 
In table 4, individuals with and without a clinical DBC score were compared regarding incontinence. In children and adolescents, there were no significant associations between psychological symptoms and incontinence, whereas in adults rates of NE, DUI and incontinence overall were significantly higher in those with a clinical DBC score. Due to differences of the DBC-P and DBC-A (different items and problem scales) the comparison of both groups (children/adolescents and young adults) with each other could not be conducted.

Table 4: Associations of incontinence and behavioral symptoms in the clinical range: children/adolescents and adults with Down syndrome

\begin{tabular}{|c|c|c|c|c|c|c|}
\hline & $\begin{array}{l}\text { Children and } \\
\text { adolescents } \\
\text { (4-17) with } \\
\text { clinical DBC-P- } \\
\text { scores }\end{array}$ & $\begin{array}{l}\text { Children and } \\
\text { adolescents } \\
\text { (4-17) with } \\
\text {-subclinical } \\
\text { DBC-P-scores }\end{array}$ & $\begin{array}{l}\text { Significance }(p) \\
\left(\chi^{2} \text {-test }\right)\end{array}$ & $\begin{array}{l}\text { (Young) Adults } \\
(\geq 18) \text { with } \\
\text { clinical DBC-A- } \\
\text { scores }\end{array}$ & $\begin{array}{l}\text { (Young) } \\
\text { Adults }(\geq 18) \\
\text { with } \\
\text { subclinical } \\
\text { DBC-A-scores }\end{array}$ & $\begin{array}{l}\text { Significance } \\
(p) \\
\left(\chi^{2} \text {-test }\right)\end{array}$ \\
\hline$N$ & 14 & 89 & & 11 & 120 & \\
\hline $\begin{array}{l}\text { Any incontinence \% } \\
\text { (n) }\end{array}$ & $61.5(8 / 13)$ & $38.8(33 / 85)$ & .122 & $55.6(5 / 9)$ & $11.9(13 / 109)$ & $.004 * * a$ \\
\hline NE \% (n) & $42.9(6 / 14)$ & $25.6(22 / 86)$ & $.207^{\mathrm{a}}$ & $30.0(3 / 10)$ & $6.8(8 / 118)$ & $.041^{* a}$ \\
\hline DUI \% (n) & $46.2(6 / 13)$ & $26.7(23 / 86)$ & $.193^{\mathrm{a}}$ & $40.0(4 / 10)$ & $5.2(6 / 116)$ & $.003 * * a$ \\
\hline $\mathrm{Fl} \%(\mathrm{n})$ & $38.5(5 / 13)$ & $23.9(21 / 88)$ & $.261^{\mathrm{a}}$ & $20.0(2 / 10)$ & $6.3(7 / 112)$ & $.160^{\mathrm{a}}$ \\
\hline Constipation \% (n) & $30.8(4 / 13)$ & $16.3(13 / 67)$ & $.247^{\mathrm{a}}$ & $33.3(3 / 9)$ & $13.2(15 / 114)$ & $.126^{a}$ \\
\hline $\begin{array}{l}\text { LUTS-score } \geq 13 \% \\
\text { (n) }\end{array}$ & $0.0(0 / 14)$ & $1.1(1 / 89)$ & $1.00^{\mathrm{a}}$ & - & - & \\
\hline
\end{tabular}

a Fisher's Exact test

\section{Discussion}

This is the largest study in individuals with DS focusing on incontinence, LUTS, constipation and its association with psychological symptoms. Also, the sample ranges from young children to older adults, allowing a lifespan comparison.

The rates for NE (49.4\%) and DUI (47.3\%) are comparable to other studies on children with DS. Kitamura et al. reported overall rates of $47 \%$ for urinary incontinence in 5-15 year-old children with DS (Kitamura et al., 2014). In a smaller sample ( $n=15)$, urinary leakages affected $73 \%$ of 7-10 year old children with DS (Brushini et al., 2003). In another study of 78 persons with DS and a mean age of 10.3 years (range $0-27$ years), $46 \%$ had urinary incontinence in total ( $20 \%$ had NE only, 35\% DUI only, and $45 \%$ both) (Powers et al., 2015).

One explanation for these higher rates of NE and DUI in children with DS is a general delay of bladder control, which is strongly associated with the severity of ID (Brushini et al., 2003; Powers et al., 2015). Central nervous system (CNS) mechanisms are involved in 
DUI and NE (Franco et al., 2015). During micturition, regions in the brainstem (periaqueductal gray (PAG), pontine micturition center), as well as the prefrontal cortex, anterior cingulate cortex, insula, thalamus and hypothalamus are active (Franco et al., 2015). In continent persons, the PAG receives information from the median prefrontal cortex, the anterior cingulate gyrus and the insula, implying that neuronal pathways between these regions exist. In DS, neuroanatomic alterations (reduced brain weight, smaller volumes of hippocampus, temporal lobes and cerebellum) and histological findings (decreased number of neurons, neuronal density, neuronal distribution and synaptic density) support the hypothesis of an abnormal neuronal connectivity (Lott, 2012). It can be hypothesized that the neuronal pathways which influence controlled micturition could also be disturbed in DS.

Incontinence is not only related to the degree of ID in DS, which was not a significant predictor of pathological uroflows in one study (Kitamura et al., 2014). LUTS were also associated with urinary incontinence in DS (De Carvalho Mrad et al., 2014). In the present sample, only $0.6 \%$ of persons had clinically relevant LUTS scores. This could be due to the high cut-off value in the ICIQ-CLUTS, which was validated in typically developing children and could be inappropriate for the DS sample (De Gennaro et al., 2010). The rates for specific LUTS as urgency or straining are in line with findings in other publications (Chicoine \& Sulo, 2015; De Carvalho Mrad et al., 2014; Kitamura et al., 2014) and present a risk factor for incontinence.

$\mathrm{FI}$ is less studied in children with DS. The rate of encopresis was much lower $(3.7 \%)$ in one Turkish study of 107 DS children (Karaman, 2010), compared to the present sample (40.8\%). Two reasons could be responsible for this difference. First, this study did not focus on encopresis alone, but on other psychiatric disorders, possibly resulting in underreporting of Fl. Second, the mean age of the Turkish sample was 2.5 years (range 06 ), which means that many children were too young for a diagnosis of encopresis (4 years).

While $\mathrm{Fl}$ is by definition a functional disorder (exclusion of organic causes), HSCR, is a common cause of organic FI in DS. A meta-analysis found a significantly higher risk for soiling in individuals with DS and HSCR $(\mathrm{OR}=3.6)$, but not for constipation (OR=1.4) (Friedmacher \& Puri, 2013). In our sample, only 4 persons had HSCR (1.3\%), lower than in other studies (2.6\%) (Friedmacher \& Puri, 2013). This could be due to underreporting, as other current medical conditions were not assessed. HSCR is usually operated on earlier in childhood and might therefore not have been reported. Of the four persons with HSCR, one had FI and two had constipation. Regarding histopathological findings, patients with DS and HSCR have a reduced distribution of neurites in the rectosigmoid circular muscle layer (Moore, 2008), indicating a reduced innervation in the enteric nervous system (ENS). Possible candidate genes for the association of DS and HSCR are ret proto-oncogene (RET) and endothelin receptor type B (EDNRB), which play a role in HSCR and abnormal ENS development (Moore, 2008). 
Other disorders of the lower gastro-intestinal (GI) tract (e.g. chronic constipation, diarrhea) could also contribute toward the higher rates of $\mathrm{FI}$ in children with DS (Moore, 2008). GI tract disorders in DS emerge from deficits in the development of the ENS, similar to those of the CNS. Hypoganglionosis of the colon in DS mouse models and reduced plexus ganglia neurons in the esophagus of DS patients would support the assumption (Moore, 2008). The superoxide dismutase-1 (SOD-1) gene (located on chromosome 21 and overexpressed in DS persons) is a likely candidate gene for neurological alterations in the ENS, as it is involved in the neuroregulation of the neuromuscular junction (Moore, 2008). Based on those findings, Moore hypothesizes that disrupted signaling pathways between CNS and ENS could lead to functional defects of the GI tract in DS (Moore, 2008).

In adolescents and young adults in the present study, incontinence drops to $10.3 \%$ and $12.8 \%$, but increases again in older adults (22.2\%). Rates for NE remain at a similar level in older adults, but rise for DUI and FI to $10 \%$ and $15.8 \%$, respectively. Lin et al. report similar rates of $11 \%$ of incontinence in a sample of DS over 15 years of age (Lin et al., 2015). The increasing prevalence of incontinence in older adults with DS could be due to early onset of $A D$, other types of dementia and neurological impairments, affecting most individuals from the age of 40 years onwards (Dykens, 2007). AD may be associated with the loss of acquired abilities, e.g. bladder and bowel control. Incontinence was identified as an onset aging condition in adults with DS (Lin et al., 2015). Further, the APP (amyloid precursor protein) gene (overexpressed in DS) causes an accumulation of the amyloid- $\beta$-protein, AD (Lott, 2012) and neurodegeneration of the CNS and ENS, thereby inducing incontinence.

Psychological symptoms in the present study (13.6\% in children and adolescents, $8.4 \%$ in adults) are lower than in other studies (20\% in children, 23.7\% in adults) (Dykens, 2007; Mantry et al., 2008). For the DBC, norms for mild ID were used leading to lower rates of psychological problems than if instruments for typically developed persons had been used. Despite these methodological factors, persons with DS are less affected by psychological problems than those with other syndromes with mild ID, e.g. 20-30\% in Williams Syndrome (von Gontard et al., 2016). Protective factors in DS, e.g. sociability, humor, kindness and other positively perceived features (as the "babyfaced" facial appearance) could lead to these lower rates (Dykens, 2007).

In a study of 186 adults with DS (mean age=41.1 years), rates of $16.7 \%$ for bowel and $22.6 \%$ for urinary incontinence in the non-psychiatric group and of $35.5 \%$ and $42.9 \%$ in the group with psychiatric disorders were reported (Mantry et al., 2008). These findings are in line with the present study, in which incontinence is higher in adults with clinically relevant psychological symptoms. Incontinence and psychopathology may both be associated with early onset AD. Decreased occupational and social functioning, depressive symptoms, sleep problems, loss of language, memory, vision and hearing ability, as well as incontinence was found in studies examining onset symptoms of $A D$ in older individuals with DS (Lin et al., 2015). These symptoms are incapacitating and can lead to further psychological symptoms, e g. anxiety, disruptive and aggressive behavior. 


\section{Strengths and limitations}

Strengths of the study are the large sample size including different age groups, the use of validated questionnaires, of DSM-5 and ICCS criteria and the differentiation between different subtypes of incontinence. Limitations are the cross-sectional design that prohibits the analysis of causal associations, as well as the lack of IQ tests and clinical examinations (such as physical examination, sonography and uroflowmetry). Also, due to the small sample sizes in adults with clinically relevant psychological symptoms these results should be interpreted cautiously.

\section{Conclusions}

Incontinence is a major problem especially in children with DS. Rates decline significantly into adolescence and young adulthood and increase in older adults which could be associated with AD. The rate of psychological problems is low in contrast to other genetic syndromes with ID and is only associated with incontinence in adulthood. As treatment guidelines for functional incontinence in children with special needs (e.g. genetic syndromes, ID) exist (von Gontard, 2013), detailed assessment and treatment options should always be offered to affected persons. 


\section{References}

American Psychiatric Association (APA) (2013). Diagnostic and statistical manual of mental disorders -Fifth edition (DSM 5). Washington, D.C.: APA.

Austin, P.F., Bauer, S.B., Bower, W., Chase, J., Franco, I., Hoebeke, P., ... , Yang, S. S. (2016). The Standardization of Terminology of Lower Urinary Tract Function in Children and Adolescents: Update Report from the Standardization Committee of the International Children's Continence Society. Neurourology \& Urodynamics, 35(4), 471-481.

Brown III, F. R., Greer, M. K., Aylward, E. H., \& Hunt, H. H. (1990). Intellectual and adaptive functioning in individuals with Down syndrome in relation to age and environmental placement. Pediatrics, 85(3 SUPPL.), 450-452.

Brushini, H., Faria, N., Garcez, E., \& Srougi, M. (2003). Development of bladder control in mentally handicapped children. International Braz J Urol, 29(5), 455-458.

Charleton, P. M., Dennis, J., \& Marder, E. (2010). Medical management of children with Down syndrome. Paediatrics and Child Health, 20(7), 331-337.

Chicoine, B., \& Sulo, S. (2015). Rate of urinary retention in adults with Down syndrome: A prospective study. Journal of the American Board of Family Medicine, 28(1), 115-117.

De Carvalho Mrad, F. C., De Bessa, J., De Rezende Duarte, A. M. B., Vieira, A. A. P., Araujo, F. C. C., De Camargo, M. L. S., . . Netto, J. M. B. (2014). Prevalence of lower urinary tract symptoms in individuals with Down syndrome. Journal of Pediatric Urology, 10(5), 844-849.

De Gennaro, M., Niero, M., Capitanucci, M. L., von Gontard, A., Woodward, M., Tubaro, A., \& Abrams, P. (2010). Validity of the international consultation on incontinence questionnaire-pediatric lower urinary tract symptoms: A screening questionnaire for children. Journal of Urology, 184(4 SUPPL.), 1662-1667.

Dykens, E. M. (2007). Psychiatric and behavioral disorders in persons with Down syndrome. Mental Retardation and Developmental Disabilities Research Reviews, 13(3), 272-278.

Einfeld, S., Tonge, B., \& Steinhausen, H. (2007). Verhaltensfragebogen bei Entwicklungsstörungen. Göttingen: Hogrefe.

Franco, I., Austin, P. F., Bauer, S., von Gontard, A., \& Homsy, Y. (Eds.). (2015). Pediatric incontinence - Evaluation and clinical management. Chicester, UK: Wiley Blackwell.

Friedmacher, F., \& Puri, P. (2013). Hirschsprung's disease associated with Down syndrome: A meta-analysis of incidence, functional outcomes and mortality. Pediatric Surgery International, 29(9), 937-946.

Karaman, A. (2010). Medical problems in children with Down syndrome in the erzurum area of turkey. Genetic Counseling, 21(4), 385-395.

Kitamura, A., Kondoh, T., Noguchi, M., Hatada, T., Tohbu, S., Mori, K. -.., . . Moriuchi, H. (2014). Assessment of lower urinary tract function in children with Down syndrome. Pediatrics International, 56(6), 902-908.

Lin, J., Lin, L., Hsu, S., Chen, W., Lin, F., Wu, J., \& Chu, C. (2015). Are early onset aging conditions correlated to daily activity functions in youth and adults with Down syndrome? Research in Developmental Disabilities, 36, 532-536.

Lott, I. T. (2012). Neurological phenotypes for Down syndrome across the life span. In Progress in brain research, 197, 101-121.

Mantry, D., Cooper, S., Smiley, E., Morrison, J., Allan, L., Williamson, A., . . Jackson, A. (2008). The prevalence and incidence of mental ill-health in adults with Down syndrome. Journal of Intellectual Disability Research, 52(2), 141-155.

Moore, S. W. (2008). Down syndrome and the enteric nervous system. Pediatric Surgery International, 24(8), 873-883.

Niemczyk, J., Schaefer, S., Becker, N., Wagner, C., Equit, M., \& von Gontard, A. (2016). Evaluation of the 'parental questionnaire: Enuresis/Urinary incontinence'. International Children's Continence Society (ICCS 2016) Program and Abstracts, Kyoto, Japan.

Powers, M. K., Brown, E. T., Hogan, R. M., Martin, A. D., Ortenberg, J., \& Roth, C. C. (2015). Trends in toilet training and voiding habits among children with down syndrome. Journal of Urology, 194(3), 783-787. 
Rasquin, A., Di Lorenzo, C., Forbes, D., Guiraldes, E., Hyams, J. S., Staiano, A., \& Walker, L. S. (2006). Childhood functional gastrointestinal disorders: Child/Adolescent. Gastroenterology, 130(5), 1527-1537.

Steinhausen, H. -., \& Metzke, C. W. (2011). The Developmental Behavior checklist for adults. psychometric properties and norms of the German version. [Der Verhaltensfragebogen bei Entwicklungsstörungen im Erwachsenenalter (VFE-ER)] Zeitschrift Fur Klinische Psychologie Und Psychotherapie, 40(3), 160-171.

von Gontard, A. (2012a). Encopresis. In J. M. Rey (Ed.), IACAPAP e-textbook of child and adolescent mental health. Geneva: International Association for Child and Adolescent Psychiatry and Allied Professions. http://iacapap.org/wp-content/uploads/C.5-ENCOPRESIS-0072012.pdf. Accessed 11.03.16.

von Gontard, A. (2012b). Enuresis. In J. M. Rey (Ed.), IACAPAP e-textbook of child and adolescent mental health. Geneva: International Association for Child and Adolescent Psychiatry and Allied Professions. http://iacapap.org/wp-content/uploads/C.4-ENURESIS-072012.pdf. Accessed 11.03.16.

von Gontard, A. (2013). Urinary incontinence in children with special needs. Nature Reviews Urology, 10(11), 667-674.

von Gontard, A., Niemczyk, J., Borggrefe-Moussavian, S., Wagner, C., Curfs, L., \& Equit, M. (2016). Incontinence in children, adolescents and adults with Williams syndrome. Neurourology and Urodynamics, 35(8), 10001005.

von Wendt, L., Simila, S., Niskanen, P., \& Jarvelin, M. (1990). Development of bowel and bladder control in the mentally retarded. Developmental Medicine and Child Neurology, 32(6), 515-518. 

Chapter 2.2

\section{Incontinence in persons with Noonan Syndrome}

Niemczyk, J., Equit, M., Borggrefe-Moussavian, S., Curfs, L., \& von Gontard, A. (2015). Journal of Pediatric Urology, 11(4), 201.e1-201.e5. 


\section{Abstract}

Noonan Syndrome (NS) is an autosomal neurodevelopmental disorder with a high phenotypic variability. Mutations in several genes of the RasMAPK signaling pathways are now known to be responsible for NS. Most of the children with NS are of average intelligence, one third has a mild intellectual disability (ID) (IQ 50-79). So far, no studies have assessed incontinence in persons with NS. The aim of this study therefore was to investigate the prevalence of incontinence and psychological problems in persons with NS.

19 children (5-17 years) and 10 adults (18-48 years) with NS were recruited through a German parent support group (58.6\% male, mean age=15.26 years). The "Parental Questionnaire: Enuresis/Urinary Incontinence", "Encopresis Questionnaire - Screening Version" and the German version of the International-Consultation-on-IncontinenceQuestionnaire - Pediatric Lower Urinary Tract Symptom (ICIQ-CLUTS) were completed by parents or care-givers to assess incontinence and lower urinary tract symptoms (LUTS). The Developmental Behavior Checklist for parents (DBC-P) or the Developmental Behavior Checklist for adults (DBC-A) were filled out to assess psychological symptoms.

$27.3 \%$ of the children (4-12 years) had nocturnal enuresis (NE), 36.4\% had daytime urinary incontinence (DUI) and $11.1 \%$ had fecal incontinence (FI). Only one adolescent (13-17 years) had NE (14.3\%) and one young adult (18-30 years) had FI (11.1\%). 36.4\% of the children, $33.3 \%$ of the adolescents and $12.5 \%$ of young adults had a DBC score in the clinical range. No adult (>30 years) had incontinence or a critical DBC score. Children and adolescents with NE had significantly higher scores in the DBC total score as well in the "self-absorbed" and "social relating" subscales than continent children and adolescents, whereas no significant difference was found between children and adolescents with DUI compared to the continent group.

A significant proportion of children with NS is affected by incontinence. Incontinence is a relevant problem in children and adolescents with NS, but does not persist into adulthood. Psychological problems are especially present in children and adolescents with NE. Screening for both incontinence and psychological symptoms are recommended in children with NS. As most of the children with NS have average intelligence or a mild ID, they can be treated effectively with standard methods. 


\section{Introduction}

Noonan Syndrome (NS) is an autosomal dominant, neurodevelopmental disorder with a high phenotypic variability. It was first described in 1963 by Noonan and Ehmke in a group of patients with similar anomalies (Noonan \& Ehmke, 1963). The prevalence of NS is 1 in 1000-2500 births (Roberts, Allanson, Tartaglia, \& Gelb, 2013). As shared genetic cause, mutations in several genes of the RAS-MAPK signaling pathways on the chromosomal band 12q24.1 were found (Roberts et al., 2013). Recent overviews show that about 50\% of all persons with NS have a mutation in the PTPN11 gene, 10\% in the SOS1 gene, $10 \%$ in RAF1, $<2 \%$ in KRAS and $<1 \%$ in NRAS. Other genes affected are BRAF and SHOC2 (Roberts et al., 2013; Romano et al., 2010).

Typical signs and symptoms in NS are congenital heart defects, auditory deficits, short stature, abnormal pigmentation, cryptorchidism and typical facial features (ptosis, hypertelorism, low-set ears, depressed nasal root) (Roberts et al., 2013; Tartaglia, Gelb, \& Zenker, 2011). About 20-30\% have an intellectual disability (ID) (IQ<70), further $37 \%$ have a below average or borderline (70-89) IQ (Lee, Portnoy, Hill, Gillberg, \& Patton, 2005).

There are only few publications on psychological problems in NS. Behavioral and developmental difficulties were described in about $25 \%-50 \%$ of children with NS (Lee et al., 2005; Sarimski, 2000; Wood, Massarano, Super, \& Harrington, 1995). The most common symptoms reported in children with NS were stubbornness, clumsiness, mood and communication problems and faddy eating (Wood et al., 1995). In adults with NS, disorders such as panic disorder, alexithymia, obsessive-compulsive disorder, bipolar disorder, schizophrenia, anxiety and depression can occur (Verhoeven, Wingbermühle, Egger, Van Der Burgt, \& Tuinier, 2008; Wingbermühle, Egger, Verhoeven, Van Der Burgt, \& Kessels, 2012). Higher levels of alexithymia (inability of expressing emotions) and social distress were found in 40 adults with NS compared to a control group (Wingbermühle et al., 2012).

Functional incontinence such as nocturnal enuresis (NE), daytime urinary incontinence (DUI) and fecal incontinence (FI) are common in normally developed children with prevalence rates of $10 \%$ for NE, 2-3\% for DUI and 1-3\% for FI in 7-year-old children (von Gontard \& Nevéus, 2006). In children with special needs, e.g. children with ID, incontinence rates are much higher (Von Wendt, Simila, Niskanen, \& Jarvelin, 1990). Also, children with incontinence are more often affected by psychological disorders; the rates are especially high in children with FI (Joinson, Heron, \& von Gontard, 2006; Joinson, Heron, Butler, \& von Gontard, 2006; Joinson, Heron, Emond, \& Butler, 2007).

The aim of this study was to investigate the prevalences of incontinence, lower urinary tract symptoms (LUTS) and psychological problems in persons with NS. It was hypothesized that incontinence occurs more often in NS than in the normal population. Another aim was to analyze the associations between psychological problems and incontinence in persons with NS. 


\section{Material \& Methods}

Subjects were recruited through a German Noonan syndrome support group. Packages with questionnaires, information sheets and return envelopes for children and adults were sent to the chairperson of the support group who distributed them among all 107 member families. Following informed consent, parents/caregivers were asked to complete the questionnaires and send them back anonymously. 29 questionnaires were returned. The study was approved by the local ethics committee.

Incontinence and lower urinary tract symptoms (LUTS) were assessed by the "Parental Questionnaire: Enuresis/Urinary Incontinence" (von Gontard, 2012b), "Encopresis Questionnaire - Screening Version" (von Gontard, 2012a) and the German version of the International-Consultation-on-Incontinence-Questionnaire - Pediatric Lower Urinary Tract Symptom (ICIQ-CLUTS) (De Gennaro et al., 2010). NE and DUI were diagnosed from the age of 5 years when wetting occurs at least once per month, according to the International Children's Continence Society (ICCS) criteria (Austin et al., 2014). FI was diagnosed from the age of 4 years according to DSM-5 criteria, i.e. when soiling occurs at least once per month (American Psychiatric Association (APA), 2013). The 10 questions of the ICIQ-CLUTS build a LUTS-score with clinically relevant scores higher than 13.

Behavioral and psychological symptoms were assessed with the German version of the Developmental Behavior Checklist (DBC) (Einfeld, Tonge, \& Steinhausen, 2007). The parental questionnaire consists of 96 items, which are rated with " 0 - not true as far as you know", "1 - somewhat or sometimes true" and " 2 - very true or often true". Parents/Caregivers of children and adolescents ( $<18$ years) completed the parental version (DBC-P), those of adults ( $\geq 18$ years) the adult version (DBC-A), respectively. The DBC-P comprises the subscales "Disruptive/Antisocial" (DA), "Self-Absorbed" (SA), "Communication Disturbance" (CD), "Anxiety" (A) and "Social Relating" (SR) and the "Total Behavior Problem Score" (TBPS). The DBC-A has the same subscales except that the fourth scale is termed "Anxiety/Depression" (AD). A TBPS above 46 in the DBC-P and above 51 in the DBC-A are considered as clinically relevant (Einfeld \& Tonge, 1995). German norms are available for children and adults with mild, moderate and severe intellectual disability for both the DBC-P and the DBC-A (Einfeld \& Tonge, 1995; Steinhausen \& Metzke, 2011). The DBC-P and DBC-A questionnaires were evaluated according to the norms of mild intellectual disability.

Completed questionnaires of 19 children (5-17 years of age, mean age $=11.2$ years $(S D=4.1), 57.9 \%$ male) and 10 adults (18-48 years of age, mean age $=23.9$ years $(S D=9.4)$, $60 \%$ males) were included in the study.

The data was analyzed with IBM SPSS Statistics 22, using descriptive statistics and performing nonparametric ( $\chi 2$-tests, Fisher's Exact tests, Mann Whitney U-tests) for categorical data and parametric tests for interval data (Student t-tests, Welch tests). Results were considered significant at a $p$-value $<0.05$. 


\section{Results}

The sample included 11 children between 4 and 12 years old (39.3\%), 7 adolescents between 13 and 18 years old (25.0\%), 9 young adults (18 - 30 years) (32.1\%) and one adult older than 30 years (3.6\%). In one case age was not stated. Descriptive data and prevalence of incontinence in the 4 age groups are outlined in table 5.

$26.1 \%$ of the total sample was affected by at least one subtype of incontinence. Within the subgroups, incontinence was higher in children than in adolescent and adult groups ( $44.4 \%$ vs. $14.3 \%$ vs. $16.7 \%$ vs. $0 \%$ ). NE was found in $27.3 \%$ of children, $14.3 \%$ of adolescents and in none of (young) adults. DUI was only present in children (36.4\%). FI was found in one child and one young adult. No subject reached a LUTS score in the clinical range ( $>13$ ). $36.4 \%$ of children, $33.3 \%$ of adolescents and $12.5 \%$ of young adults reached a DBC-P/A total score in the clinically relevant range (table 5).

Table 5: Descriptive data, prevalence of incontinence and DBC data in the total sample and age groups in Noonan syndrome

$\left.\begin{array}{llllll}\hline & \begin{array}{l}\text { Total Sample } \\ \mathrm{n}=29\end{array} & \begin{array}{l}\text { Children } \\ (4-12 \mathrm{y}) \\ \mathrm{n}=11\end{array} & \begin{array}{l}\text { Adolescents } \\ (13-17 \mathrm{y}) \\ \mathrm{n}=7\end{array} & \begin{array}{l}\text { Young Adults } \\ (18-30 \mathrm{y})\end{array} & \begin{array}{l}\text { Adults } \\ (>30 \mathrm{y})\end{array} \\ \mathrm{n}=1\end{array}\right)$

${ }^{1}$ DBC-P mean T-values are reported in children and adolescents, DBC-A mean T-values are reported in young adults and adults

${ }^{2}$ Clinical Cut-off for the DBC-P is a Total score $>46$, clinical Cut-off for the DBC-A is a Total score $>51$ [21]

As incontinence was mainly present in children and adolescents, mean LUTS-, DBC total and subscale scores in continent children and adolescents, as well as those with NE and DUI were compared (table 6). Mean LUTS scores were significantly higher in the NE (1.73 vs. 6.0; $U=-2.12 ; p=.035$ ) and DUI groups (1.73 vs. 8.25; $U=-2.64 ; p=.003$ ) compared to continent children and adolescents. 
Table 6: Noonan syndrome: mean age, LUTS-score and psychological problems in continent children and adolescents (5-17 years), those with NE and those with DUI

\begin{tabular}{llll}
\hline & $\begin{array}{l}\text { Continent group } \\
(\mathrm{n}=11)\end{array}$ & NE group $(\mathrm{n}=4)$ & DUI group $(\mathrm{n}=4)$ \\
\hline Mean age in years (SD) & $12.05(3.4)$ & $10.38(3.4)$ & $7.46(1.7)^{2}$ \\
LUTS-score mean (SD) & $1.73(2.1)$ & $6.0(3.3)^{2 *}$ & $8.25(2.6)^{2 * *}$ \\
DBC-P Total mean T-value (SD) & $44.0(14.9)$ & $63.0(13.5)^{*}$ & $55.0(18.9)$ \\
Subscales mean T-values (SD): & & & \\
Disruptive/Antisocial & $43.2(15.5)$ & $55.5(8.2)$ & $47.0(8.9)$ \\
Self-Absorbed & $42.4(10.4)$ & $57.0(10.0)^{*}$ & $52.0(14.3)$ \\
Communication Disturbance & $46.6(10.3)$ & $60.25(22.8) 1$ & $59.5(23.1) \#$ \\
Anxiety & $45.2(15.0)$ & $56.5(7.2)^{2}$ & $49.0(6.8)^{2}$ \\
Social Relating & $43.8(7.3)$ & $58.0(10.7)^{2 *}$ & $53.5(14.7)^{2}$ \\
\hline
\end{tabular}

* Significant differences $(p<.05)$ in student t-Tests when comparing this subgroup to the continent group

** Significance $p<.01$

${ }^{1}$ Welch-Test was conducted due to missing variance homogeneity

${ }^{2}$ Mann-Whitney U-test (Exact test) was conducted due to violations of normal distribution

The DBC-P total T score was also significantly higher in children and adolescents with NE compared to the continent group (mean $\mathrm{T}=63.0$ vs. 44.0; $t=2.20 ; p=.048$ ). Regarding the subscales, the NE group had significantly higher scores in the "self-absorbed" and "social relating" scales than the continent group (table 6).

\section{Discussion}

This is the first systematic study examining the prevalence of incontinence and their association with psychological symptoms in persons with NS. The present study shows that incontinence is a major problem in persons with NS, that mainly children are affected and that NE is the most common subtype.

So far, no systematic studies on incontinence in persons with NS have been conducted. In a case report, a 33-year old male with NS and detrusor-sphincter-dyssynergia, difficulty in urination, urinary frequency and incontinence was described (Ohashi, Okuno, \& Mizuo, 1992). In another study, children with NS achieved a delayed bladder and bowel control at 41.4 months of age on average (Sarimski, 2000). Further, malformations of the urogenital tract, such as renal anomalies (in about 10\% of cases) were reported (George, Patton, El Sawi, Sharland, \& Adam, 1993; Noonan, 1994; Sommerschild \& Soerland, 1974), which can be associated with recurrent urinary tract infections in NS (Romano et al., 2010). Abdominal sonography in 44 persons with NS revealed renal anomalies in $11 \%$ of cases, such as absent kidney, ectopic kidney, duplex kidney, bilateral cysts with scarring or dilated renal pelvis (George et al., 1993). 
In the present sample, (mean age 8.2 years), $27 \%$ of children with NS had NE, 36\% DUI and $11 \% \mathrm{FI}$, respectively. In young adults (mean age 20.8 years), only $16.7 \%$ had incontinence. Due to the small sample size, incontinence prevalence in the present study should be interpreted cautiously. But it does show, that incontinence usually does not persist into adulthood in persons with NS.

Overall, $38 \%$ of 7-year old children with ID are affected of NE, 39\% of DUI and $30.5 \%$ are affected of $\mathrm{Fl}$ in population-based samples (Von Wendt et al., 1990). At the age of 20 years, the representative rates for incontinence in persons with ID are reduced to $19-20 \%$ (Von Wendt et al., 1990). There is also an inverse relationship between incontinence and IQ: the lower the IQ, the higher are the rates of incontinence (Von Wendt et al., 1990). In a study of persons with Prader-Willi-syndrome (PWS) and Fragile-X Syndrome (FXS) with a lower IQ-range than in NS, incontinence rates in childhood were 33.3\% (in PWS) and 70.6\% (in FXS), respectively, and were still high in adults (PWS 25\%, FXS 26.9\%) (Equit, Piro-Hussong, Niemczyk, Curfs, \& von Gontard, 2013).

As the IQ-range in persons with NS is higher than in PWS and FXS, this could be one explanation for the lower prevalence of incontinence in NS. To analyze to what extent incontinence rates in persons with NS are associated with ID, further research including a measurement of $I Q$ is needed.

20-30\% of 7-year-old typically developing children with NE, about 30-40\% of 7 -year old children with DUI and about 30-50\% of children with frequent FI are affected by psychological comorbidity (Joinson, Heron, Butler et al., 2006; Joinson, Heron, \& von Gontard, 2006; Joinson et al., 2007).

Psychological problems of clinical severity in the present sample are found mainly in children (36\%) and adolescents (33\%), comparable with the previous studies on NS (Lee et al., 2005; Wood et al., 1995). These psychological problems were more present in children with NE, although in typically developing children, they are even more common in children with DUI (Joinson, Heron \& von Gontard, 2006).

In children with NS and NE, self-absorbed" and "social relating" behaviors predominate, which are associated with ID and autism (Einfeld \& Tonge, 1995). The "self-absorbed" subscale includes items like "chews or mouths objects, or body parts", "grinds teeth" or "repeated movements of hands, body, head or face e.g. handflapping or rocking" which is more often present in children with severe ID (Einfeld \& Tonge, 1995). The "social relating" subscale comprises 10 items, e.g. "doesn't show affection", prefers to do things on his/her own; tends to be a loner" or "resists being cuddled, touched or held" which is an indicator for autistic behavior (Einfeld \& Tonge, 1995). Autism spectrum disorders are neurodevelopmental disorders with impairment in social communication and interaction and affected persons showing repetitive patterns of behavior (APA, 2013). Autistic disorders were already reported in children with NS (Wingbermühle et al., 2012).

In the present study, children with NS and NE (but not DUI) show higher prevalences of psychological problems. But due to small sample sizes, these findings have to be replicated in studies with a larger sample of persons with NS. 
Regarding treatment, guideline-based therapy options for all subtypes of incontinence are available (von Gontard, 2012a; von Gontard, 2012b) and can be applied to children and adolescents with NS in the same way than to typically developing children. In children/persons with NS with ID and psychological problems, standard treatment should be modified accordingly (von Gontard, 2013). Due to renal anomalies and other medical complications typical for NS, medical guidelines in the management of NS should always be followed, as well (Romano et al., 2010).

\section{Strengths and Limitations}

This is the first study that assesses incontinence in children, adolescents and adults with NS. Strengths are the prospective design, the use of standardized instruments in assessing psychological symptoms and the use of international guidelines in defining subtypes of incontinence (ICCS, DSM-5) (Austin et al., 2014; APA, 2013). Unfortunately, selection biases cannot be excluded, e.g. because of the small rates of returned questionnaires. Also, due to the study design, IQ could not be measured by a validated intelligence test and affected persons have not been examined clinically.

\section{Conclusions}

The present study provides the first information on incontinence and its association to psychological problems in children, adolescents and adults with Noonan syndrome. Incontinence is a relevant problem in children and adolescents with NS, but does not persist into adulthood. Psychological problems are especially present in NS and NE. Screening for both incontinence and psychological symptoms is recommended in children with NS. As most of the children with NS have average intelligence or a mild ID, they can be treated effectively with standard methods.

\section{Acknowledges}

We would like to thank the German support group Noonan-Kinder e.V. Deutschland and the chairperson Manuela Schnabel for giving us the opportunity to cooperate and conduct this study with help of the members of the support group.

\section{Ethical Approval}

The study was approved by the local ethics committee. 


\section{References}

American Psychiatric Association (APA). (2013). Diagnostic and statistical manual of mental disorders - Fifth edition (DSM 5). Washington, D.C.: APA.

Austin, P. F., Bauer, S. B., Bower, W., Chase, J., Franco, I., Hoebeke, P., . . Nevéus, T. (2014). The standardization of terminology of lower urinary tract function in children and adolescents: Update report from the standardization committee of the international children's continence society. Journal of Urology, 191(6), 18631865.

De Gennaro, M., Niero, M., Capitanucci, M. L., von Gontard, A., Woodward, M., Tubaro, A., \& Abrams, P. (2010). Validity of the international consultation on incontinence questionnaire-pediatric lower urinary tract symptoms: A screening questionnaire for children. Journal of Urology, 184(4 SUPPL.), 1662-1667.

Einfeld, S., \& Tonge, B. (1995). Manual for the Developmental Behavior checklist - primary carer version (DBC-P) \& teacher version (DBC-T)(2nd ed.). Clayton, Melbourne: Monash University Centre for Developmental Psychiatry and Psychology.

Einfeld, S., Tonge, B., \& Steinhausen, H. (2007). Verhaltensfragebogen bei Entwicklungsstörungen. Göttingen: Hogrefe.

Equit, M., Piro-Hussong, A., Niemczyk, J., Curfs, L., \& von Gontard, A. (2013). Elimination disorders in persons with Prader-willi and Fragile-X syndromes. Neurourology and Urodynamics, 32(7), 986-992.

George, C. D., Patton, M. A., El Sawi, M., Sharland, M., \& Adam, E. J. (1993). Abdominal ultrasound in Noonan syndrome: A study of 44 patients. Pediatric Radiology, 23(4), 316-318.

Joinson, C., Heron, J., Butler, U., \& von Gontard, A. (2006). Psychological differences between children with and without soiling problems. Pediatrics, 117(5), 1575-1584.

Joinson, C., Heron, J., Emond, A., \& Butler, R. (2007). Psychological problems in children with bedwetting and combined (day and night) wetting: A UK population-based study. Journal of Pediatric Psychology, 32(5), 605-616.

Joinson, C., Heron, J., \& von Gontard, A. (2006). Psychological problems in children with daytime wetting. Pediatrics, 118(5), 1985-1993.

Lee, D. A., Portnoy, S., Hill, P., Gillberg, C., \& Patton, M. A. (2005). Psychological profile of children with Noonan syndrome. Developmental Medicine and Child Neurology, 47(1), 35-38.

Noonan, J. A. (1994). Noonan syndrome: An update and review for the primary pediatrician. Clinical Pediatrics, 33(9), 548-555.

Noonan, J. A., \& Ehmke, D. A. (1963). Complications of ventriculovenous shunts for control of hydrocephalus. report of three cases with thromboemboli to the lungs. The New England Journal of Medicine, 269, 70-74.

Ohashi, H., Okuno, T., \& Mizuo, T. (1992). A case of Noonan syndrome with neurogenic bladder. Japanese Journal of Urology, 83(11), 1902-1905.

Roberts, A. E., Allanson, J. E., Tartaglia, M., \& Gelb, B. D.Noonan syndrome. The Lancet, 381(2013), 333-342.

Romano, A. A., Allanson, J. E., Dahlgren, J., Gelb, B. D., Hall, B., Pierpont, M. E., . . Noonan, J. A. (2010). Noonan syndrome: Clinical features, diagnosis, and management guidelines. Pediatrics, 126(4), 746-759.

Sarimski, K. (2000). Developmental and behavioral phenotype in Noonan syndrome? Genetic Counseling, 11(4), 383-390.

Sommerschild, H. C., \& Soerland, S. J. (1974). Urinary tract malformations in noonan's syndrome (XX, XY turner phenotype). Zeitschrift für Kinderchirurgie, 14(4), 422-425.

Steinhausen, H. -., \& Metzke, C. W. (2011). The developmental behavior checklist for adults. Psychometric properties and norms of the German version. [Der Verhaltensfragebogen bei Entwicklungsstörungen im Erwachsenenalter (VFE-ER)] Zeitschrift für Klinische Psychologie Und Psychotherapie, 40(3), 160-171.

Tartaglia, M., Gelb, B. D., \& Zenker, M. (2011). Noonan syndrome and clinically related disorders. Best Practice and Research: Clinical Endocrinology and Metabolism, 25(1), 161-179.

Verhoeven, W., Wingbermühle, E., Egger, J., Van Der Burgt, I., \& Tuinier, S. (2008). Noonan syndrome: Psychological and psychiatric aspects. American Journal of Medical Genetics, Part A, 146(2), 191-196. 
von Gontard, A., \& Nevéus, T. (2006). Management of bladder and bowel control in children. London: MacKeith Press.

von Gontard, A. (2012a). Encopresis. In J. M. Rey (Ed.), IACAPAP e-textbook of child and adolescent mental health. Geneva: International Association for Child and Adolescent Psychiatry and Allied Professions. http://iacapap.org/wp-content/uploads/C.5-ENCOPRESIS-0072012.pdf. Accessed 20.11.14.

von Gontard, A. (2012b). Enuresis. In J. M. Rey (Ed.), IACAPAP e-textbook of child and adolescent mental health. Geneva: International Association for Child and Adolescent Psychiatry and Allied Professions. http://iacapap.org/wp-content/uploads/C.4-ENURESIS-072012.pdf. Accessed 20.11.14.

von Gontard, A. (2013). Urinary incontinence in children with special needs. Nature Reviews Urology, 10(11), 667-674.

von Wendt, L., Simila, S., Niskanen, P., \& Jarvelin, M. -. (1990). Development of bowel and bladder control in the mentally retarded. Developmental Medicine and Child Neurology, 32(6), 515-518.

Wingbermühle, E., Egger, J. I. M., Verhoeven, W. M. A., Van Der Burgt, I., \& Kessels, R. P. C. (2012). Affective functioning and social cognition in noonan syndrome. Psychological Medicine, 42(2), 419-426.

Wood, A., Massarano, A., Super, M., \& Harrington, R. (1995). Behavioral aspects and psychiatric findings in noonan's syndrome. Archives of Disease in Childhood, 72(2), 153-155. 
Chapter 2.3

\section{Incontinence in persons with Angelman Syndrome}

Wagner, C. ${ }^{1}$, Niemczyk, J. ${ }^{1}$, Equit, M., Curfs, L. \& von Gontard, A. (2017). European Journal of Pediatrics, 176(2), 225-232.

\footnotetext{
${ }^{1}$ Equal contribution
} 


\section{Abstract}

Angelman Syndrome (AS) is a congenital syndrome with a prevalence of 1:15.000. Individuals with AS often have severe intellectual disability, typical dysmorphic signs and behavioral problems. The aim of the study was to investigate the rate of incontinence and associated psychological problems in children and adults with AS.

90 children (4-18 years) and 54 adults (18-31 years) with AS were recruited through a parent support group (55.6\% male, mean age 15.1 years). The Parental Questionnaire: Enuresis/Urinary Incontinence, the Incontinence Questionnaire-Pediatric Lower Urinary Tract Symptoms (ICIQ-CLUTS), as well as the Developmental Behavior Checklist for parents (DBC-P) or for adults (DBC-A) were filled out by parents or care-givers.

$85.6 \%$ of individuals with AS were affected by at least one subtype of incontinence (82.7\% nocturnal enuresis (NE), 64.7\% daytime urinary incontinence (DUI), 57.1\% fecal incontinence $(\mathrm{FI})$ ). $52.5 \%$ of the children and $32.6 \%$ of adults reached a clinically relevant DBC score. Incontinence was not associated with behavioral problems. NE and DUI were associated with genotype and epilepsy.

Children with AS have high rates of incontinence. Many adults are still affected by NE, DUI or even FI. Screening, assessment and treatment of incontinence in individuals with AS is recommended. 


\section{Introduction}

\section{Angelman Syndrome}

Angelman Syndrome (AS) is a congenital genetic disorder, which primarily affects the central nervous system. The prevalence of the syndrome is 1: 15000 (Thibert, Larson, Hsieh, Raby, \& Thiele, 2013). It is caused by a microdeletion or uniparental disomy (UPD) of chromosome 15q11-13, which leads to a loss of the maternal UBE3A gene (Thibert et al., 2013). This results in the characteristic symptoms of the disease: a developmental delay, severe intellectual disability with an IQ usually $<40$, severe speech impairment and ataxia. Most patients also show seizures and microcephaly. People with AS are characterized by a specific appearance with coarse facial features, unusually fair skin and light hair. Many suffer from scoliosis. Life expectancy for people with AS is almost normal (Thibert et al., 2013).

The developmental delay begins between the 6th and 12th month of life, while the other symptoms manifest themselves for the first time in early childhood (Thibert et al., 2013).

Children with AS usually show a cheerful but easily excitable behavior with frequent, often inappropriate laughter and a fascination with water. Hyperactivity and a short attention span are also widespread. Affected children often show abnormalities of the sleep-wake cycle and seem to need less sleep (5-6 hours/night) compared to typically developing children, but this improves with age. Adults with AS appear less easily excitable, though the intellectual impairment, epilepsy and speech problems remain (Bird, 2014).

\section{Incontinence}

According to the International Children's Continence Society (ICCS), nocturnal enuresis (NE) is defined as intermittent incontinence of discrete amounts of urine during sleep in a child aged 5 years or older after organic causes have been ruled out (Austin et al., 2016). Daytime urinary incontinence (DUI) is defined as loss of discrete amounts of urine during the day. Functional or non-organic DUI comprises heterogeneous conditions e.g. overactive bladder, voiding postponement and dysfunctional voiding. The DSM-5 differentiates between functional constipation (with or without fecal incontinence (FI)) and non-retentive $\mathrm{Fl}$ (without constipation) from the age of 4 years onwards after excluding organic causes (American Psychiatric Association (APA), 2013).

In typically developing children, functional (or non-organic) incontinence, including $\mathrm{NE}, \mathrm{DUI}$ and $\mathrm{FI}$ are common. Prevalence rates of 9.1-18.2\% for NE, 4.4-16.9\% for DUI and 1.4-5.4\% for FI for 6-7.5 year old children have been reported (von Gontard, 2012a; von Gontard, 2012b). 
Incontinence in children with intellectual disability and Angelman Syndrome

In children with intellectual disability (ID), incontinence rates are much higher. In a population-based sample, $38 \%$ of 7-year old children with ID had NE, 39\% had DUI and 30.5\% had FI (von Wendt, Simila, Niskanen, \& Jarvelin, 1990). The rates for incontinence in persons with ID still were 19-20\% at the age of 20 (von Wendt et al., 1990). Incontinence in children with special needs (e.g. ID or autism) often persists into adolescence and adulthood, although effective treatment options are available (von Gontard, 2013).

The rates of incontinence in individuals with AS have differed in publications so far. 95\% of patients with AS (5-44 years) were affected by incontinence in one study (Didden, Korzilius, Smits, \& Curfs, 2004). Buntinx et al. (1995) found a reduction of incontinence from $63 \%$ in children to $12.5 \%$ in adults. In another study, $43 \%$ of 28 adults with AS aged 20-53 years had DUI (Laan, Den Boer, Hennekam, Renier, \& Brouwer, 1996). These studies had no control group and small sample sizes and did not differentiate between different types of incontinence. Radstaake et al. (2013) examined 71 persons with AS and matched controls with non-specific ID. The controls had higher rates of DUI (54\% vs. 38\%) and $\mathrm{FI}(51 \%$ vs. $43 \%)$, while NE was the most common form of incontinence in both groups (controls: 58\%, AS: 62\%). Adaptive disabilities and epilepsy increased the risk for incontinence in young persons with AS (Radstaake et al., 2013).

\section{Aim of the study and hypotheses}

Therefore, the aim of this study was to assess the prevalence of NE, DUI and FI, as well as associated behavioral symptoms in a large sample of children, adolescents and adults with AS. Specifically, it was hypothesized that incontinence rates decrease with age and that there is an association between incontinence and behavioral comorbidity.

\section{Methods}

\section{Sample and Procedure}

Subjects were recruited through a German Angelman syndrome parent support group (Angelman e. V.). Packages with questionnaires, information sheets and return envelopes for children and adults were sent out to 427 member families (308< 18 years, $119 \geq 18$ years) over 6 months (August 2013 - January 2014) by the chairperson of the support group, so contact addresses weren't available and anonymity for the families was granted. Following informed consent, parents/caregivers were asked to complete the questionnaires and send them back anonymously. 156 questionnaires were returned (36.5\%). Due to data protection regulations, contact addresses were no longer available 
after sending out the packages. So, unfortunately, participants could not have been contacted again to achieve a higher response rate. The study was approved by the local ethics committee.

\section{Instruments}

To assess different subtypes of incontinence the "Parental Questionnaire: Enuresis/Urinary Incontinence" (von Gontard, 2012b) and the "Encopresis Questionnaire - Screening Version" (von Gontard, 2012a) were administered. Additionally, the German version of the International-Consultation-on-Incontinence-Questionnaire - Pediatric Lower Urinary Tract Symptom (ICIQ-CLUTS) was used to assess lower urinary tract symptoms (LUTS) (De Gennaro et al., 2010). The 10 questions of the ICIQ-CLUTS build a LUTS-score with clinically relevant scores higher than 13 . Validity and reliability were confirmed in a group on incontinent and continent children (De Gennaro et al., 2010). NE and DUI were diagnosed from the age of 5 years when wetting occurs at least once per month, according to the International Children's Continence Society (ICCS) criteria (Austin et al., 2016). FI was diagnosed from the age of 4 years according to DSM-5 criteria, i.e. when soiling occurs at least once per month (APA, 2013).

Behavioral and psychological symptoms were assessed with the German version of the Developmental Behavior Checklist (DBC) (Einfeld \& Tonge, 1995). The DBC is a reliable and valid instrument with separate norms for individuals with mild, moderate, or severe intellectual disability (Einfeld \& Tonge, 1995). The parental questionnaire consists of 96 items, which are rated with " 0 - not true as far as you know", " 1 - somewhat or sometimes true" and "2 - very true or often true". Parents/Caregivers of children and adolescents ( $<18$ years) completed the parental version (DBC- $P$ ), those of adults ( $\geq 18$ years) the adult version (DBC-A), respectively. The DBC-P comprises the subscales "Disruptive/Antisocial" (DA), "Self-Absorbed" (SA), "Communication Disturbance" (CD), "Anxiety" (A) and "Social Relating" (SR) and the "Total Behavior Problem Score" (TBPS). The DBC-A has the same subscales except that the fourth scale is termed "Anxiety/Depression" (AD). A TBPS above 46 in the DBC-P and above 51 in the DBC-A are considered as clinically relevant (Einfeld \& Tonge, 1995). German norms are available for children and adults with mild, moderate and severe intellectual disability for both the DBC-P and the DBC-A (Einfeld, Tonge, \& Steinhausen, 2007; Steinhausen \& Metzke, 2011). The DBC-P and DBC-A questionnaires were evaluated according to the norms of severe intellectual disability.

Of the 156 questionnaires returned, 3 were excluded due to age $<4$ years. In the remaining 153 cases, age data was missing in 9 cases and gender data in 2 cases.

Completed incontinence questionnaires of 90 children (4-17 years of age, mean age $=10.4$ years $(S D=3.9))$ and 54 adults $(18-31$ years of age, mean age $=22.9$ years $(S D=3.5))$ were included in the study. Complete DBC questionnaires were available for 81 children and adolescents and 44 adults. 


\section{Statistical analysis}

The data was analyzed with IBM SPSS Statistics 23, using descriptive statistics and performing nonparametric tests for categorical data ( $\chi 2$-tests, Fisher's Exact tests) and parametric tests for interval data (Student t-tests, Welch tests). Results were considered significant at a $p$-value $<.05$.

\section{Results}

\section{Descriptives}

Descriptive data on medical condition, psychological symptoms and diagnoses are outlined in table 7. $85.6 \%(n=153)$ of the total sample had at least one subtype of incontinence: $81 \%$ had NE, 61.4\% DUI and 53.9\% had FI. Constipation was reported in $46.1 \%$ (table 1). Only males (3.6\%) but no female had a LUTS score in the clinical range. The DBC score was in the clinical range in $50.6 \%$ of children and adolescents ( $<18$ years) and in $34.1 \%$ of adults (table 1). There were no significant differences between males and females neither in incontinence rates nor in clinical DBC scores (table 7). 70.6\% persons with AS had epilepsy and $85.0 \%$ were on anticonvulsants. Again, there were no gender differences (table 7).

Table 7: Angelman syndrome: descriptive data and gender comparisons, medication

\begin{tabular}{|c|c|c|c|c|}
\hline & $\begin{array}{l}\text { Total } \\
\mathrm{N}=1531\end{array}$ & $\begin{array}{l}\text { Male } \\
N=84\end{array}$ & $\begin{array}{c}\text { Female } \\
\mathrm{N}=67\end{array}$ & Significance \\
\hline Mean age in years (SD) & $15.10(7.16)$ & $14.75(7.33)$ & $15.56(6.98)$ & n. s. \\
\hline Incontinence overall \% (n) & $85.6(119 / 139)$ & $85.1(63 / 74)$ & $85.9(55 / 64)$ & n. s. \\
\hline NE \% (n) & $81.0(115 / 142)$ & $77.6(59 / 76)$ & $84.6(55 / 65)$ & n. s. \\
\hline DUI \% (n) & $61.4(86 / 140)$ & $60.8(45 / 74)$ & $62.5(40 / 64)$ & n. s. \\
\hline $\mathrm{FI} \%(\mathrm{n})$ & $53.9(76 / 141)$ & $52.0(39 / 75)$ & $56.3(36 / 64)$ & n. s. \\
\hline Constipation \% (n) & $46.1(65 / 141)$ & $44.0(33 / 75)$ & $48.4(31 / 64)$ & n. s. \\
\hline LUTS $\geq 13 \%(n)$ & $2.0(3 / 153)$ & $3.6(3 / 84)$ & $0.0(0 / 67)$ & n. s. \\
\hline LUTS mean score (SD) & $6.22(2.61)$ & $6.26(2.98)$ & $6.15(2.08)$ & n. $s^{5}$ \\
\hline DBC-P $P^{2}($ score $>46) \%(n)$ & $50.6(41 / 81)$ & $52.2(24 / 46)$ & $50.0(17 / 34)$ & n. s. \\
\hline DBC- $P^{2}$ Total mean T-value (SD) & $51.9(8.02)$ & $51.0(8.54)$ & $53.2(7.31)$ & n. $s^{4}$ \\
\hline DBC-A ${ }^{3}($ score $>51) \%(n)$ & $34.1(15 / 44)$ & $26.1(6 / 23)$ & $42.9(9 / 21)$ & n. s. \\
\hline DBC-A ${ }^{3}$ Total mean T-value (SD) & $47.1(9.24)$ & $45.9(9.68)$ & $48.3(8.79)$ & n. $s^{4}$ \\
\hline Epilepsy \% (n) & $70.6(108 / 153)$ & $70.2(59 / 84)$ & $70.1(47 / 67)$ & n. s. \\
\hline Medication \% (n) & $85.0(130 / 150)$ & $84.3(70 / 83)$ & $89.2(58 / 65)$ & n. s. \\
\hline Anticonvulsants & $78.5(113 / 144)$ & $73.5(61 / 83)$ & $75.4(49 / 65)$ & \\
\hline - Sodium valproate & $47.2(68 / 144)$ & $47.0(39 / 83)$ & $43.1(28 / 65)$ & \\
\hline - Ethosuximide & $22.9(33 / 144)$ & $21.7(18 / 83)$ & $24.6(16 / 65)$ & \\
\hline - Clobazam & $11.8(17 / 144)$ & $10.8(9 / 83)$ & $12.3(8 / 65)$ & \\
\hline
\end{tabular}




\begin{tabular}{|c|c|c|c|c|}
\hline & $\begin{array}{l}\text { Total } \\
\mathrm{N}=1531\end{array}$ & $\begin{array}{l}\text { Male } \\
\mathrm{N}=84\end{array}$ & $\begin{array}{c}\text { Female } \\
N=67\end{array}$ & Significance \\
\hline - Levetiracetam & $10.4(15 / 144)$ & $10.8(9 / 83)$ & $13.8(9 / 65)$ & \\
\hline - Others & $19.4(28 / 144)$ & $18.1(15 / 83)$ & $20.0(13 / 65)$ & \\
\hline Methylphenidate & $0.6(1 / 150)$ & $0.0(0 / 83)$ & $0.6(1 / 65)$ & \\
\hline Neuroleptics /Benzodiazepines & $4.6(7 / 150)$ & $3.6(3 / 83)$ & $4.6(3 / 65)$ & \\
\hline Melatonin & $8.0(12 / 150)$ & $8.4(7 / 83)$ & $6.2(4 / 65)$ & \\
\hline Laxatives & $16.0(24 / 150)$ & $15.7(13 / 83)$ & $16.9(11 / 65)$ & \\
\hline Thyroid Medication & $4.6(7 / 150)$ & $3.6(3 / 83)$ & $6.2(4 / 65)$ & \\
\hline $\begin{array}{l}\text { Antacids/Anti-inflammatory Medi- } \\
\text { cation }\end{array}$ & $8.0(12 / 150)$ & $6.0(5 / 83)$ & $3.1(2 / 65)$ & \\
\hline
\end{tabular}

${ }^{1}$ Gender data not available for $n=2$

${ }^{2}$ DBC-P data is available for 81 persons $<18$ years ( 46 males, 34 females, 1 missing)

${ }^{3}$ DBC-A data is available for 44 persons $\geq 18$ years ( 23 males, 21 females)

${ }^{4}$ Student t-tests

${ }^{5}$ Welch-test due to missing homogeneity of variance

\section{Incontinence and behavior over the age groups}

To analyze age effects, the sample was divided into 3 age groups: children (4-12 years), teens (13-17 years) and adults ( $\geq 18$ years) (table 8 ). The overall rates of incontinence were high through all age groups (96.6\% in children; $92.6 \%$ in teens; $74.0 \%$ in adults). Comparing the three age groups (children, teens and adults), there was a significant difference in the frequencies of $\mathrm{NE}\left(\chi^{2}=8.5 ; \mathrm{df}=2 ; \mathrm{p}=.015\right)$, and incontinence overall $\left(\chi^{2}=13.4\right.$; $\mathrm{df}=2 ; \mathrm{p}=.001)$ between the age groups: Children were more affected by incontinence overall and NE than adults. Constipation rates were similar in all age groups (45.1-50.0\%). Symptoms of urgency were highest in adolescents (44.4\%), but other LUTS were not a major problem (table 8).

Clinically relevant behavioral scores (DBC) were found in $45.5 \%$ and $52.5 \%$ of adolescents and children, respectively, whereas only $34.1 \%$ of adults had a DBC score in the clinical range. All subgroups had the highest T-values in the "self-absorbed" subscale (table 8). 
Table 8: Incontinence, LUTS and DBC-P/A data over the age groups in Angelman syndrome

\begin{tabular}{|c|c|c|c|c|c|}
\hline & $\begin{array}{l}\text { Total } \\
(\mathrm{N}=153)\end{array}$ & $\begin{array}{l}\text { Children } \\
\text { (4-12 years) } \\
(\mathrm{N}=63)\end{array}$ & $\begin{array}{l}\text { Teens } \\
(13-17 \text { years }) \\
(\mathrm{N}=27)\end{array}$ & $\begin{array}{l}\text { Young adults } \\
\text { (18-30 years) } \\
(\mathrm{N}=53)\end{array}$ & $\begin{array}{l}\text { Adults } \\
\text { (>30 years) } \\
(\mathrm{N}=1)\end{array}$ \\
\hline Any incontinence \% (n) & $85.6(119 / 139)$ & $96.6(57 / 59)$ & $92.6(25 / 27)$ & $73.5(36 / 49)$ & $100.0(1 / 1)$ \\
\hline Nocturnal enuresis (NE) \% (n) & $82.7(115 / 139)$ & $88.5(54 / 61)$ & $92.6(25 / 27)$ & $70.0(35 / 50)$ & $100.0(1 / 1)$ \\
\hline $\begin{array}{l}\text { Daytime urinary incontinence } \\
\text { (DUI) \% (n) }\end{array}$ & $64.7(86 / 133)$ & $70.7(41 / 58)$ & $70.4(19 / 27)$ & $53.2(25 / 47)$ & $100.0(1 / 1)$ \\
\hline Fecal incontinence (FI) \% (n) & $57.1(76 / 133)$ & $64.937 / 57)$ & $57.7(15 / 26)$ & $46.9(23 / 49)$ & $100.0(1 / 1)$ \\
\hline Constipation \% (n) & $46.1(65 / 141)$ & $47.4(27 / 57)$ & $50.0(12 / 24)$ & $45.1(23 / 51)$ & $0(0 / 0)$ \\
\hline LUTS-score $\geq 13 \%$ (n) & $2.0(3 / 153)$ & $1.6(1 / 63)$ & $3.7(1 / 27)$ & $0.0(0 / 53)$ & $100.0(1 / 1)$ \\
\hline LUTS mean score (SD) & $6.31(2.57)$ & $6.59(2.47)$ & $6.52(2.56)$ & $5.75(2.51)$ & $13.0(-)$ \\
\hline Urgency $^{2} \%(n)$ & $32.8(19 / 58)$ & $35(7 / 20)$ & $44.4(4 / 9)$ & $28.6(8 / 28)$ & $0(0 / 0)$ \\
\hline Postponement ${ }^{2} \%$ (n) & 0 & - & - & - & - \\
\hline Straining $2 \%(n)$ & $4.9(3 / 61)$ & $4.9(3 / 61)$ & $0(0 / 0)$ & $0(0 / 0)$ & $0(0 / 0)$ \\
\hline DBC-P $(\text { score }>46)^{3} \%(n)$ & $50.6(41 / 81)$ & $52.5(31 / 59)$ & $45.5(10 / 22)$ & - & - \\
\hline DBC-A (score > 51$)^{4} \%(n)$ & $34.1(15 / 44)$ & - & - & $32.6(14 / 43)$ & $100.0(1 / 1)$ \\
\hline $\begin{array}{l}\text { DBC-P/A Total mean T-value } \\
(S D)^{5}\end{array}$ & & $52.44(8.63)$ & $48.9(12.85)$ & $46.8(9.24)$ & $56.0(-)$ \\
\hline \multicolumn{6}{|l|}{ Subscales mean T-values (SD): } \\
\hline Disruptive/Antisocial & & $50.98(8.23)$ & $48.55(6.82)$ & $43.67(8.58)$ & 52.00 \\
\hline Self-Absorbed & & $52.66(8.14)$ & $51.0(6.87)$ & $56.19(7.55)$ & 62.00 \\
\hline Communication Disturbance & & $49.36(7.92)$ & $49.45(5.86)$ & $45.86(6.22)$ & 48.00 \\
\hline Anxiety & & $47.54(9.74)$ & $45.18(11.61)$ & $44.42(5.97)$ & 54.00 \\
\hline Social Relating & & 44.54 (8.97) & $46.0(7.56)$ & $42.09(8.84)$ & 52.00 \\
\hline
\end{tabular}

\footnotetext{
${ }^{1}$ Age data not available for $n=9$

${ }^{2}$ Items 7, 8 and 9 of the ICIQ-CLUTS scored as 'most of the time' or 'all of the time'

${ }^{3}$ DBC- $P$ data refer to $n=81$ persons between $4-17$ years

${ }^{4}$ DBC-A data refer to $n=44$ persons 18 years or older

${ }^{5}$ DBC-P mean T-values for children and teens, DBC-A mean T-values for young adults and adults
}

In table 9, the association between behavioral data and incontinence was analyzed. The rates of incontinence did not differ between groups with a clinical DBC-score and those with a subclinical DBC-score (table 9). 
Table 9: Associations of incontinence and behavioral symptoms in the clinical range: children and teens and adults with Angelman syndrome

\begin{tabular}{|c|c|c|c|c|c|c|}
\hline Age groups (years) & $\begin{array}{l}\text { Children and } \\
\text { teens (4-17) } \\
\text { with clinical } \\
\text { DBC-P- } \\
\text { scores }\end{array}$ & $\begin{array}{l}\text { Children and } \\
\text { teens (4-17) } \\
\text { with subclinical } \\
\text { DBC-P-scores }\end{array}$ & $\begin{array}{l}\text { Significance } \\
\text { (p) }\left(\chi^{2} \text {-test }\right)\end{array}$ & $\begin{array}{l}\text { (Young) Adults } \\
\text { ( } \geq 18) \text { with } \\
\text { clinical DBC-A- } \\
\text { scores }\end{array}$ & $\begin{array}{l}\text { (Young) Adults } \\
(\geq 18) \text { with } \\
\text { subclinical } \\
\text { DBC-A-scores }\end{array}$ & $\begin{array}{l}\text { sSignificance } \\
(p) \\
\left(\chi^{2} \text {-test }\right)\end{array}$ \\
\hline $\mathrm{N}$ & 40 & 39 & & 15 & 27 & \\
\hline $\begin{array}{l}\text { At least one type } \\
\text { of incontinence \% } \\
\text { (n) }\end{array}$ & $100.0(40 / 40)$ & $91.9(34 / 37)$ & n. s. ${ }^{1}$ & $66.7(10 / 15)$ & $73.1(19 / 26)$ & n. s. ${ }^{1}$ \\
\hline NE \% (n) & $97.5(39 / 40)$ & $84.6(33 / 39)$ & n. s. ${ }^{1}$ & $66.7(10 / 15)$ & $70.4(19 / 27)$ & n. s. ${ }^{1}$ \\
\hline DUI \% (n) & $74.4(29 / 39)$ & $67.6(25 / 37)$ & n. s. ${ }^{1}$ & $40.0(6 / 15)$ & $52.0(13 / 25)$ & n. s. \\
\hline $\mathrm{FI} \%(\mathrm{n})$ & $64.1(25 / 39)$ & $61.1(22 / 36)$ & n. s. & $46.7(7 / 15)$ & $40.0(10 / 25)$ & n. s. \\
\hline Constipation \% (n) & $43.6(17 / 39)$ & $50.0(17 / 34)$ & n. s. & $61.5(8 / 13)$ & $39.3(11 / 28)$ & n. s. ${ }^{1}$ \\
\hline $\begin{array}{l}\text { LUTS-score } \geq 13 \% \\
\text { (n) }\end{array}$ & $2.4(1 / 41)$ & $2.5(1 / 40)$ & n. s. ${ }^{1}$ & $6.7(1 / 15)$ & $0.0(0 / 29)$ & n. s. ${ }^{1}$ \\
\hline
\end{tabular}

\footnotetext{
${ }^{1}$ Fisher's Exact test
}

\section{Further results}

Table 10 shows the distribution of incontinence for the underlying AS genotypes. Patients with an UPD had the highest rates of incontinence, followed by patients with deletion at 15q11-13, an UBE3A- or imprinting mutation. The distribution differed significantly for all subtypes of incontinence (NE, DUI and FI), but not for constipation or DBC-scores.

Table 10: Incontinence and DBC-P/A data over the genotypes of Angelman syndrome

\begin{tabular}{|c|c|c|c|c|c|c|}
\hline & $\begin{array}{l}\text { Total } \\
(\mathrm{N}=153)\end{array}$ & $\begin{array}{l}\text { Deletion } \\
15 q 11-13 \\
(\mathrm{~N}=92)\end{array}$ & $\begin{array}{l}\text { Uniparental } \\
\text { Disomy } \\
(\mathrm{N}=12)\end{array}$ & $\begin{array}{l}\text { Imprinting } \\
\text { mutation } \\
(\mathrm{N}=12)\end{array}$ & $\begin{array}{l}\text { UBE3a } \\
\text { mutation } \\
(\mathrm{N}=8)\end{array}$ & Significance \\
\hline Any incontinence \% (n) & $85.6(119 / 139)$ & $90.6(77)$ & $100.0(12)$ & $50.0(5)$ & $66.7(4)$ & $.005^{* *}$ \\
\hline $\begin{array}{l}\text { Nocturnal enuresis (NE) \% } \\
\text { (n) }\end{array}$ & $\% 82.7(115 / 139)$ & $85.9(73 / 85)$ & $100(12 / 12)$ & $45.5(5 / 11)$ & $57.1(4 / 7)$ & $.005^{* *}$ \\
\hline $\begin{array}{l}\text { Daytime urinary inconti- } \\
\text { nence (DUI) \% (n) }\end{array}$ & $64.7(86 / 133)$ & $67.9(57 / 84)$ & $75.0(9 / 12)$ & $16.7(2 / 12)$ & $37.5(3 / 8)$ & $.002 * *$ \\
\hline $\begin{array}{l}\text { Fecal incontinence }(\mathrm{FI}) \% \\
\text { (n) }\end{array}$ & $57.1(76 / 133)$ & $58.3(49 / 84)$ & $72.7(8 / 11)$ & $9.1(1 / 11)$ & $42.9(3 / 7)$ & $.022 *$ \\
\hline Constipation \% (n) & $46.1(65 / 141)$ & $50.0(42 / 84)$ & $50.0(6 / 12)$ & $27.3(3 / 11)$ & $37.5(3 / 8)$ & .126 \\
\hline DBC-P $(\text { score }>46)^{3} \%(n)$ & $50.6(41 / 81)$ & $47.8(22 / 46)$ & $20.0(2 / 10)$ & $50.0(3 / 6)$ & $66.7(2 / 3)$ & .535 \\
\hline DBC-A $(\text { score }>51)^{4} \%(n)$ & $34.1(15 / 44)$ & $32.1(9 / 28)$ & - & $25.0(1 / 4)$ & $33.3(1 / 3)$ & .570 \\
\hline
\end{tabular}

\footnotetext{
${ }^{1}$ Age data not available for $\mathrm{n}=29$

${ }^{2}$ Items 7, 8 and 9 of the ICIQ-CLUTS scored as 'most of the time' or 'all of the time'

${ }^{3}$ DBC- $P$ data refer to $n=81$ persons between $4-17$ years

${ }^{4}$ DBC-A data refer to $n=44$ persons 18 years or older

${ }^{5}$ DBC-P mean T-values for children and teens, DBC-A mean T-values for young adults and adults
} 
NE and DUI were found more often in AS patients with compared to those without epilepsy (table 11). In contrast, there was no difference for $\mathrm{FI}$, constipation or DBC-scores in AS patients with or without comorbid epilepsy.

Table 11: Incontinence and DBC-P/A data for patients with Angelman syndrome and epilepsy

\begin{tabular}{|c|c|c|c|c|}
\hline & $\begin{array}{l}\text { Total } \\
(\mathrm{N}=153)\end{array}$ & $\begin{array}{l}\text { AS Patients with } \\
\text { comorbid epilepsy } \\
\text { (N=108) }\end{array}$ & $\begin{array}{l}\text { AS Patients without } \\
\text { comorbid epilepsy } \\
(\mathrm{N}=45)\end{array}$ & Significance \\
\hline Any incontinence \% (n) & $\begin{array}{l}85.6 \\
(119 / 139)\end{array}$ & $87.0(87 / 100)$ & $13.0(13 / 100)$ & .455 \\
\hline Nocturnal enuresis (NE) \% (n) & $\begin{array}{l}82.7 \\
(115 / 139)\end{array}$ & $85.1(86 / 101)$ & $14.9(15 / 101)$ & $.047^{*}$ \\
\hline $\begin{array}{l}\text { Daytime urinary incontinence (DUI) } \\
\%(n)\end{array}$ & $64.7(86 / 133)$ & $67.0(67 / 100)$ & $33.0(33 / 100)$ & $.032 *$ \\
\hline Fecal incontinence (FI) \% (n) & $57.1(76 / 133)$ & $56.3(58 / 103)$ & $43.7(45 / 103)$ & .345 \\
\hline Constipation \% (n) & $46.1(65 / 141)$ & $49.0(49 / 100)$ & $51.0(51 / 100)$ & .186 \\
\hline DBC-P $(\text { score }>46)^{3} \%(n)$ & $50.6(41 / 81)$ & $53.4(31 / 58)$ & $46.6(27 / 58)$ & .287 \\
\hline DBC-A $(\text { score }>51)^{4} \%(n)$ & $34.1(15 / 44)$ & $35.5(11 / 31)$ & $64.5(20 / 31)$ & .525 \\
\hline
\end{tabular}

\section{Discussion}

This is the largest study on incontinence in individuals with AS, showing that incontinence is a major problem throughout the life span.

\section{Incontinence overall}

Despite the decreasing rates from childhood to adulthood, rates remain high. As seen in previous studies, a more severe level of ID is generally associated with higher rates of incontinence (von Wendt et al., 1990). In the present study, the rates of incontinence in children (88.5\% NE, 70.7\% DUI, 64.9\% FI, mean age 8.3 years) were higher than in a population-based study on 7-year-olds with severe ID (33.3\% NE, 38.1\% DUI, 38.1\% FI), and also higher than in 20-year-olds with severe ID (19-24\% vs. $73.5 \%$ of young adults (mean age 22.7 years) (von Wendt et al., 1990). Radstaake et al. (2013) found similar incontinence rates in AS, as well (89\% NE, 54\% DUI, 61\% FI). In that study, rates were only significantly lower in DUI, compared to persons with ID and other genetic syndromes.

\section{Developmental and behavioral problems}

Individuals with AS are not only highly impaired in their cognitive development, but also show multiple somatic complaints and medical condition (e.g. epilepsy). All these problems may contribute to the high incontinence rates. The movement or speech development in persons with AS is affected (Thibert et al., 2013), as well, which may also lead to practical problems in toileting behavior (e.g. motor problems to get undressed or to sit 
properly on the toilet), causing more incontinent episodes. This is also supported by findings of DUI and FI rates being higher in wheelchair bound persons with AS (Radstaake et al., 2013).

Additionally, it could be speculated that behavioral problems, such as hyperactivity and attention problems, could be responsible for the high rates of incontinence. The results in the present study show that incontinence occurs irrespective of behavioral problems. This is in congruence with the findings in a comparable study on Williams syndrome (von Gontard et al., 2016).

\section{Incontinence and genotype}

In the present study, there were significant differences in the incontinence rates for the underlying AS genotypes. Although AS patients with UPD tend to have a milder impaired phenotype with less seizures and better physical growth, motor skills and receptive language than deletion patients (Bird, 2014), they were more often affected by incontinence than other underlying genotypes. AS patients with deletions are the most common subgroup with prevalence rates up to $75 \%$ (Thibert et al., 2013). They usually have a more severe phenotype with microcephaly, seizures, motor difficulties and language impairment (Bird, 2014), but were found to be less affected of incontinence in the present study. However, subsample sizes are small and results should be interpreted cautiously. Nevertheless, the results show that incontinence is a severe problem in all patients with AS, regardless of genotype.

\section{Nocturnal enuresis and sleep problems in persons with AS}

NE was found to be the most common type of incontinence in persons with AS (Radstaake et al., 2013). This result is in line with studies on such diverse syndromes as Rett, PraderWilli and Williams. Sleep difficulties are reported in all four syndromes (Bird, 2014; Thibert et al., 2013). About half of the persons with AS have sleep difficulties, e.g. difficulty to initiate sleep, a shorter sleep duration or heightened arousability (Thibert et al., 2013; Takaesu, Komada, \&Inoue, 2012), which all are associated with epilepsy (Thibert et al., 2013). Braam, Didden, \& Smits (2008) observed an improved quality and quantity of sleep after melatonin supplementation in patients with AS, but also high salivary melatonin levels. A disturbed melatonin metabolism with decreased melatonin levels was suggested. Takaesu et al. (2012) found the nighttime melatonin levels in 15 AS patients significantly lower than in age-matched controls. Melatonin treatment in children with developmental disabilities was associated with a significant decrease in sleep onset latency time (Schwichtenberg \& Malow, 2015). However, the effects on NE were not assessed. Melatonin supplementation in typically developing children had no effects on NE or on the sleep-wake cycle (Merks, Burger, Willemsen, van Gool, \& de Jong, 2012). 


\section{Incontinence and epilepsy}

The present study found the presence of epilepsy in AS positively related to NE, in line with the results of Radstaake et al. (2013): In AS individuals with epilepsy, the risk of NE was 13 times higher than in AS without epilepsy. In the present study, rates of NE were higher in AS with epilepsy than in those without (85.1\% vs. $70.7 \%)$, as well. Severe epilepsy is a frequent clinical feature in persons with AS, with prevalence rates from 80 to 95\% (Thibert et al., 2013). However, this is the first study which found an association between epilepsy and DUI.

To understand the association between epilepsy and incontinence in AS, further research is needed. Modern neuroimaging studies using diffusion tensor imaging techniques revealed white matter alterations throughout the brain with alterations in temporal pathways being correlated to clinical symptoms, myelination delay and thinning of the corpus callosum in persons with AS (Peters et al., 2011). It can be speculated that common central nervous system factors could be responsible for the association between incontinence, epilepsy and sleep problems.

\section{Strengths and Limitations}

Strengths of the study are the large sample size, the use of standardized instruments in assessing psychological symptoms and the adherence to ICCS-definitions (Austin et al., 2016). Limitations include the cross-sectional design and the reliance on parent and caregiver information. Also, the study did not include IQ measured by a validated intelligence test and a clinical examination of the affected persons. In future studies, objective assessment (e.g. ultrasound, uroflowmetry, voiding diaries) in individuals with AS would add important information.

\section{Conclusions}

The present study shows that especially children and teens with AS are at risk for incontinence. Incontinence decreases in adolescence and adulthood, but remains at a high level. Comorbid epilepsy is significantly associated with NE and DUI. There is no association between incontinence and behavioral problems. Nevertheless, specific programs for persons with intellectual disability will be needed in the care of children, adolescents and adults with AS. These should include necessarily a detailed assessment and treatment for incontinence.

\section{Funding}

None. 


\section{Conflict of interest}

All authors declare that they have no conflict of interest.

\section{Acknowledges}

We would like to thank the German support group Angelman e. V. Deutschland for giving us the opportunity to cooperate and conduct this study with help of the members of the support group.

\section{Compliance with ethical standards:}

\section{Ethical approval}

All procedures performed in studies involving human participants were in accordance with the ethical standards of the institutional and/or national research committee and with the 1964 Helsinki declaration and its later amendments or comparable ethical standards.

Informed consent

Informed consent was obtained from all individual participants included in the study. 


\section{References}

American Psychiatric Association (APA). (2013). Diagnostic and Statistical Manual of Mental Disorders, Fifth Edition (DSM-5). Arlington, VA: American Psychiatric Association.

Austin, P. F., Bauer, S. B., Bower, W., Chase, J., Franco, I., Hoebeke, P., ... Nevéus, T. (2016). The standardization of terminology of lower urinary tract function in children and adolescents: Update report from the standardization committee of the international children's continence society. Neurourology and Urodynamics, 35, 471-481.

Bird, L. M. (2014). Angelman syndrome: review of clinical and molecular aspects. Application of Clinical Genetics, 7, 93-104.

Braam, W., Didden, R., Smits, M. G., \& Curfs, L. M. (2008). Melatonin for chronic insomnia in Angelman syndrome: a randomized placebo-controlled trial. Journal of Child Neurology, 23(6), 649-654.

Buntinx, I. M., Hennekam, R., Brouwer, O. F., Stroink, H., Beuten, J., Mangelschots, K., \& Fryns, J. P. (1995). Clinical profile of Angelman syndrome at different ages. American Journal of Medical Genetics, 56(2), 176183.

De Gennaro, M., Niero, M., Capitanucci, M. L., von Gontard, A., Woodward, M., Tubaro, A., \& Abrams, P. (2010). Validity of the international consultation on incontinence questionnaire-pediatric lower urinary tract symptoms: a screening questionnaire for children. The Journal of urology, 184(4), 1662-1667.

Didden, R., Korzilius, H., Smits, M. G., \& Curfs, L. M. G. (2004). Sleep problems in individuals with Angelman syndrome. American Journal on Mental Retardation, 109(4), 275-284.

Einfeld, S., \& Tonge, B. (1995). Manual for the Developmental Behavior Checklist - primary carer version (DBCP) \& teacher version (DBC-T) (2nd ed.). Clayton, Melbourne: Monash University Centre for Developmental Psychiatry and Psychology.

Einfeld, S., Tonge, B., \& Steinhausen, H. (2007). Verhaltensfragebogen bei Entwicklungsstörungen. Göttingen: Hogrefe.

Laan, L. A. E. M., Den Boer, A. T., Hennekam, R. C. M., Renier, W. O., \& Brouwer, O. F. (1996). Angelman syndrome in adulthood. American Journal of Medical Genetics, 66(3), 356-360.

Merks, B. T., Burger, H., Willemsen, J., van Gool, J. D., \& De Jong, T. P. V. M. (2012). Melatonin treatment in children with therapy-resistant monosymptomatic nocturnal enuresis. Journal of pediatric urology, 8(4), 416-420.

Peters, S. U., Kaufmann, W. E., Bacino, C. A., Anderson, A. W., Adapa, P., Chu, Z., ... \& Wilde, E. A. (2011). Alterations in white matter pathways in Angelman syndrome. Developmental Medicine \& Child Neurology, 53(4), 361-367.

Radstaake, M., Didden, R., Giesbers, S., Korzilius, H., Peters-Scheffer, N., Lang, R., . . Curfs, L. M. G. (2013). Incontinence in individuals with Angelman syndrome: A comparative study. Research in Developmental Disabilities, 34(11), 4184-4193.

Schwichtenberg, A. J., \& Malow, B. A. (2015). Melatonin treatment in children with developmental disabilities. Sleep medicine clinics, 10(2), 181-187.

Steinhausen, H., \& Metzke, C. W. (2011). The Developmental Behavior Checklist for adults. Psychometric properties and norms of the German version [Der Verhaltensfragebogen bei Entwicklungsstörungen im Erwachsenenalter (VFE-ER)]. Zeitschrift für klinische Psychologie und Psychotherapie, 40(3), 160-171.

Takaesu, Y., Komada, Y., \& Inoue, Y. (2012). Melatonin profile and its relation to circadian rhythm sleep disorders in Angelman syndrome patients. Sleep medicine, 13(9), 1164-1170.

Thibert, R. L., Larson, A. M., Hsieh, D. T., Raby, A. R., \& Thiele, E. A. (2013). Neurologic manifestations of Angelman syndrome. Pediatric neurology, 48(4), 271-279.

von Gontard, A. (2013). Urinary incontinence in children with special needs. Nature Reviews Urology, 10(11), 667-674.

von Gontard, A. (2012a). Encopresis. In J. M. Rey (Ed.), IACAPAP e-textbook of child and adolescent mental health. Geneva: International Association for Child and Adolescent Psychiatry and Allied Professions. http://iacapap.org/wp-content/uploads/C.5-ENCOPRESIS-0072012.pdf. Accessed 11.03.16. 
von Gontard, A. (2012b). Enuresis. In J. M. Rey (Ed.), IACAPAP e-textbook of child and adolescent mental health. Geneva: International Association for Child and Adolescent Psychiatry and Allied Professions. http://iacapap.org/wp-content/uploads/C.4-ENURESIS-072012.pdf. Accessed 11.03.16.

von Gontard, A., Niemczyk, J., Borggrefe-Moussavian, S., Wagner, C., Curfs, L., \& Equit, M. (2016). Incontinence in children, adolescents and adults with Williams syndrome. Neurourology and Urodynamics, 35(8), $1000-$ 1005.

von Wendt, L., Simila, S., Niskanen, P., \& Jarvelin, M. (1990). Development of bowel and bladder control in the mentally retarded. Developmental Medicine and Child Neurology, 32(6), 515-518. 



\section{Chapter 2.4}

\section{Incontinence and psychological symptoms in individuals with Mowat-Wilson Syndrome}

Niemczyk, J., Einfeld, S., Mowat, D., Equit, M., Wagner, C., Curfs, L. \& von Gontard, A. (2017). Research in Developmental Disabilities, 62, 230-237. 


\section{Abstract}

Mowat-Wilson Syndrome (MWS) is caused by deletion/mutation of the ZEB2 gene on chromosome $2 q 22$. MWS is characterized by a distinctive facial appearance, severe intellectual disability and other anomalies, e.g. seizures and/or Hirschsprung disease (HSCR). Most individuals have a sociable demeanor, but one third show psychological problems. The aim was to investigate incontinence and psychological problems in MWS.

26 children (4-12 years), 13 teens (13-17 years) and 8 adults (>18 years) were recruited through a MWS support group. The Parental Questionnaire: Enuresis/Urinary Incontinence, as well as the Developmental Behavior Checklist (DBC) were completed by parents or care-givers.

97.7\% of persons with MWS had incontinence (nocturnal enuresis $74.4 \%$; daytime urinary incontinence $76.2 \%$; fecal incontinence $81.4 \%$ ). Incontinence remained high over age groups (children $95.8 \%$, teens $100 \%$, adults $100 \%$ ). $46.2 \%$ of children, $25 \%$ of teens and $37.5 \%$ of adults exceeded the clinical cut-off on the DBC. The ability to use the toilet for micturition improved with age.

MWS incontinence rates are very high. All had physical disabilities including anomalies of the genitourinary and gastrointestinal tract. Due to the high prevalence rates, a screening for incontinence and psychological problems in MWS is recommended. 


\section{Introduction}

\section{Mowat-Wilson Syndrome}

Mowat-Wilson Syndrome (MWS) is a congenital syndrome caused by a deletion or mutation of the ZEB2 gene on chromosome 2q22 (Mowat \& Wilson, 2010). It was first described by Mowat et al. in 1998 in six individuals with symptoms of severe intellectual disability (ID), microcephaly, short stature and Hirschsprung disease (HSCR) (Mowat et al., 1998). Further characteristics of MWS are typical facial features (prominent nasal tip and chin, cupped ears with upturned lobes, deep-set eyes, hypertelorism, broad medially sparse eyebrows), severe developmental delay, seizures, constipation and a happy, social demeanor (Adam et al., 2006; Mowat \& Wilson, 2010). Prevalence is estimated at 1 : 50,000-70,000 (Mowat \& Wilson, 2010).

\section{Behavioral phenotype of Mowat-Wilson Syndrome}

The behavioral phenotype in MWS was examined by Evans et al. in a sample on 61 individuals, who found less depressive or mood problems, more oral (as chewing objects or grinding teeth) and stereotyped behaviors and an underreaction to pain in comparison to a group of non-syndromatic persons with ID (Evans et al., 2012). Further descriptions of MWS point out the happy demeanor, sociability and frequent laughter, but also selfinjuring and hyperactive behavior (Adam, Justice, Bean, \& Fernhoff, 2008; Mowat \& Wilson, 2010). Sleep disturbances with an association to psychological problems are also found in MWS (Evans, Mowat, Wilson, \& Einfeld, 2016). Intelligence in MWS is mostly in the range of severe ID (Evans et al., 2012; Garavelli et al., 2009).

\section{Incontinence}

Functional incontinence (including nocturnal enuresis (NE), daytime urinary incontinence (DUI) or fecal incontinence (FI)) is a common disorder affecting about 1-10\% of typically developing children and decreasing to $<1 \%$ in adolescence and adulthood (Franco, Austin, Bauer, von Gontard, \& Homsy, 2015). In individuals with ID, incontinence rates are much higher (approx. 30-40\%), and are associated with the level of ID (von Wendt, Simila, Niskanen, \& Jarvelin, 1990). In a population-based sample, 33-38\% of 7-year-old children with severe ID had some subtype of incontinence, and at the age of 20 years, $19-24 \%$ of individuals with severe ID still had incontinence problems (von Wendt et al., 1990).

\section{Incontinence in Mowat-Wilson Syndrome}

Incontinence has not been systematically examined in MWS. In a report on 12 cases with MWS aged 0-23 years, 3 of the 8 individuals who were older than 4 years were not toilet trained, one was in the process of toilet training and 3 were continent (Adam et al., 2006). 
HSCR is a condition often associated with constipation and $\mathrm{FI}$ and is found in approximately $45 \%$ of MWS patients (Coyle \& Puri, 2015). In a review of published cases, constipation was reported in 30\%, genitourinary and renal anomalies in 52\% (Garavelli et al., 2009).

\section{Aim of the study}

The aim of this study was to examine incontinence subtypes, associated conditions (constipation, lower urinary tract symptoms (LUTS), anomalies of the genitourinary and gastrointestinal tract), adaptive toileting skills and behavioral symptoms in different age groups of individuals with MWS.

\section{Material and methods}

\section{Procedure}

Packages with questionnaires were sent to all member families of the German MowatWilson Syndrome support group "Mowat-Wilson Deutschland". As it comprises only 10 families, the study was also announced on the homepage of the International MowatWilson Foundation. Questionnaires in four languages were provided (English, German, French, Italian), which could be requested online by interested families. Following informed consent, parents or caregivers were asked to complete the questionnaires and send them back. Questionnaires were sent out and received over 28 months (June 2013 - October 2015).

\section{Instruments}

Incontinence was assessed by the "Parental Questionnaire: Enuresis/Urinary Incontinence" (von Gontard, 2012b), "Encopresis Questionnaire - Screening Version" (von Gontard, 2012a). Six questions about adaptive toileting skills were added to the questionnaire. LUTS were assessed by the German version of the "International-Consultation-onIncontinence-Questionnaire - Pediatric Lower Urinary Tract Symptom" (ICIQ-CLUTS) (de Gennaro et al., 2010). The 10 questions of the ICIQ-CLUTS build a LUTS-score with clinically relevant scores over 13. According to the International Children's Continence society (ICCS), NE and DUI were diagnosed in persons older than 5 years when wetting occurs at least once per month (Austin et al., 2016). According to DSM-5, FI was diagnosed from the age of 4 years when soiling occurs at least once per month (American Psychiatric Association (APA), 2013).

Psychological problems were assessed by the Developmental Behavior Checklist (DBC) (Einfeld \& Tonge, 2002; Mohr, Tonge, Einfeld \& Taffe, 2011). The DBC is composed 
of five subscales ("Disruptive/Antisocial", "Self-Absorbed", "Communication Disturbance", "Anxiety" and "Social Relating") that add up to the Total Behavior Problem Score (TBPS). Parents or caregivers filled out either the parental version of the DBC (DBC-P) for children or adolescents, or the adult version (DBC-A) for adults. The DBC-A has an additional scale "Depression".

Clinically relevant scores are defined as a TBPS $>46$ in the DBC-P and as a TBPS $>51$ in the DBC-A, respectively (Einfeld \& Tonge, 2002; Mohr et al., 2011). In addition, DBC$\mathrm{P} / \mathrm{A}$ Total scores can be expressed in percentiles according to norms for children and adults with mild, moderate and severe intellectual disability, that are available for both, DBC-P and DBC-A (Einfeld \& Tonge, 2002; Mohr et al., 2011). Mean Item scores are provided for the subscales. The DBC has a high reliability (DBC-P: $r=.80-.83$; DBC-A: $r=.69$ .72 ) and a significant concurrent validity with questionnaires and expert rating (DBC-P: $r=.72-.86$; DBC-A: $r=.52-.63$ ) (Einfeld \& Tonge, 2002; Mohr et al., 2011). DBC-P and DBCA questionnaires were evaluated according to the norms of severe intellectual disability in the present sample.

The study was approved by the local ethics committee.

\section{Statistical analysis}

Statistical analyses performed by IBM SPSS Statistics 23 included descriptive statistics, and nonparametric tests ( $\chi 2$-tests, Fisher's Exact tests) for categorical data and parametric tests (univariate ANOVA, Student t-tests, Welch tests) for parametric data. Results were considered significant at a $p$-value $<.05$.

\section{Results}

Packages were sent to 10 German families with a member affected by MWS. Further, 110 online requests of questionnaires were received from 18 different countries, but most from the USA, Australia and the UK. 48 questionnaires were completed and sent back. Due to an age of less than four years, one participant was excluded. The majority of questionnaires was completed by the mother (91.5\%), in $6.4 \%$ by the father and in $2.1 \%(n=1)$ the person was unknown.

\section{Descriptive data}

Descriptive data are outlined in table 12. Mean age of the sample was 13.0 years (range 4-33 years) with a nearly equal gender distribution (20 males, 27 females). Medical conditions were frequent with HSCR reported in $38.3 \%$ and genitourinary/renal anomalies in $36.2 \%$. A DBC score in the clinical range was found in $39.1 \%$. 


\section{Incontinence and $D B C$ data in the total sample}

Incontinence data are available for 43 persons. All but one person were affected by incontinence (97.5\%). Rates of FI (82.1\%) were higher than of NE (72.5\%) or DUI $(74.4 \%)$ in the total sample. The mean LUTS score was 5.2 ( $S D=2.1$, range $0-8$ ), but was only calculated in persons who did not wear a diaper all day $(n=6)$. There were neither significant gender differences in the clinical $D B C$ scores $\left(\mathrm{Chi}^{2}=.120 ; \mathrm{df}=1 ; \mathrm{p}=.729\right)$ nor in the rates of incontinence (Fisher's Exact test; $\mathrm{p}=.419$ ).

Table 12: Descriptive data, somatic conditions and subgroups of incontinence of the total sample with MowatWilson syndrome

\begin{tabular}{|c|c|}
\hline & Total $(\mathrm{N}=47)$ \\
\hline Mean age in years (SD) & $13.0(6.8)$ \\
\hline Males \% (n) & $42.6(20 / 47)$ \\
\hline Females \% (n) & $57.4(27 / 47)$ \\
\hline Medical conditions \% (n) & $91.5(43 / 47)$ \\
\hline Seizures & $85.1(40 / 47)$ \\
\hline Heart defects & $42.6(20 / 47)$ \\
\hline Hirschprung disease & $38.3(18 / 47)$ \\
\hline Urogenitary/renal tract anomalies & $36.2(17 / 47)$ \\
\hline Clinical DBCa \% (n) & $39.1(18 / 46)$ \\
\hline DBC-P Total mean percentile (SD) & $48.5(22.9)$ \\
\hline DBC-A Total mean percentile (SD) & $54.4(26.8)$ \\
\hline Incontinence overallb \% (n) & $97.7(42 / 43)$ \\
\hline Nocturnal Enuresis (NE) & $74.4(32 / 43)$ \\
\hline Daytime Urinary Incontinence (DUI) & $76.2(32 / 42)$ \\
\hline Fecal Incontinence (FI) & $81.4(35 / 43)$ \\
\hline Constipation \% (n) & $28.6(12 / 42)$ \\
\hline Combinations of Incontinencec & $\mathrm{n}$ \\
\hline NE isolated & 2 \\
\hline DUI isolated & 1 \\
\hline $\mathrm{NE}+\mathrm{DUI}$ & 3 \\
\hline Fl isolated & 4 \\
\hline $\mathrm{FI}+\mathrm{DUI}$ & 3 \\
\hline $\mathrm{FI}+\mathrm{DUI}+\mathrm{NE}$ & 24 \\
\hline No incontinence & 1 \\
\hline
\end{tabular}

$\mathrm{DBC}=$ Developmental Behavior Checklist; TBPS $=$ Total Behavior Problem Score

${ }^{a}$ Clinical DBC is defined as a TBPS $>46$ in the DBC-P or a TBPS $>51$ in the DBC-A

${ }^{b}$ At least one subtype of incontinence

c Data available from $n=38$ 


\section{Incontinence and DBC data over age groups}

The sample was subdivided into three age groups (4-12 years, 13-17 years, $\geq 18$ years). Table 13 shows rates of incontinence, constipation, clinical DBC scores and mean item scores of the DBC subscales over the age groups. Rates of incontinence did not change significantly over age but remained at a high level. Also, the age groups did not differ regarding clinical DBC scores. The rates of constipation increased significantly from $12 \%$ in childhood to $54.5 \%$ in adolescence and $50 \%$ in adulthood, respectively.

The analysis of subtypes of incontinence (NE ( $n=31)$, DUI $(n=31), F I(n=34))$ and clinical DBC scores $(n=16)$ revealed no significant associations (Fisher's Exact tests; $p=.481$ for $\mathrm{NE} ; \mathrm{p}=1.00$ for DUI; $\mathrm{p}=.688$ for FI). Regarding mean item scores of the DBC subscales, there was a significant difference in the "self-absorbed" subscale.

Table 13: Incontinence, constipation and clinical DBC over the age groups in Mowat-Wilson syndrome

\begin{tabular}{|c|c|c|c|c|c|}
\hline & $\begin{array}{l}\text { Total } \\
\mathrm{N}=47\end{array}$ & $\begin{array}{l}\text { Children (4-12 } \\
\text { years) } \\
\mathrm{N}=26\end{array}$ & $\begin{array}{l}\text { Teens (13-17 } \\
\text { years) } \\
\mathrm{N}=13\end{array}$ & $\begin{array}{l}\text { Adults ( } \geq 18 \\
\text { years) } \\
\mathrm{N}=8\end{array}$ & Significancea \\
\hline Mean age in years (SD) & $13.0(6.8)$ & $8.4(2.9)$ & $15.1(1.5)$ & $24.8(5.1)$ & \\
\hline Incontinence overall \% (n) & $97.7(42 / 43)$ & $95.8(23 / 24)$ & $100(12 / 12)$ & $100(7 / 7)$ & n. s. \\
\hline Nocturnal Enuresis \% (n) & $74.4(32 / 43)$ & $70.8(17 / 24)$ & $90.9(10 / 11)$ & $62.5(5 / 8)$ & n. s. \\
\hline $\begin{array}{l}\text { Daytime Urinary Incontinence } \\
\%(n)\end{array}$ & $76.2(32 / 42)$ & $72.7(16 / 22)$ & $91.7(11 / 12)$ & $62.5(5 / 8)$ & n. s. \\
\hline Fecal Incontinence \% (n) & $81.4(35 / 43)$ & $88.0(22 / 25)$ & $75.0(9 / 12)$ & $66.7(4 / 6)$ & n. s. \\
\hline Constipation \% (n) & $28.6(12 / 42)$ & $12.0(3 / 25)$ & $54.5(6 / 11)$ & $50.0(3 / 6)$ & $.031^{*}$ \\
\hline Clinical DBCb \% (n) & $39.1(18 / 46)$ & $46.2(12 / 26)$ & $25.0(3 / 12)$ & $37.5(3 / 8)$ & n. s. \\
\hline $\begin{array}{l}\text { DBC-P/A Total mean percentile } \\
\text { (SD) }\end{array}$ & & $49.5(23.6)$ & $48.7(20.4)$ & $54.4(26.8)$ & \\
\hline \multicolumn{6}{|l|}{$\underline{D B C}$ Mean item scores ${ }^{\mathrm{C}}(\mathrm{SD})$ : } \\
\hline Total & & $0.46(0.2)$ & $0.46(0.2)$ & $0.38(0.2)$ & n. s. \\
\hline Disruptive/Antisocial & & $0.36(0.2)$ & $0.35(0.3)$ & $0.43(0.4)$ & n. s. \\
\hline Self-Absorbed & & $0.70(0.2)$ & $0.69(0.2)$ & $0.32(0.2)$ & $.001^{* *}$ \\
\hline Communication Disturbance & & $0.33(0.3)$ & $0.45(0.3)$ & $0.55(0.3)$ & n. s. \\
\hline Anxiety & & $0.47(0.4)$ & $0.35(0.3)$ & $0.14(0.2)$ & n. s. \\
\hline Depression $^{d}$ & & n. $a$. & n. $a$. & $0.49(0.3)$ & n. a. \\
\hline Social Relating & & $0.30(0.2)$ & $0.33(0.3)$ & $0.26(0.1)$ & n. s. \\
\hline
\end{tabular}

$\mathrm{SD}=$ standard deviation; DBC = Developmental Behavior Checklist; $\mathrm{n}$. a. = not available

a Fisher's Exact tests for categorial data; univariate analyses of variance (ANOVAs) for parametric data; ${ }^{*}=p<.05$;

$* *=p<.01 ; * * *=p<.001 ; n$. $s .=$ not significant $(p \geq .05)$

${ }^{b}$ Clinical DBC is defined as a TBPS $>46$ in the DBC-P or a TBPS $>51$ in the DBC-A

${ }^{c}$ Mean Items scores are calculated as the scale raw score divided by the number of items in the scale

d The subscale "depression" is only a subscale in the DBC-A 


\section{Adaptive toileting skills}

In table 14, adaptive toileting skills in the total sample, as well as specific symptoms in individuals with NE, DUI and FI are outlined in the three age groups. The majority of individuals wore diapers all day (87\%) and needed help with toileting. The ability to use the toilet for micturition increased significantly with age (from $11.5 \%$ in children to $75 \%$ in adults). There was a trend that the ability to use the toilet for bowel movements increased over age, too (from 11.5 to $50 \%$ ).

In individuals with NE, most wet the bed every night. This rate remained high over age. No individual had had a dry period before. The ability to wake up after wetting or to go to the toilet at night increased significantly with age. In individuals with DUI, no difference between the age groups was found regarding the rates of wetting frequency or the ability to notice wetting.

The frequency of FI did not change over the age, but there was a significant change in the size of stool masses during soiling, as adults had a higher rate of "smears". In children, stool masses were more often "moderate" or "large", whereas in teens or adults more smears or small amounts of soiling occurred. The consistency and episodes of nighttime soiling did not vary between the groups.

Table 14: Adaptive toileting skills and symptoms of incontinence over the age groups in Mowat-Wilson syndrome

\begin{tabular}{|c|c|c|c|c|c|}
\hline & Total & $\begin{array}{l}\text { Children } \\
\text { (4-12 years) }\end{array}$ & $\begin{array}{l}\text { Teens } \\
\text { (13-17 years }\end{array}$ & $\begin{array}{l}\text { Adults } \\
\text { ( }(\geq 18 \text { years) }\end{array}$ & Significance $^{b}$ \\
\hline Adaptive toileting skillsa (Total N) & 47 & 26 & 13 & 8 & \\
\hline Does he/she wear diapers during the day? \% & 87.0 & 88.5 & 91.7 & 75.0 & n. s. \\
\hline Does he/she use the toilet to pass urine? $\%$ & 25.5 & 11.5 & 23.1 & 75.0 & $.021^{*}$ \\
\hline Does he/she use the toilet to pass stools? \% & 21.7 & 11.5 & 25.0 & 50.0 & n. s. \\
\hline $\begin{array}{l}\text { Does he/she tell you when he/she has to go to } \\
\text { the toilet? \% }\end{array}$ & 17.4 & 16.0 & 15.4 & 25.0 & n. s. \\
\hline $\begin{array}{l}\text { Does he/she need help when he/she goes to } \\
\text { the toilet? \% }\end{array}$ & 82.8 & 79.2 & 76.9 & 100 & n. s. \\
\hline Nocturnal enuresis ${ }^{a}$ (Total N) & 42 & 17 & 10 & 5 & \\
\hline \multicolumn{6}{|l|}{ How often does he/she wet the bed? } \\
\hline Every night & 65.6 & $76.5(13)$ & $60.0(6)$ & $40.0(2)$ & n. s. \\
\hline $2 x /$ week or more & 25.0 & $17.6(3)$ & $30.0(3)$ & $40.0(2)$ & \\
\hline $1 x / m o n t h$ or more & 9.4 & $5.9(1)$ & $10.0(1)$ & $20.0(1)$ & \\
\hline $\begin{array}{l}\text { Has he/she ever been dry during the night for } \\
\text { more than } 6 \text { months? \% }\end{array}$ & 0 & 0 & 0 & 0 & \\
\hline Does he/she wake up to go to the toilet? \% & 9.7 & 0 & 0 & $60.0(3)$ & $.002 * *$ \\
\hline $\begin{array}{l}\text { Is he/she a deep sleeper, i.e. difficult to wake } \\
\text { up? \% }\end{array}$ & 21.9 & $23.5(4)$ & $20.0(2)$ & $20.0(1)$ & n. s. \\
\hline Does he/she wake up after wetting the bed? \% & 12.5 & 0 & $10.0(1)$ & $60.0(3)$ & $.009 * *$ \\
\hline Daytime urinary incontinence ${ }^{a}$ (Total $N$ ) & 32 & 16 & 11 & 5 & \\
\hline
\end{tabular}




\begin{tabular}{|c|c|c|c|c|c|}
\hline & Total & $\begin{array}{l}\text { Children } \\
\text { (4-12 years) }\end{array}$ & $\begin{array}{l}\text { Teens } \\
\text { (13-17 years) }\end{array}$ & $\begin{array}{l}\text { Adults } \\
(\geq 18 \text { years })\end{array}$ & Significance $^{b}$ \\
\hline \multicolumn{6}{|l|}{$\begin{array}{l}\text { How often does he/she wet himself/herself } \\
\text { during the day? }\end{array}$} \\
\hline Every day & 84.4 & $93.8(15)$ & $81.8(9)$ & $60.0(3)$ & n. s. \\
\hline $2 x /$ week or more & 12.5 & $6.3(1)$ & $9.1(1)$ & $40.0(2)$ & \\
\hline $1 x /$ month or more & 3.1 & 0 & $9.1(1)$ & 0 & \\
\hline \multicolumn{6}{|l|}{ How many times a day does he/she wet? } \\
\hline Once or twice & 32.3 & $25.0(4)$ & $30.0(3)$ & $60.0(3)$ & n. s. \\
\hline 3-4 times & 45.2 & $43.8(7)$ & $50.0(5)$ & $40.0(2)$ & \\
\hline $5-6$ times & 19.4 & $25.0(4)$ & $20.0(2)$ & 0 & \\
\hline More & 3.2 & $6.3(1)$ & 0 & 0 & \\
\hline Does he/she notice when he/she wets? & 37.9 & $35.7(5)$ & $36.4(4)$ & $50.0(2)$ & n. s. \\
\hline Fecal incontinence ${ }^{a}$ (Total $\left.N\right)$ & & 22 & 9 & 4 & \\
\hline \multicolumn{6}{|l|}{ How many times a week does he/she soil? } \\
\hline Every day & 68.6 & $72.7(16)$ & $66.7(6)$ & $50.0(2)$ & n. s. \\
\hline $2 x /$ week or more & 25.7 & $22.7(5)$ & $22.2(2)$ & $50.0(2)$ & \\
\hline $1 x /$ month or more & 5.7 & $4.5(1)$ & $11.1(1)$ & 0 & \\
\hline \multicolumn{6}{|l|}{ How often does he/she soil per day? } \\
\hline Once or twice & 68.8 & $61.9(13)$ & $87.5(7)$ & $66.7(2)$ & n. s. \\
\hline 3-4 times & 28.1 & $33.3(7)$ & $12.5(1)$ & $22.2(1)$ & \\
\hline $5-6$ times & 3.1 & $4.8(1)$ & 0 & 0 & \\
\hline \multicolumn{6}{|l|}{ How large are the stool masses? } \\
\hline Smears & 12.9 & 0 & $28.6(2)$ & $50.0(2)$ & $.005^{* *}$ \\
\hline Small amounts & 3.2 & 0 & $14.3(1)$ & 0 & \\
\hline Moderate amounts & 77.4 & $95.0(19)$ & $42.9(3)$ & $50.0(2)$ & \\
\hline Large amounts & 6.5 & $5.0(1)$ & $14.3(1)$ & 0 & \\
\hline \multicolumn{6}{|l|}{ What is the consistency of his/her stool? } \\
\hline hard & 20.0 & $22.7(5)$ & $11.1(1)$ & $25.0(1)$ & n. s. \\
\hline soft & 37.1 & $36.4(8)$ & $55.6(5)$ & 0 & \\
\hline watery & 5.7 & 0 & $11.1(1)$ & $25.0(1)$ & \\
\hline Varying consistency & 37.1 & 40.9 (9) & $22.2(2)$ & $50.0(2)$ & \\
\hline Does he/she soil during sleep/the night? & 51.4 & 40.9 (9) & $66.7(6)$ & $75.0(3)$ & n. s. \\
\hline
\end{tabular}

Numbers in parentheses refer to the absolute numbers

a The percentage of the answer "yes", if not otherwise specified

${ }^{b}$ Fisher's Exact tests; ${ }^{*}=p<.05 ;{ }^{* *}=p<.01 ; * * *=p<.001 ; n . s .=$ not significant $(p \geq .05)$ 


\section{Discussion}

\section{Incontinence overall}

This is the first study that examines incontinence systematically in MWS. The results show that incontinence is a major problem in MWS, as nearly all individuals of the sample were affected. The rates were much higher than those of persons with severe ID and more comparable to those with profound ID (85-100\%) (von Wendt et al., 1990). The combinations of incontinence reveal that two thirds of persons with MWS have all three subtypes (NE, DUI, FI).

As there are no other systematic studies on MWS and incontinence, comparisons with other genetic syndromes could be revealing. Even though MWS has some similarity to Angelman Syndrome (AS) (seizures, severe ID, sociability) (Evans et al., 2012; Mowat, Wilson, \& Goossens, 2003), incontinence rates differ in both syndromes. Incontinence in AS ranges between $89-95 \%$ for NE, $43-54 \%$ for DUI and 61\% for FI showing that NE is the most common subtype (Didden, Korzilius, Smits, \& Curfs, 2004; Laan, Den Boer, Hennekam, Renier, \& Brouwer, 1996; Radstaake et al., 2013). In the present sample, overall incontinence in MWS (97.7\%) was even higher than in AS. But in contrast, $\mathrm{Fl}$ is the most common subtype (81.4\%) followed by DUI and NE (74-76\%) in MWS, while persons with AS were most affected by NE.

\section{Fecal incontinence and HSCR}

An explanation why $\mathrm{Fl}$ is the most common incontinence subtype in MWS could be the strong association between MWS and HSCR. In a review of MWS cases, HSCR is estimated to be present in $45 \%$ of cases (Coyle \& Puri, 2015), comparable to the rates in the present sample (38.3\%). Complications after HSCR surgery are frequent in MWS (Bonnard et al., 2009), as $38.5 \%$ of MWS patients continued to have further symptoms as constipation or soiling despite surgery (Coyle \& Puri, 2015).

Despite the high prevalence of HSCR, the rates of constipation in childhood were low, whereas half of adolescents and adults were affected. It could be speculated, that parents of affected children pay more attention to regular bowel movements after HSCR surgery (which is performed in childhood) and therefore reduce the risk of constipation (e.g. by treatment with laxatives etc.). In later age, it can be speculated further that bowel management is possibly less strict so that some individuals may develop behaviors (e.g. a lowfiber diet, insufficient liquid intake) predisposing towards constipation. Persons with ID are known to have insufficient liquid intake and higher rates of constipation (van Laecke, Raes, Vande Walle, \& Hoebeke, 2009). Case reports show that constipation is not necessarily associated with HSCR: about the half of cases without HSCR ( 3 out of 6 and 6 out of 10 cases, respectively) had constipation, too (Adam et al., 2006; Garavelli et al., 2009). The possibility of very short segment HSCR ought to be considered in these individuals. 


\section{Associations with intellectual disability}

The persisting high rates of incontinence over age could be due to the severity of ID. In other syndromes with moderate or mild ID (such as Noonan, Williams, Fragile-X- or Prader-Willi Syndrome), incontinence rates decreased from childhood into adulthood (Equit, Piro-Hussong, Niemczyk, Curfs, \& von Gontard, 2013; Niemczyk, Equit, BorggrefeMoussavian, Curfs, \& von Gontard, 2016; von Gontard et al., 2016). According to von Wendt et al. (1990), the level of intellectual impairment plays a major role in gaining bladder and bowel control, not only in ID in general, but also in specific syndromes.

In addition, severe ID is often associated with somatic disabilities or medical conditions, which could lead also to higher rates of somatic (not functional) forms of incontinence that cannot be diagnosed by a questionnaire. In the present study, 36.2\% persons with MWS had anomalies of the genitourinary or renal tract. This high rate could therefore indicate higher rates of organic incontinence, but these can only be assessed by a medical examination in the individual patient.

\section{Differences between age groups}

Although incontinence rates do not decrease over age, there are indicators that some aspects of bladder and bowel control do improve in MWS. The majority (75-91.7\%) of persons with MWS in the present study still wore diapers all day indicating that they were not toilet-trained, yet. However, other adaptive skills (ability to use the toilet for micturition and bowel movements) did improve with age, $75 \%$ and $50 \%$ of adults were able to use the toilet to pass urine or stools, respectively. These increasing skills show that persons with MWS can be toilet-trained, as had been shown in case reports (Adam et al., 2006). In persons with $\mathrm{Fl}$, the stool masses diminished from childhood to adulthood which also indicates that bowel control could have improved. In adults with NE, the rates of waking up at night to go to the toilet (nocturia) or after wetting are much higher than in adolescents or children with MWS. As NE is caused by maturational deficits in centers of the brainstem (Franco et al., 2015), the improvement of nighttime waking in MWS could be a sign of improving maturational processes.

\section{Behavioral problems}

In the present sample, behavioral symptoms were present in $39.1 \%$ of individuals with MWS which is similar to the rates of Evans et al. (33.3\%) in a comparable group (Evans et al., 2012). These psychological symptoms were also related to sleep problems (Evans et al., 2016). In the present study no significant associations between psychological symptoms and incontinence were found, in contrast to other genetic syndromes with mild ID (Noonan, Williams, Fragile-X-Syndrome) (Equit et al., 2013; Niemczyk et al., 2015; von Gontard et al., 2016). The difference in level of ID is the most likely explanation, as the 
association between psychopathology and incontinence is found only in children with average intelligence (Franco et al., 2015) or mild ID, while incontinence in severe ID is possibly more closely associated with somatic conditions.

\section{Strengths and limitations}

A major strength of the study is the novelty of the results, i.e. that it is the first description of incontinence and associated factors in a larger group of individuals with MWS. Further, validated questionnaires were used and incontinence was diagnosed according to DSM5 and ICCS criteria. Limitations are the cross-sectional design and that due to study design further clinical examinations (IQ test, physical examination, sonography and uroflowmetry) could not be performed.

\section{Conclusions}

The present study shows that nearly all individuals with MWS are affected by incontinence. Although some adaptive toileting skills improve from childhood to adulthood (e.g. using the toilet, waking at night to urinate, smaller soiled stool amounts), most individuals still wear diapers. It is presumed that the high rates of incontinence in MWS emerge from a co-existence of functional and organic incontinence forms.

\section{Clinical Implications}

Nearly all individuals with MWS are affected by incontinence, which is often neglected because of other medical conditions. Due to higher rates of constipation in older individuals, these should always be screened for bowel movement frequency and consistency of stools, which are good indicators for constipation. Further, all individuals should be screened for psychological symptoms. As effective interventions for incontinence are available for persons with ID in general (von Gontard, 2013), assessment and treatment of incontinence are recommended in persons with MWS, as well. 


\section{References}

Adam, M. P., Justice, A. N., Bean, L. J. H., \& Fernhoff, P. M. (2008). Mowat-Wilson syndrome with craniosynostosis: A case report [1]. American Journal of Medical Genetics, Part A, 146(2), 245-246.

Adam, M. P., Schelley, S., Gallagher, R., Brady, A. N., Barr, K., Blumberg, B., . . Hudgins, L. (2006). Clinical features and management issues in Mowat-Wilson syndrome. American Journal of Medical Genetics, Part $A$, 140(24), 2730-2741.

American Psychiatric Association (APA) (2013). Diagnostic and statistical manual of mental disorders - Fifth edition (DSM 5). Washington, D.C.: APA.

Austin, P.F., Bauer, S.B., Bower, W., Chase, J., Franco, I., Hoebeke, P., ... , Yang, S. S. (2016). The Standardization of Terminology of Lower Urinary Tract Function in Children and Adolescents: Update Report from the Standardization Committee of the International Children's Continence Society. Neurourology \& Urodynamics, 35(4), 471-481.

Bonnard, A., Zeidan, S., Degas, V., Viala, J., Baumann, C., Berrebi, D., . . El Ghoneimi, A. (2009). Outcomes of hirschsprung's disease associated with Mowat-Wilson syndrome. Journal of Pediatric Surgery, 44(3), 587591.

Coyle, D., \& Puri, P. (2015). Hirschsprung's disease in children with Mowat-Wilson syndrome. Pediatric Surgery International, 31(8), 711-717.

de Gennaro, M., Niero, M., Capitanucci, M. L., von Gontard, A., Woodward, M., Tubaro, A., \& Abrams, P. (2010). Validity of the international consultation on incontinence questionnaire-pediatric lower urinary tract symptoms: A screening questionnaire for children. Journal of Urology, 184(4 SUPPL.), 1662-1667.

Didden, R., Korzilius, H., Smits, M. G., \& Curfs, L. M. G. (2004). Sleep problems in individuals with Angelman syndrome. American Journal on Mental Retardation, 109(4), 275-284.

Einfeld, S., \& Tonge, B. (2002). Manual for the Developmental Behavior Checklist - primary carer version (DBCP) \& teacher version (DBC-T) (2nd ed.). Clayton, Melbourne: Monash University Centre for Developmental Psychiatry and Psychology.

Equit, M., Piro-Hussong, A., Niemczyk, J., Curfs, L., \& von Gontard, A. (2013). Elimination disorders in persons with Prader-Willi and Fragile-X syndromes. Neurourology and Urodynamics, 32(7), 986-992.

Evans, E., Einfeld, S., Mowat, D., Taffe, J., Tonge, B., \& Wilson, M. (2012). The behavioral phenotype of MowatWilson syndrome. American Journal of Medical Genetics, Part A, 158 A(2), 358-366.

Evans, E., Mowat, D., Wilson, M., \& Einfeld, S. (2016). Sleep disturbance in Mowat-Wilson syndrome. American Journal of Medical Genetics, Part A, 170(3), 654-660.

Franco, I., Austin, P. F., Bauer, S., von Gontard, A., \& Homsy, Y. (Eds.). (2015). Pediatric incontinence - evaluation and clinical management. Chicester, UK: Wiley Blackwell.

Garavelli, L., Zollino, M., Cerruti Mainardi, P., Gurrieri, F., Rivieri, F., Soli, F., . . Neri, G. (2009). Mowat-Wilson syndrome: Facial phenotype changing with age: Study of 19 italian patients and review of the literature. American Journal of Medical Genetics, Part A, 149(3), 417-426.

Laan, L. A. E. M., Den Boer, A. T., Hennekam, R. C. M., Renier, W. O., \& Brouwer, O. F. (1996). Angelman syndrome in adulthood. American Journal of Medical Genetics, 66(3), 356-360.

Mohr, C., Tonge, B., Einfeld, S. \& Taffe, J. (2011). Manual for the Developmental Behavior Checklist for Adults (DBC-A) (revised). Clayton, Melbourne: Monash University Centre for Developmental Psychiatry and Psychology.

Mowat, D., \& Wilson, M. (2010). Mowat-Wilson syndrome. Management of genetic syndromes: Third edition (pp. 517-527)

Mowat, D. R., Croaker, G. D. H., Cass, D. T., Kerr, B. A., Chaitow, J., Adès, L. C., . . Wilson, M. J. (1998). Hirschsprung disease, microcephaly, mental retardation, and characteristic facial features: Delineation of a new syndrome and identification of a locus at chromosome 2q22-q23. Journal of Medical Genetics, 35(8), 617623.

Mowat, D. R., Wilson, M. J., \& Goossens, M. (2003). Mowat-Wilson syndrome. Journal of Medical Genetics, 40(5), 305-310. 
Niemczyk, J., Equit, M., Borggrefe-Moussavian, S., Curfs, L., \& von Gontard, A. (2015). Incontinence in persons with Noonan syndrome. Journal of Pediatric Urology, 11(4), 201.e1-201.e5.

Radstaake, M., Didden, R., Giesbers, S., Korzilius, H., Peters-Scheffer, N., Lang, R., . . Curfs, L. M. G. (2013). Incontinence in individuals with Angelman syndrome: A comparative study. Research in Developmental Disabilities, 34(11), 4184-4193.

van Laecke, E., Raes, A., Vande Walle, J., \& Hoebeke, P. (2009). Adequate fluid intake, urinary incontinence, and physical and/or intellectual disability. Journal of Urology, 182(4 SUPPL.), 2079-2084.

von Gontard, A. (2012a). Encopresis. In J. M. Rey (Ed.), IACAPAP e-textbook of child and adolescent mental health. Geneva: International Association for Child and Adolescent Psychiatry and Allied Professions. http://iacapap.org/wp-content/uploads/C.5-ENCOPRESIS-0072012.pdf. Accessed 11.03.16.

von Gontard, A. (2012b). Enuresis. In J. M. Rey (Ed.), IACAPAP e-textbook of child and adolescent mental health. Geneva: International Association for Child and Adolescent Psychiatry and Allied Professions. http://iacapap.org/wp-content/uploads/C.4-ENURESIS-072012.pdf. Accessed 11.03.16.

von Gontard, A. (2013). Urinary incontinence in children with special needs. Nature Reviews Urology, 10(11), 667-674.

von Gontard, A., Niemczyk, J., Borggrefe-Moussavian, S., Wagner, C., Curfs, L., \& Equit, M. (2016). Incontinence in children, adolescents and adults with Williams syndrome. Neurourology and Urodynamics, 35(8), 10001005.

von Wendt, L., Simila, S., Niskanen, P., \& Jarvelin, M. (1990). Development of bowel and bladder control in the mentally retarded. Developmental Medicine and Child Neurology, 32(6), 515-518. 


\section{Chapter}

\section{Detailed assessment of incontinence in boys with Fragile-X-Syndrome in a home setting}

(2016). European Journal of Pediatrics, 175(10), 1325-1334. 


\section{Abstract}

Fragile-X-Syndrome (FXS) is caused by a mutation on the X-chromosome (Xq27.3). Males with a full mutation have typical dysmorphic signs, moderate intellectual disability and psychological disorders. $25-50 \%$ are affected by incontinence. The aim of the study was to assess subtypes of incontinence and psychological problems in children with FXS in their home environments.

22 boys with FXS (mean age 11.0 years) and 22 healthy controls (mean age 11.1 years) were examined with sonography, uroflowmetry, 48-h-bladder diary, physical examination, IQ test, parental psychiatric interview and questionnaires regarding incontinence and psychological symptoms in a home setting.

Boys with FXS had higher rates of incontinence than controls (59.1\% vs. $4.8 \%)$. The most common subtypes in FXS boys were primary non-monosymptomatic nocturnal enuresis, urge incontinence and non-retentive faecal incontinence. $90.9 \%$ boys with FXS had a psychological comorbidity. Incontinence and behavioral symptoms were not associated.

Boys with FXS have a higher risk for physical disabilities, psychological disorders and incontinence than healthy boys. Constipation is not a major problem in FXS. As effective treatment is available for children with ID, we recommend offering assessment and therapy to all children with FXS and incontinence. 


\section{Introduction}

According to the Fifth Edition of the Diagnostic and Statistical Manual of Mental Disorders (DSM-5), nocturnal enuresis (NE) is diagnosed as voiding of urine into bed during sleep from the age of 5 onwards after ruling out medical conditions (American Psychiatric Association (APA), 2013). The International Children's Continence Society (ICCS) divides enuresis into 4 subgroups, classified as either primary (no dry period $>6$ months before) or secondary (previous dry period $>6$ months) and as either non-monosymptomatic (daytime symptoms of the lower urinary tract (LUTS) are present) or monosymptomatic (enuresis without LUTS) (Austin et al., 2016). Daytime urinary incontinence (DUI) is defined as intermittent leakage of urine during the day after excluding organic causes (Austin et al., 2016). In children, the most common subtypes are DUI with urgency (or urge incontinence, UI), DUI with voiding postponement (VP) and dysfunctional voiding (DV) (Austin et al., 2016). Faecal incontinence (FI) or encopresis is defined as repeated passage of faeces into inappropriate places in children 4 years or older after ruling out medical conditions (APA, 2013; Rasquin et al., 2006). The ROME-III criteria for childhood functional gastrointestinal disorders distinguish functional constipation which can occur with faecal incontinence (FI-C) or without from nonretentive faecal incontinence (FI-NR) (Rasquin et al., 2006).

Fragile-X-Syndrome (FXS; OMIM no. \#300624) is caused by a mutation of the FMR1 gene located on the $X$ chromosome which leads to an increase of CGG-repeats (2002,000) on Xq27.3 (Brown, 2002). In typically developing persons, the number of CGGrepeats is 5-55, in persons with a premutation, frequency is 56-200 (Brown, 2002). FXS is the second most common genetic cause of intellectual disability (ID) after Down syndrome with a prevalence of 1:4000-6000 of live births (Duker \& Dekkers, 1992; Turner, Webb, Wake, \& Robinson, 1996).

Males with FXS have typical dysmorphic features such as a long narrow face, prominent ears, hyper-extendible finger joints, and macroorchidism (Gallagher \& Hallahan, 2012). Regarding cognitive abilities, moderate or severe ID is present in most of individuals (Gallagher \& Hallahan, 2012). Boys with FXS have a typical behavioral phenotype: hyperactivity, attention problems, autism spectrum disorders, social anxiety, stereotyped behavior, speech and motor difficulties (Backes et al., 2000; Gabis, Baruch, Jokel, \& Raz, 2011; Gallagher \& Hallahan, 2012; Tranfaglia, 2011).

Males with FXS have more marked dysmorphic features and are more often affected by ID than females with a full mutation (Gallagher \& Hallahan, 2012).

In two population-based studies of 7-year old children, the prevalence of enuresis in children with ID was around $25-30 \%$ and remained high at the age of 20 years (17-16\%) (Jarvelin, Vikevainen-Tervonen, Moilanen, \& Huttunen, 1988; von Wendt, Simila, Niskanen, \& Jarvelin, 1990). In typically developing 7-year-old-children, rates of NE are 10\%, of DUI 2-3\% and of FI 1-3\% (Joinson, Heron, Emond, \& Butler, 2007; Joinson, Heron, 
Butler, \& von Gontard, 2006; Joinson, Heron, \& von Gontard, 2006). Also, more symptoms of incontinence, LUTS and a smaller bladder capacity were found in children with ID compared to normally developed children (Yang, Meng, \& Chou, 2010).

Only few studies and case reports have focused on incontinence in FXS (Backes et al., 2000; Equit, Piro-Hussong, Niemczyk, \& von Gontard, 2011; Equit, Sambach, von Gontard, 2011) so far. In 49 boys with FXS, rates of NE and FI were $27 \%$ and $20 \%$, respectively, being two of the highest psychological comorbidities after ADHD (74\%) and conduct disorder (29\%) (Backes et al., 2000). Gabis et al. (2011) found a total prevalence of $40.9 \%$ for $\mathrm{NE}$ and $36.4 \%$ for $\mathrm{FI}$ in individuals with a full mutation of FXS vs. $0 \%$ in their siblings. There was also an age effect: younger children (4-12 years) were more often affected by incontinence than older children (>12 years) $(71.4 \%-85.7 \%$ vs. $20 \%)$. Overall rates of incontinence (48.8\%) were even higher in individuals with FXS than in those with PraderWilli-Syndrome (PWS) (29.1\%) (Equit et al., 2013). Persons with FXS were more often affected by DUI (29.9 vs. $12.0 \%$ ) and FI (28.9 vs. $12.6 \%$ ) than those with PWS, whereas the rates of NE were similar (28.9 vs. $22.0 \%$ ). Rates of psychological problems were high in both groups (59.4\% in FXS and 59.3\% in PWS), but incontinence and psychological problems have only been associated in the FXS group.

Most of these studies either relied on questionnaire data or diagnosed broad categories of incontinence. Therefore, the aim of the study was to examine incontinence in FXS more specifically. In their own home-setting, boys with FXS and a control group were examined medically and psychologically, allowing the diagnosis of specific subtypes of incontinence, medical disorders as well as psychological comorbidities.

It was hypothesized that the FXS group has higher rates of all subtypes of incontinence, lower urinary tract and gastrointestinal symptoms (e.g. constipation, post-void residual, bladder wall thickness) and more psychological problems.

\section{Materials and methods}

\section{Sample}

Two groups of male children and adolescents between 4 and 18 years of age were examined: boys with a full mutation FXS and an age-matched control group of typically developed boys. The FXS group included 22 boys with a mean age of 11.0 years (SD=3.8 years; range 4-17 years), the control group 22 boys with a mean age of 11.1 years ( $S D=3.7$ years; range $4-17$ years).

\section{Procedure}

Boys with FXS were recruited through the German Fragile-X support group (Interessensgemeinschaft Fragiles-X e.V.), the control group through newspaper advertisements. Interested parents were informed per phone about the study. Following informed 
consent, questionnaires and the 48-h-bladder diary were sent to the families and a date was set at which the family was visited by two medical students who examined the child in their home-setting. Both medical students completed a clinical traineeship in a specialized outpatient clinic for incontinence at a child and adolescent psychiatric hospital and were trained by child psychiatrists and pediatric nurses to perform ultrasound, uroflowmetry and paediatric/neurological examinations. The study was approved by the local ethics committee.

\section{Instruments}

Parents filled out the 'Child Behavior Checklist' (CBCL) (Achenbach, 1991) to assess child psychopathology and the German version of the 'Social Communication Questionnaire' (SCQ) ("Fragebogen zur Sozialen Kommunikation - Autismus Screening"; Bölte \& Poustka, $2006)$ to assess autistic symptoms. The Child Behavior Checklist (CBCL) is a reliable and valid instrument with norms for boys/girls in two age groups (4-11 years/12-17 years) (Achenbach, 1991). The SCQ consists of 40 items on autistic symptoms in children and adolescents. Internal consistency (Cronbach's $\alpha=.83)$, and retest reliability $(r=.76)$ are satisfying, validity (referring to autism diagnoses) is moderate (Bölte \& Poustka, 2006).

At the appointment at home, a structured interview (Kinder-DIPS) (Schneider, Margraf, \& Unnewehr, 1995) was conducted with parents of both groups to assess comorbid psychiatric disorders. Additionally, IQ was measured by a one-dimensional intelligence test (Coloured Progressive Matrices (CPM) or Standard Progressive Matrices (SPM)) in children (Raven, Raven, \& Court, 2006; Raven, 1998).

The 'Parental Questionnaire: Enuresis/Urinary Incontinence', 'Encopresis Questionnaire - Screening Version' (von Gontard, 2012a; 2012b) and the German version of the 'International-Consultation-on-Incontinence-Questionnaire - Pediatric Lower Urinary Tract Symptom' (ICIQ-CLUTS) (de Gennaro et al., 2010) were administered to gain information on incontinence and LUTS. The 10 questions of the ICIQ-CLUTS (with four answer options each rated with points of 0 to 3 ) build a LUTS-score with clinically relevant scores over 13. In a group on incontinent and continent children, validity and reliability was confirmed (de Gennaro et al., 2010).

Parents were also asked to measure voiding frequency, voided volumes and fluid intake in a 48-h bladder diary. Additionally, the students took the medical and family history regarding incontinence and developmental milestones (initiation to walk and talk). The child was examined physically and neurologically including measurement of height and weight. Bladder wall thickness, transverse rectum diameter and post-void residual urine were assessed by sonography (Sonoace R3, Samsung). If possible, uroflowmetry was conducted with a portable device (FloPoint Elite System, Verathon) at the home toilet.

NE and DUI were diagnosed according to the International Children's Continence Society (ICCS) criteria (Austin et al., 2016), i.e. from the age of 5 years onwards when wetting occurred at least once per month. FI was diagnosed according to DSM-5 criteria from the 
age of 4 years if soiling occurred at least once per month (APA, 2013). A mean LUTSscore $>13$ in the ICIQ-CLUTS was considered as clinically relevant (de Gennaro et al., 2010).

Subtypes of NE, DUI and FI were diagnosed according to the ICCS and Rome-III guidelines (Austin et al., 2016; Rasquin et al., 2006) in group consent of an expert team consisting of a psychiatrist, psychologist and paediatrician with expertise in incontinence treatment. In children with NE, the subtypes 'primary monosymptomatic', 'primary nonmonosymptomatic', 'secondary monosymptomatic' and 'secondary non-monosymptomatic' were distinguished. In children with DUI, the subtypes urge incontinence (UI), DUI with voiding postponement (DUI+VP) and DUI with dysfunctional voiding (DUI+DV) were differentiated. DUI not otherwise specified (DUI-NOS) was considered when the available information were insufficient to define a subtype of DUI. Constipation was diagnosed according to the ROME-III criteria (Rasquin et al., 2006). FI with constipation (FI-C) and nonretentive $\mathrm{FI}$ (FI-NR) were differentiated according to the presence of constipation.

In sonographic exam, a transverse rectal diameter of $>30 \mathrm{~mm}$ was regarded as clinically relevant (Austin et al., 2016). Abnormal post-void residual (PVR) was considered when $>30 \mathrm{ml}$ in children aged $4-6$ years and $>20 \mathrm{ml}$ in children older than 6 years (Austin et al., 2016; Nevéus et al., 2006). BMI percentiles were calculated, overweight and obesity were defined according to standardized guidelines as $85-94^{\text {th }}$ BMI-percentile and $\geq 95^{\text {th }}$ BMI-percentile, respectively (Kuczmarski, Ogden, \& Grummer-Strawn, 2000).

Psychiatric disorders were diagnosed according to DSM-IV criteria assessed by the Kinder-DIPS. The $\mathrm{CBCL}$ total, internalizing and externalizing scales were regarded as clinically relevant at a cut-off of a T-value>63 (90th percentile) (Arbeitsgruppe Deutsche CBCL, 1999). A total score of $>15$ in the SCQ was regarded clinically relevant (with good sensitivity and specifity) and as an indicator of an autism spectrum disorder (ASD) (Bölte \& Poustka, 2006).

Statistical analyses were conducted with IBM SPSS Statistics 22 using nonparametric tests ( $\chi 2$-tests, Fisher's Exact tests) for categorical data and parametric tests (Student ttests, Welch test) for interval-scaled data. To determine normal distribution of interval data, the Shapiro-Wilk test was used. In case of interval data not being normally distributed, a nonparametric test (Mann-Whitney U-test) was used. Results were considered significant at a p-value $<0.05$.

\section{Results}

Descriptive data on medical conditions, psychological symptoms and diagnoses of both groups are outlined in table 15. IQ test data are available for 16 boys in the FXS group and 22 in the control group. Because of severe cognitive impairment, six FXS boys could not complete the IQ test. The mean IQ was significantly lower in the FXS group than in the control group (table 15). The mean BMI percentile was significantly higher in the FXS 
group (56.3 vs. 38.5), but the difference in rates of overweight and obesity did not reach statistical significance (table 15).

All FXS children had somatic symptoms and impairments. 95.5\% had hypotonia, $36.4 \%$ renal or genitourinary anomalies, and $18.2 \%$ seizures. $68.2 \%$ were on medication, mostly anticonsulvants, followed by stimulants (methylphenidate), neuroleptics and benzodiazepines. In comparison to controls, the mean age of initiation of walking and talking was significantly delayed in FXS boys (table 15).

In the $\mathrm{CBCL}$ parental questionnaire, FXS boys had significantly more clinically relevant internalizing (40.9\% vs. 9.1\%) and total scores (68.2\% vs. $5.3 \%$ ) than the controls. 13 boys in the FXS group (59.1\%), but none in the control group had a SCQ-score in the clinical range of an ASD. 90.9\% of the FXS group fulfilled the criteria for at least one psychiatric disorder, but only one control child. The most common psychiatric disorder was ADHD (72.7\%), followed by specific phobia, separation anxiety disorder, ODD, tic disorder and OCD (see table 15).

Table 15: Descriptive data: age, IQ, medical data, behavioral symptoms, psychological disorders (DSM-5) in boys with Fragile-X-syndrome and controls

\begin{tabular}{|c|c|c|c|}
\hline & FXS group $(n=22)$ & $\begin{array}{l}\text { Control group } \\
(n=22)\end{array}$ & Significance $^{a}(p)$ \\
\hline Mean age in years (SD) & $11.0(3.8)$ & $11.1(3.7)$ & .950 \\
\hline Mean IQ (SD) & $70.9(13.6)$ & $111.1(12.3)$ & $<.001 * * *$ \\
\hline Intellectual disability $\%$ (n) & $59.1(13 / 20)$ & - & \\
\hline Mean BMI percentile (SD) & $56.3(33.27)$ & $38.5(30.72)$ & $.04993 *^{*} \mathrm{c}$ \\
\hline Overweight/Obesity (BMI>84 th percentile) \% (n) & $27.3(6 / 22)$ & $9.1(2 / 22)$ & $.240 d$ \\
\hline \multicolumn{4}{|l|}{ Somatic disorders in \% (n): } \\
\hline Hypotonia (low muscle tone) & $95.5(21 / 22)$ & - & \\
\hline Seizures & $18.2(4 / 22)$ & - & \\
\hline Anomalies of renal and genitourinary tract & $36.4(8 / 22)$ & $4.5(1 / 22)$ & \\
\hline Macroorchidism & $31.2(7 / 22)$ & - & \\
\hline Circumcision & $4.5(1 / 22)$ & - & \\
\hline Duplex kidney & - & $4.5(1 / 22)$ & \\
\hline Medication in \% ( $n$ ) & $68.2(15 / 22)$ & $27.3(6 / 22)$ & $.007 * *$ \\
\hline Anticonvulsants & $22.7(5 / 22)$ & $4.5(1 / 22)$ & \\
\hline Methylphenidate & $9.1(2 / 22)$ & $4.5(1 / 22)$ & \\
\hline Neuroleptics & $9.1(2 / 22)$ & - & \\
\hline Benzodiazepines & $9.1(2 / 22)$ & - & \\
\hline Anticholinergics & - & $4.5(1 / 22)$ & \\
\hline \multicolumn{4}{|l|}{ Speech and motor development } \\
\hline Mean age of initiation of walking in months (SD) & $21.5(10.57)$ & $13.7(2.51)$ & $<.001 * * * \mathrm{c}$ \\
\hline Mean age of initiation of speech in months (SD) & $31.2(13.25)$ & $16.7(3.84)$ & $<.001^{* * *} \mathrm{C}$ \\
\hline \multicolumn{4}{|l|}{ Psychological Symptoms } \\
\hline Mean CBCL Total T-value (SD) & $61.6(10.53)$ & $46.6(9.74)$ & $<.001^{* * *}$ \\
\hline Mean CBCL Ext T-value (SD) & $57.2(7.30)$ & $46.7(8.91)$ & $<.001^{* * *}$ \\
\hline
\end{tabular}




\begin{tabular}{|c|c|c|c|}
\hline & FXS group $(n=22)$ & $\begin{array}{l}\text { Control group } \\
(n=22)\end{array}$ & Significance $^{a}(p)$ \\
\hline Mean CBCL Int T-value (SD) & $68.0(7.64)$ & $46.7(10.67)$ & $<.001^{* * *} \mathrm{c}$ \\
\hline CBCL Total score >90th percentile $\mathrm{n}(\%)$ & $68.2(15 / 22)$ & $4.5(1 / 22)$ & $<.001 * * *$ \\
\hline CBCL Ext score $>90$ th percentile $n(\%)$ & $9.1(2 / 22)$ & - & $.488 d$ \\
\hline CBCL Int score >90th percentile n (\%) & $40.9(9 / 22)$ & $9.1(2 / 22)$ & $.015^{*}$ \\
\hline SCQ (Score > 15) \% (n) & $59.1(13 / 22)$ & - & $<.001^{* * *}$ \\
\hline Psychiatric Diagnoses in \% (n) & $90.9(20 / 22)$ & $4.5(1 / 22)$ & $<.001^{* * *}$ \\
\hline \multicolumn{4}{|l|}{ Externalizing Disorders } \\
\hline ADHD & $72,7(16 / 22)$ & - & \\
\hline ODD & $4.5(1 / 22)$ & - & \\
\hline Tic disorders & $9.1(2 / 22)$ & - & \\
\hline \multicolumn{4}{|l|}{ Internalizing Disorders } \\
\hline Specific Phobia & $54.5(12 / 22)$ & $4.5(1 / 22)$ & \\
\hline Separation Anxiety Disorder & $9.1(2 / 22)$ & - & \\
\hline OCD & $9.1(2 / 22)$ & - & \\
\hline Social Phobia & $9.1(2 / 22)$ & - & \\
\hline
\end{tabular}

Ext=Exernalizing, Int=Internalizing, ADHD=Attention-Deficit/Hyperactivity Disorder, ODD=Oppositional Defiant Disorder, OCD=Obsessive-compulsive Disorder

${ }^{a}$ Chi ${ }^{2}$-tests for non-parametric data and t-tests for continous variables (= in italics)

${ }^{b}$ Intellectual disability is defined as $I Q<70$ or a special education for ID in school (if IQ is not available)

c Mann-Whitney U-test was conducted due to violations of normal distribution

${ }^{\mathrm{d}}$ Fisher's Exact test was conducted

\section{Incontinence}

Boys with FXS were significantly more often affected by incontinence than controls (59.1\% vs. 5.6\%). $10 \mathrm{FXS}$ boys had NE (45.5\%), 8 had DUI (36.4\%) and $7 \mathrm{FI} \mathrm{(31.8 \% ),}$ whereas only one boy in the control group had NE (table 16). All 10 boys with NE in the FXS group had primary NE, 2 with monosymptomatic NE and 8 with non-monosymptomatic NE. Three of the 8 boys with DUI showed symptoms of urgency (frequent voiding, small voiding volumes) and one showed symptoms of voiding postponement (infrequent voiding, postponing in typical situations e.g. while playing). DUI could not be specified in those children wearing diapers at day and night $(n=4)$. All seven Fl cases were non-retentive, no child had constipation. The only affected control child had a primary monosymptomatic NE (table 2).

\section{Urodynamic findings}

Valid uroflowmetry results are available from $6 \mathrm{FXS}$ and 8 control children. In other cases, uroflowmetry results were invalid due to measurement errors or too small voiding volumes. Some children were too fearful (because of noises of the device) or refused to use the uroflowmeter. In the FXS group, 5 curves were bell-shaped and one continent child had a staccato curve which could be an indicator for dysfunctional voiding. In the control 
group, 7 curves were bell-shaped and 1 intermittent-shaped. There were neither significant differences in uroflowmetry curves nor in the mean voided volumes between the groups (table 16).

Sonography showed significant thicker bladder wall in FXS than in controls $(2.5 \mathrm{~mm}$ vs. $2.2 \mathrm{~mm}$ ). The rectum diameter was distended (> $30 \mathrm{~mm}$ ) in $22.7 \%$ of FXS and $22.7 \%$ of control boys. Neither the number of boys with a distended rectum diameter, an elevated PVR nor the mean PVR (17.4 ml vs. $9.3 \mathrm{ml}$ ) differed significantly between the groups.

Maximum voided volume (MVV) (307.5 vs. $306.5 \mathrm{ml}$ ), mean daily fluid intake (1483.8 vs. $1441.5 \mathrm{ml}$ ) and number of micturitions during the day ( 8.9 in both groups) were comparable between FXS and control boys.

Table 16: Incontinence, LUTS and urological findings in boys with Fragile-X-syndrome and controls

\begin{tabular}{|c|c|c|c|}
\hline & FXS group $(n=22)$ & Control group $(n=22)$ & Significance $^{a}(p)$ \\
\hline Incontinence overall $\%$ (n) & $59.1(13 / 22)$ & $4.8(1 / 21)$ & $<.001^{* * *}$ \\
\hline Nocturnal enuresis (NE) \% (n) & $45.5(10 / 22)$ & $4.5(1 / 22)$ & $.002 * *$ \\
\hline Primary monosymptomatic & $9.1(2 / 22)$ & $4.5(1 / 22)$ & \\
\hline Primary non-monosymptomatic & $36.4(8 / 22)$ & - & \\
\hline Daytime urinary incontinence (DUI) \% (n) & $36.4(8 / 22)$ & $0(0 / 22)$ & $.004^{* *}$ \\
\hline DUI with urgency & $13.6(3 / 22)$ & - & \\
\hline DUI with voiding postponement & $4.5(1 / 22)$ & - & \\
\hline DUI not otherwise specified (NOS) & $18.2(4 / 22)$ & - & \\
\hline Fecal incontinence $(\mathrm{Fl}) \%(\mathrm{n})$ & $31.8(7 / 22)$ & $0(0 / 21)$ & $.009 * *$ \\
\hline $\mathrm{Fl}$ and constipation & - & - & \\
\hline Nonretentive FI & $31.8(7 / 22)$ & - & \\
\hline Mean LUTS-score (SD) & $6.4(4.47)$ & $3.0(1.85)$ & $.003^{* *}$ \\
\hline LUTS-score >13 \% (n) & $13.6(3 / 22)$ & $0(0 / 22)$ & $.233 c$ \\
\hline Urgee & $20.0(3 / 15)$ & $0(0 / 20)$ & $.070 c$ \\
\hline Postponemente & $0(0 / 15)$ & $0(0 / 20)$ & - \\
\hline Straininge & $7.1(1 / 14)$ & $0(0 / 20)$ & $.412 c$ \\
\hline \multicolumn{4}{|l|}{ 48-h bladder diary } \\
\hline Mean MVV in ml (SD) & $307.5(178.65)$ & $306.5(150.33)$ & $.947 d$ \\
\hline Mean amount of micturitions/day (SD) & $8.9(3.56)$ & $8.9(3.65)$ & 1.00 \\
\hline Mean fluid intake in ml/day (SD) & $1483.8(636.14)$ & $1441.5(608.76)$ & .840 \\
\hline \multicolumn{4}{|l|}{ Sonography } \\
\hline Mean bladder wall thickness in mm (SD) & $2.5(0.54)$ & $2.2(0.51)$ & $.006 d^{* *}$ \\
\hline Mean rectal diameter in $\mathrm{mm}(S D)$ & $23.4(6.77)$ & $22.0(9.47)$ & .582 \\
\hline Rectal distension (>30mm) \% (n) & $22.7(5 / 22)$ & $22.7(5 / 22)$ & 1.00 \\
\hline Mean PVR in $m /(S D)$ & $17.4(38.87)$ & $9.2(9.06)$ & $.851^{d}$ \\
\hline Elevated PVR \% (n) & $13.6(3 / 22)$ & $9.1(2 / 22)$ & $1.00^{\mathrm{c}}$ \\
\hline \multicolumn{4}{|l|}{ Uroflowmetry } \\
\hline Mean voided volume in $\mathrm{ml}$ (SD) & $160.8(130.97)$ & $111.3(90.75)$ & $.262 d$ \\
\hline Bell shape & $71.4(5 / 7)$ & $77.8(7 / 9)$ & $1.00 \mathrm{c}$ \\
\hline Staccato or intermittent shape & $14.3(1 / 7)$ & $11.1(1 / 9)$ & \\
\hline
\end{tabular}


${ }^{a}$ Chi ${ }^{2}$-tests for non-parametric data and t-tests for parametric variables

${ }^{b}$ At least one subtype of incontinence

c Fisher's Exact test was conducted

dMann-Whitney U-test was conducted due to violations of normal distribution

eItems 7, 8 and 9 of the ICIQ-CLUTS scored as 'most of the time' or 'all of the time'

In table 17, continent and incontinent FXS boys are compared. Incontinent boys were significantly younger, had more clinically relevant scores in the externalizing scale of the $\mathrm{CBCL}$, had a higher LUTS-score and a lower fluid intake. The mean rectal diameter was higher in continent boys, but the rate of clinically relevant distension $(>30 \mathrm{~mm}$ ) did not differ between the groups (table 17).

Table 17: Comparison of continent and incontinent boys with Fragile-X-syndrome

\begin{tabular}{llll}
\hline & $\begin{array}{l}\text { Incontinent FXS group } \\
(\mathrm{n}=13)\end{array}$ & $\begin{array}{l}\text { Continent FXS group } \\
(\mathrm{n}=9)\end{array}$ & Significancea $(\mathrm{p})$ \\
\hline Mean age in years (SD) & $9.5(3.21)$ & $13.2(3.74)$ & $.024^{*}$ \\
Mean IQ (SD) & $74.1(9.51)$ & $67.8(16.75)$ & .365 \\
Mean CBCL Total T-value (SD) & $70.5(6.20)$ & $64.4(8.44)$ & .741 \\
Mean CBCL Ext T-value (SD) & $60.2(6.63)$ & $52.9(6.23)$ & $.018^{*}$ \\
Mean CBCL Int T-value (SD) & $62.2(9.74)$ & $60.7(12.13)$ & .068 \\
SCQ (Score > 15) \% (n) & $61.5(8 / 13)$ & $55.6(5 / 9)$ & $1.00 \mathrm{~b}$ \\
Psychiatric Disorder \% (n) & $100.0(13 / 13)$ & $77.8(7 / 9)$ & $.156 \mathrm{~b}$ \\
Mean LUTS-score (SD) & $9.2(3.44)$ & $2.3(1.94)$ & $<.001^{* * *}$ \\
48-h bladder diary & & & \\
Mean MVV in ml (SD) & $218.6(175.94)$ & $432.0(90.11)$ & $.073 c$ \\
Mean number of micturitions/day (SD) & $8.9(2.58)$ & $8.9(4.51)$ & $.671 \mathrm{c}$ \\
Mean fluid intake in ml/day (SD) & $1176.3(614.0)$ & $1791.3(523.45)$ & $.049^{*}$ \\
Sonography & & & \\
Mean bladder wall thickness in mm (SD) & $2.5(0.31)$ & $2.6(0.76)$ & $.886 \mathrm{c}$ \\
Mean rectal diameter in mm (SD) & $20.9(5.09)$ & $27.0(7.51)$ & $.033^{*}$ \\
Rectal distension (>30mm) \% (n) & $7.7(1 / 13)$ & $44.4(4 / 9)$ & $.116 \mathrm{~b}$ \\
Mean PVR in ml (SD) & $9.4(12.74)$ & $29.0(58.87)$ & $.171^{c}$ \\
Elevated PVR \% (n) & $7.7(1 / 13)$ & $22.2(2 / 9)$ & $.544^{\mathrm{b}}$ \\
\hline
\end{tabular}

${ }^{a} \mathrm{Chi}^{2}$-tests for non-parametric data and t-tests for continuous variables (italic)

${ }^{b}$ Fisher's Exact test was conducted

c Mann-Whitney U-test was conducted due to violations of normal distribution

\section{Discussion}

This is the first study which assessed incontinence and associated factors in boys with FXS not only by questionnaires, but by clinical examination in comparison to typically developing boys. 
Incontinence is very common in children with FXS. Rates of incontinence in the present study (59.1\%) are similar to previous findings: Gabis et al. (2011) reported rates $85.7 \%$ of NE and $71.4 \%$ of FI in 4-12 year olds, Equit et al. (2013) found incontinence in about $70 \%$ of children (4-12 years) and $42.5 \%$ of teens (13-17 years). Regarding the subtypes of incontinence, primary non-monosymptomatic forms of NE predominate. The aetiology of NE is mainly due to maturational deficits of the central nervous system (CNS) (von Gontard, 2012b). Also, in most of cases, ID is genetically determined and involves functional deficits of the CNS leading to general delays in development (Moeschler et al., 2006). Thus, boys with FXS in the present study had not only a delayed motor and speech development, but also delays in the development of bladder and bowel control. The absence of secondary NE shows that children with FXS stay continent once having gained nighttime bladder control.

Half of the children with DUI still wore a diaper during day and night and did not use a toilet or a potty. In these cases, a subtype of DUI could not be specified because these families did not complete the 48-h-bladder diary. It can be speculated that these children have not been toilet-trained or gained bladder control yet, as in other children with ID (Brushini, Faria, Garcez, \& Srougi, 2003). Further, children with ID may have more difficulties to transfer or generalize adapted behaviors from one situation to another: In a case report on 3 children with FXS, autism and ID, the ability to empty the bladder from diaper to the toilet had to be trained in an intensive behavioral treatment (Smith, Smith, \& Lee, 2000).

Three children with DUI showed typical symptoms of urge incontinence and one of voiding postponement. These cases could be treated evidence-based by counselling, increasing micturitions (in VP) and medication (in UI). DUI with dysfunctional voiding was not present in FXS, in contrast to other syndromes, e.g. Angelman Syndrome, in which DV symptoms are much more prevalent (Radstaake et al., 2013).

An unexpected result was the lack of constipation in boys with FXS, especially in those with FI. In other syndromes with ID, rates of constipation are much higher: approx. 40\% in Williams Syndrome, 20-50\% in Down Syndrome and approx. 30\% in ID overall (Moore, 2008; Morris, Demsey, Leonard, Dilts \& Blackburn, 1988; van Laecke, Raes, Vande Walle, \& Hoebeke, 2009). A distended rectal diameter was present in $27.3 \%$ of FXS, but none of the children had additional symptoms of constipation, such as hard, painful stools and infrequent bowel movements. There are only few reports of constipation in FXS. Parents or caregivers reported a hard stool consistency in only $6.6 \%$, pain during defecation in $1.8 \%$ and infrequent bowel movements on $1-2$ days/week in $0.6 \%$ of 166 persons with FXS (4-52 years) (Equit et al., 2013). There is only a case report on a 6-year-old FXS girl who showed symptoms of encopresis and massive constipation (Equit et al., 2011). In a review on medical problems in FXS, loose stools and diarrhea were more typical than constipation (Kidd et al., 2014). The low rates of constipation indicate that other etiological factors have to be responsible for FI in FXS, such as inadequate or delayed toilet training. 
Regarding urodynamic data, boys with FXS did not differ significantly from controls except for the LUTS score and mean bladder wall thickness. A thicker bladder wall can be associated with overactive bladder (OAB) and VP (Kuhn, Natale, Siemer, Stoeckle, \& von Gontard, 2009; Yeung, Sreedhar, Leung \& Sit, 2007; Zink, Freitag \& von Gontard, 2008) and can affect therapy outcome in NE negatively (Yeung, Sreedhar, Leung \& Metreweli, 2004). Bladder wall thickness also depends on degree of bladder filling (Austin et al., 2016). As the voided volume at uroflowmetry in the present sample did not differ significantly between the FXS and the control group, this reason for the thickened bladder wall can be excluded. 3 FXS boys had an UI, indicative of OAB, which was the most common subtype of DUI.

Other findings such as bladder capacity (indicated as MVV), number of micturitions per day, PVR and fluid intake were not different from typically developing boys. Compared to continent FXS boys, fluid intake was lower in incontinent FXS boys. A lower fluid intake was a risk factor for incontinence in children with ID and could be reduced by changing drinking habits in one study (van Laecke et al., 2009). An adequate liquid intake should therefore be an essential aspect of incontinence treatment in children with FXS.

Unfortunately, uroflowmetry could not be assessed in every child. Especially boys with FXS were anxious to void into the uroflowmeter. Some controls refused uroflowmetry, as well, and measurement errors occurred due to software problems. In a few cases, voided volume was too small to evaluate the uroflow curves reliably. The available data indicates that most children with FXS can empty their bladder regularly and do not have more voiding anomalies than control children, in contrast to other syndromes, e.g. Angelman Syndrome (Radstaake et al., 2013).

Nearly all boys with FXS (90.9\%) were affected by psychiatric disorders. The most common disorder was ADHD (72.7\%), followed by specific phobias (54.5\%) with rates similar to other findings (Backes et al., 2000; Gabis et al., 2011), thereby confirming the typical behavioral phenotype of FXS. Further psychiatric disorders in the present study are within the spectrum of disorders of other publications (social phobia, separation anxiety disorder, OCD, tic disorder, ODD) (Backes et al., 2000; Gabis et al., 2011). Affective disorders (e.g. depression) and severe conduct disorders were not diagnosed and seem not to be typical of the FXS behavioral phenotype, which is supported by similar findings (Backes et al., 2000; Gabis et al., 2011; Gallagher \& Hallahan, 2012). In epidemiological studies, depression rates are generally low in individuals with ID, possibly because the diagnosis of affective disorders is more difficult or because the general diagnostic criteria are inadequate for persons with ID (Davis, Judd, \& Herrman, 1997). Therefore, it is possible, that affective disorders were underestimated in children with FXS.

In the $\mathrm{CBCL}$ parental questionnaire, $68 \%$ of parents reported clinically relevant behavioral problems, comparable with previous studies (Backes et al., 2000; Equit et al., 2013). In contrast to the psychiatric diagnoses, rates of internalizing problem behavior in the $\mathrm{CBCL}$ are much higher than externalizing rates in FXS boys (41\% vs. $9 \%$ ). One possible explanation could be that the $\mathrm{CBCL}$ data reflect the parental worries and attributions, e.g. 
the fear that the child will be socially excluded or won't find friends. Also, the CBCL is constructed for typically developing children, which reduces the reliability of assessing psychological problems in children with ID (Koskentausta, livanainen, \& Almqvist, 2004). Maybe other specialized instruments, e.g. the Developmental Behavior Checklist (Einfeld \& Tonge, 1995) would have been more reliable for the children with FXS, but then comparisons with the control group would not have been possible.

As the structured psychiatric interview (Kinder-DIPS) does not assess ASD, autistic symptoms were assessed by the SCQ questionnaire. Nearly $60 \%$ of the parents reported autistic behavior (clinically relevant score in the SCQ) in their children. This is also concordant with other findings that show that autistic symptoms or even an ASD are part of the behavioral phenotype of FXS (Gabis et al., 2011; Hagerman, Jackson, Levitas, Rimland \& Braden, 1986). Vice versa, FXS is the most common syndromal cause of ASD.

\section{Strengths and limitations}

Children with FXS and their parents were seen and examined clinically and not only assessed by questionnaires. Standardized instruments were used, the control group was carefully matched and incontinence data were evaluated according to international classification systems (DSM-5, ICCS, ROME-III). This detailed clinical assessment allowed that incontinence subtypes could be diagnosed.

A limitation is that uroflowmetry data was not available in all patients and somatic conditions could not be determined more specifically. Also, a selection bias could have occurred as families participating in the study may have been more interested in incontinence because they have an incontinent child. Because of the small sample size, the results have to be interpreted cautiously. Therefore, the effects should be replicated in a larger sample. Another limitation is the cross-sectional design of the study, as only longitudinal studies will give information on causal associations.

\section{Conclusion}

The present study shows that boys with FXS are much more often affected by incontinence and psychological disorders than their typically developing peers. UI, primary NE and FI-NR are the most common subtypes. Children with FXS do not have more LUTS or abnormal uroflowmetry or sonography findings. In contrast to children with other syndromes, constipation is a rare condition in FXS. Treatment for children with ID and incontinence is available (von Gontard, 2013) and should always be offered to affected families. 


\section{Acknowledgements}

We would like to thank the German support group 'Interessengemeinschaft Fragiles-X e. V.' and their chairman Dr. Jörg Richstein for giving us the opportunity to cooperate and conduct this study with help of the members of the support group.

\section{Funding}

The Department of Child and Adolescent Psychiatry, Saarland University Hospital, received financial support from Novartis AG to conduct this study.

\section{Conflict of interest}

The authors declare that they have no conflict of interest.

\section{Ethical approval}

All procedures performed in the present study have been approved by the local ethics committee and were in accordance with the ethical standards laid down in the 1964 Declaration of Helsinki and its later amendments. 


\section{References}

Achenbach, T.M. (1991). Manual for the Child Behavior Checklist/4-18 and 1991 Profile. Burlington, VT: University of Vermont.

American Psychiatric Association (APA) (2013). Diagnostic and statistical manual of mental disorders - Fifth Edition (DSM 5). Washington, D.C.: APA.

Arbeitsgruppe Deutsche Child Behavior Checklist (1999). Deutsche Bearbeitung der Child Behavior Checklist (CBCL/4-18) - Einführung und Anleitung zur Handauswertung. Köln: Arbeitsgruppe Kinder-, Jugend- und Familiendiagnostik.

Austin, P.F., Bauer, S.B., Bower, W., Chase, J., Franco, I., Hoebeke, P., ... , Yang, S. S. (2016). The Standardization of Terminology of Lower Urinary Tract Function in Children and Adolescents: Update Report from the Standardization Committee of the International Children's Continence Society. Neurourology \& Urodynamics, 35(4), 471-481.

Backes, M., Genç, B., Schreck, J., Doerfler, W., Lehmkuhl, G., \& von Gontard, A. (2000). Cognitive and behavioral profile of fragile X boys: Correlations to molecular data. American Journal of Medical Genetics, 95, 150156.

Bölte, S., \& Poustka, F. (2006). FSK - Fragebogen zur Sozialen Kommunikation - Autismus Screening. Bern: Verlag Hans Huber.

Brown, T. (2002). The molecular biology of the fragile $X$ mutation. In: Hagerman, R.J., Hagerman, P.J. (eds.). Fragile X syndrome: Diagnosis, treatment, and research. Baltimore: Johns Hopkins University Press.

Brushini, H., Faria, N., Garcez, E., \& Srougi, M. (2003). Development of bladder control in mentally handicapped children. International Brazilian Journal of Urology, 29, 455-458.

Davis, J.P., Judd, F.K., \& Herrman, H. (1997). Depression in adults with intellectual disability. Part 1: A review. Australian \& New Zealand Journal of Psychiatry, 31, 232-242.

de Gennaro, M., Niero, M., Capitanucci, M.L., von Gontard, A., Woodward, M., Tubaro, A., \& Abrams, P. (2010). Validity of the international consultation on incontinence questionnaire-pediatric lower urinary tract symptoms: A screening questionnaire for children. Journal of Urology, 184,1662-1667.

Duker, P.C., \& Dekkers, M. (1992). Development of diurnal bladder control in severely and profoundly mentally handicapped residents. Journal of Intellectual Disability Research 36, 177-181.

Einfeld, S., \& Tonge, B. (1995). Manual for the Developmental Behavior Checklist - Primary Carer Version (DBCP) \& Teacher Version (DBC-T). Clayton, Melbourne: Monash University Centre for Developmental Psychiatry and Psychology.

Equit, M., Piro-Hussong, A., Niemczyk, J., Curfs, L., \& von Gontard, A. (2013). Elimination disorders in persons with Prader-Willi and Fragile-X syndromes. Neurourology \& Urodynamics, 32, 986-992.

Equit, M., Sambach, H., \& von Gontard, A. (2011). Fragile X syndrome and elimination disorders in a 6-year-old girl. Klinische Pädiatrie, 223, 430-433.

Gabis, L.V., Baruch, Y.K., Jokel, A., \& Raz, R. (2011). Psychiatric and autistic comorbidity in fragile X syndrome across ages. Journal of Child Neurology, 26, 940-948.

Gallagher, A., \& Hallahan, B. (2012). Fragile X-associated disorders: A clinical overview. Journal of Neurology, 259, 401-413.

Hagerman, R.J., Jackson, III. A.W., Levitas, A., Rimland, B., \& Braden, M. (1986). An analysis of autism in fifty males with the fragile X syndrome. American Journal of Medical Genetics, 23, 359-374.

Jarvelin, M.R., Vikevainen-Tervonen, L., Moilanen, I., \& Huttunen, N. (1988). Enuresis in seven-year-old children. Acta Paediatrica Scandinavia, 77, 148-153.

Joinson, C., Heron, J., Emond, A., \& Butler, R. (2007). Psychological problems in children with bedwetting and combined (day and night) wetting: A UK population-based study. Journal of Pediatric Psychology, 32, 605616.

Joinson, C., Heron, J., Butler, U., \& von Gontard, A. (2006). Psychological differences between children with and without soiling problems. Pediatrics, 117, 1575-1584. 
Joinson, C., Heron, J., \& von Gontard, A. (2006). Psychological problems in children with daytime wetting. Pediatrics, 118, 1985-1993.

Kidd, S.A., Lachiewicz, A., Barbouth, D., Blitz, R.K., Delahunty, C., McBrien, D., ..., Berry-Kravis, E. (2014). Fragile $X$ syndrome: A review of associated medical problems. Pediatrics, 134, 995-1005.

Koskentausta, T., livanainen, M., \& Almqvist, F. (2004). CBCL in the assessment of psychopathology in Finnish children with intellectual disability. Research in Developmental Disability, 25, 341-354.

Kuczmarski, R., Ogden, C.L., \& Grummer-Strawn, L.M. (2000). CDC Growth Charts: United States. Hyattsville, MD: National Center for Health Statistics.

Kuhn, S., Natale, N., Siemer, S., Stoeckle, M., \& von Gontard, A. (2009). Clinical differences in daytime wetting subtypes: Urge incontinence and postponed voiding. Journal of Urology, 182, 1967-1972.

Moeschler, J.B., Shevell, M., Schaefer, G.B., Bull, M.J., Enns, G.M., Gruen, J.R., ... , Spire, P. (2006). Clinical genetic evaluation of the child with mental retardation or developmental delays. Pediatrics, 117, 2304-2316.

Moore, S.W. (2008). Down syndrome and the enteric nervous system. Pediatric Surgery International, 24, 873883.

Morris, C.A., Demsey, S.A., Leonard, C.O., Dilts, C., \& Blackburn, B.L. (1988). Natural history of Williams syndrome: Physical characteristics. Journal of Pediatrics, 113, 318-326.

Nevéus, T., von Gontard, A., Hoebeke, P., Hjälmås, K., Bauer, S., Bower, W., ... , Djurhuus, J.C. (2006). The Standardization of Terminology of Lower Urinary Tract Function in Children and Adolescents: Report from the Standardisation Committee of the International Children's Continence Society. Journal of Urology, 176, 314-324.

Radstaake, M., Didden, R., Giesbers, S., Korzilius, H., Peters-Scheffer, N., Lang, R., ... , Curfs, L.M.G. (2013). Incontinence in individuals with Angelman syndrome: A comparative study. Research in Developmental Disability, 34, 4184-4193.

Rasquin, A., Di Lorenzo, C., Forbes, D., Guiraldes, E., Hyams, J.S., Staiano, A., \& Walker, L.S. (2006). Childhood Functional Gastrointestinal Disorders: Child/Adolescent. Gastroenterology, 130, 1527-1537.

Raven, J., Raven, J.C., \& Court, J.H. (2006). Raven's progressive matrices und vocabulary scales. Frankfurt: Harcourt Test Services.

Raven, J.C. (1998). Standard progressive matrices. Göttingen: Beltz-Test.

Schneider, S., Margraf, J., \& Unnewehr, S. (1995). Kinder-DIPS: Diagnostisches Interview bei psychischen Störungen von Kindern und Jugendlichen. Berlin: Springer.

Smith, L., Smith, P., \& Lee, S.K.Y. (2000). Behavioral treatment of urinary incontinence and encopresis in children with learning disabilities: Transfer of stimulus control. Developmental Medicine \& Child Neurology, 42, 276-279.

Tranfaglia, M.R. (2011). The psychiatric presentation of fragile X: Evolution of the diagnosis and treatment of the psychiatric comorbidities of fragile X syndrome. Developmental Neuroscience, 33, 337-348.

Turner, G., Webb, T., Wake, S., \& Robinson, H. (1996). Prevalence of fragile X syndrome. American Journal of Medical Genetics, 64, 196-197.

van Laecke, E., Raes, A., Vande Walle, J., \& Hoebeke, P. (2009). Adequate fluid intake, urinary incontinence, and physical and/or intellectual disability. Journal of Urology, 182, 2079-2084.

von Gontard, A. (2013). Urinary incontinence in children with special needs. Nature Reviews Urology 10, 667674.

von Gontard, A. (2012a). Encopresis. In J. M. Rey (Ed.), IACAPAP e-textbook of child and adolescent mental health. Geneva: International Association for Child and Adolescent Psychiatry and Allied Professions. http://iacapap.org/wp-content/uploads/C.5-ENCOPRESIS-0072012.pdf. Accessed 11.03.16.

von Gontard, A. (2012b). Enuresis. In J. M. Rey (Ed.), IACAPAP e-textbook of child and adolescent mental health. Geneva: International Association for Child and Adolescent Psychiatry and Allied Professions. http://iacapap.org/wp-content/uploads/C.4-ENURESIS-072012.pdf. Accessed 11.03.16.

von Wendt, L., Simila, S., Niskanen, P., \& Jarvelin, M. (1990). Development of bowel and bladder control in the mentally retarded. Developmental Medicine \& Child Neurology, 32, 515-518.

Yang, P.Y., Meng, N.H., \& Chou, E.C.L. (2010). Voiding dysfunctions in children with mental retardation. Neurourology \& Urodynamics, 29, 1272-1275. 
Yeung, C.K., Sreedhar, B., Leung, V.T., \& Metreweli, C. (2004). Ultrasound bladder measurements in patients with primary nocturnal enuresis: A urodynamic and treatment outcome correlation. Journal of Urology, 171, 2589-2594.

Yeung, C., Sreedhar, B., Leung, Y.V., \& Sit, K.-F. (2007). Correlation between ultrasonographic bladder measurements and urodynamic findings in children with recurrent urinary tract infection. BJU International, 99, 651-655.

Zink, S., Freitag, C.M., \& von Gontard, A. (2008). Behavioral Comorbidity Differs in Subtypes of Enuresis and Urinary Incontinence. Journal of Urology, 179, 295-298. 



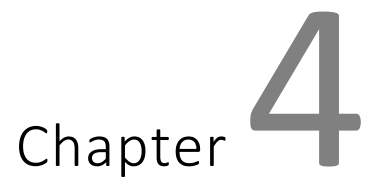

General Discussion 
In the following chapter, results of the studies from chapter $2.1-2.4$ and chapter 3 are summarized and analyzed in a broader perspective. Several aspects of incontinence, as the delayed achievement of bladder and bowel control, neurological and genetic factors are addressed. Advantages and disadvantages of the methodology are considered and associations of incontinence with psychological symptoms, as well as clinical implications of the results are discussed.

\section{Results in a broader perspective}

Overall results of incontinence rates in genetic syndromes

When regarding results on incontinence in genetic syndromes, the differences of rates are large, depending on the syndrome and the age group that was examined. Figure 1 summarizes results of incontinence rates for all five syndromes that were assessed in this thesis.

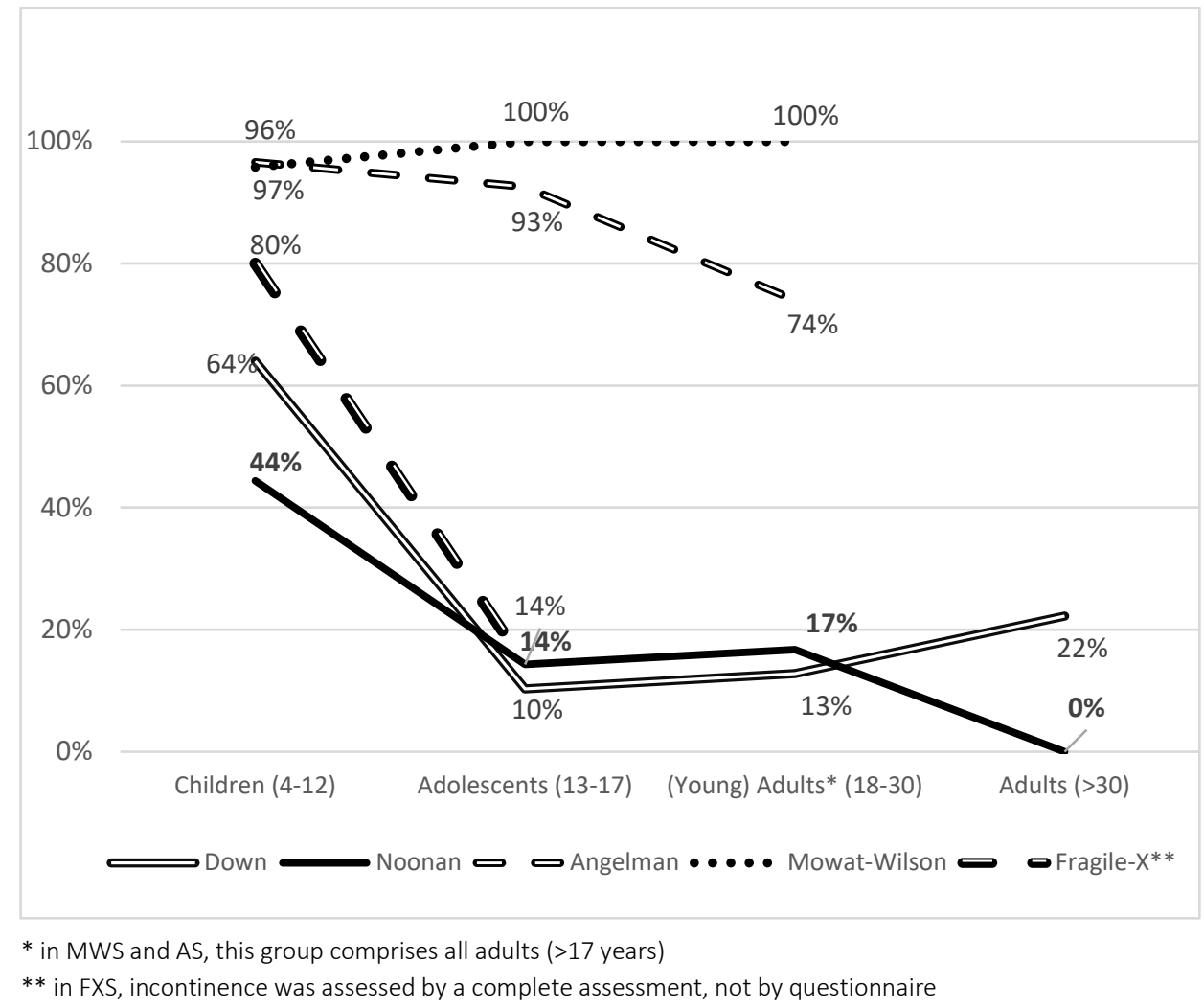

Figure 1: Rates of incontinence from studies presented in chapters $2.1-2.4$ and chapter 3 by syndrome and age group 
As shown in figure 1, there seem to be two different groups of syndromes: In the first group ("upper part" of the figure: Angelman and Mowat-Wilson Syndrome), incontinence rates are very high in all age groups. In the second group ("lower part" of the figure: Down, Fragile-X and Noonan Syndrome) incontinence is high in childhood, but much lower in adolescence and adulthood. Possible explanations for these differences are discussed in the following.

\section{Incontinence associated with level of intellectual disability (ID)}

A first explanation of these two groups is obvious and can be found in the level of ID. Both, Angelman Syndrome (AS) and Mowat-Wilson Syndrome (MWS) are genetic disorders that go along with severe or profound ID (Mowat \& Wilson, 2010; Thibert, Larson, Hsieh, Raby, \& Thiele, 2013). IQ of boys with Fragile-X syndrome (FXS) is in the moderate (to severe) level of ID (Gallagher \& Hallahan, 2012). The IQ in Down syndrome (DS) ranges widely, from mild to moderate ID (Brown, Greer, Aylward, \& Hunt, 1990). Individuals with Noonan syndrome (NS) are least impaired, with $37 \%$ having a below-average IQ and further 20-30\% a mild ID (Lee, Portnoy, Hill, Gillberg, \& Patton, 2005).

Regarding the incontinence results of the children group in these five syndromes (figure 1), the rates increase with their average IQ impairment. In NS (average - mild ID) 44\%, in DS (mild - moderate ID) 64\%, in FXS (moderate - severe ID) 80\%, and in AS and MWS (severe - profound ID), 96-97\% of persons are incontinent. In the adolescent and adult groups, these differences occur mainly between the syndromes with mild/moderate and severe/profound ID.

In the population-based study of von Wendt et al. (1990), rates of incontinence were also strongly related to level of ID in children, as well as in adults. For example, encopresis in seven-year-olds was present in $2.8 \%$ of those with mild ID, $32.4 \%$ with moderate ID, $38.1 \%$ with severe ID and in $85.7 \%$ with profound ID. In the other types of incontinence (nighttime and daytime wetting), rates are similar between moderate and severe ID, but increase from mild to profound ID (von Wendt, Simila, Niskanen, \& Jarvelin, 1990).

According to the current DSM-5 guidelines, ID is defined as a disability with deficits in both intellectual functioning (e.g. problem solving, learning from experience, planning) and adaptive skills (e.g. communication, social participation, independent living) that impair the meeting of sociocultural standards and a personal independence (American Psychiatric Association (APA), 2013). Due to memory deficits (Bray, Fletcher \& Turner, 1997), persons with ID need more intense training to learn and have problems to generalize, which is time-consuming and may lead to frustration of the caregivers. Attention processes are impaired in persons with ID (Tomporowski \& Tinsley, 1997) which reduces learning of practical skills. Therefore, one can imagine that persons with ID have problems to perceive signals of a full bladder and bowel and to link them cognitively to the act of emptying into the toilet. ID affects negatively language skills (Warren \& Yoder, 1997), 
which may also complicate communication, e.g. when the affected person cannot communicate that he/she needs to go to the bathroom.

Also, from a social perspective, children with ID have less motivation to learn, tend to be more anxious and avoiding regarding new skills (Switzky, 1997). Therefore, incontinence may be tolerated more in children with ID than in typically developing children, which may lower the expectations towards these persons to become continent. It can be hypothesized that these adaptive impairments based on intellectual deficits lead to higher incontinence rates in affected persons.

Although there seems to be a negative correlation between incontinence and $I Q$, this hypothesis has to be interpreted cautiously. The comparison of incontinence rates in different ID groups and syndromes is difficult, because intelligence was measured only in one study of the present thesis (FXS; Chapter 3). In the other syndrome studies, IQ was not measured directly due to the questionnaire study design. Similarly, von Wendt et al. (1990) do not describe how they measured the level of ID in their study. Regarding the existing literature on genetic syndromes, a significant association between incontinence and adaptive skills was only found in one study in Angelman syndrome, and only for one subtype of incontinence (DUI) (Radstaake et al., 2013).

Further, there is evidence that the level of ID is not directly associated with incontinence episodes, but is mediated by other factors e.g. developmental delays or physical dysfunctions that can affect continence. Belva et al. examined correlations between adaptive skills (measured by the Vineland Scales) and toileting problems (measured by a toileting questionnaire). Adaptive skills were negatively correlated with toileting behavior (e.g. attempts to urinate/defecate into the toilet) and physical problems, but not with toileting accidents or social/emotional problems (Belva, Matson, Barker, Shoemaker, \& Mahan, 2011). In the FXS study (Chapter 3), IQ did not differ between incontinent and continent boys. Further, in other publications the level of ID was associated with lower urinary tract symptoms (LUTS), such as higher post-void-residual urine (PVR) or smaller bladder capacity (de Waal, Tinselboer, Evenhuis, \& Penning, 2009; Yang, Meng, \& Chou, 2010), i.e. with factors that can lead to incontinence. All these results imply that ID alone does not lead to incontinence directly, but is associated with other factors that can cause incontinence.

In the next chapters, additional aspects of incontinence in genetic syndromes are discussed. First, a delay in achieving bladder and bowel control can lead to higher rates of incontinence, especially in children. Behavioral and maturational factors can play a major role in this context. Second, genetic syndromes co-occur with further physical impairments that affect the lower urinary and gastrointestinal tract and cause incontinence. These somatic conditions can also explain differences in subtypes of incontinence between genetic syndromes. And as a final aspect, the impact of psychological symptoms on incontinence is discussed. 
Incontinence associated with delayed development of bladder and bowel control

Another explanation for higher incontinence rates in individuals with genetic syndromes associated with ID could be maturational and developmental delays or other neurobiological deficits that lead to a delayed achievement of bladder and bowel control. Typically developing children achieve controlled bladder and bowel emptying in average at 24-48 months of age (Berk \& Friman, 1990). However, the variance is high. At an age of 4.5 years, $13.8 \%$ of children are incontinent for urine and $11 \%$ are incontinent for feces (Heron, Joinson, Croudace, \& von Gontard, 2008). In children with genetic syndromes and ID the achievement of bladder and bowel control is delayed. In DS, the mean age of continence accomplishment was 5.5 years (Powers et al., 2015) and in NS, 41 months (Sarimski, 2000). In MWS, 3 of 8 children over the age of 4 years were not continent (Adam et al., 2006) and in FXS, 4 out of 8 children with DUI still wore diapers (Chapter 3 ). As many children with genetic syndromes or ID develop bladder and bowel control much later than typically developing children, this also contributes towards the very high rates of incontinence in childhood in the five syndromes.

When discussing the reason why incontinence rates are so much higher in people with ID or genetic syndromes, one must understand the general mechanisms of incontinence and bladder/bowel control in typically developing children.

One crucial requirement to develop urinary continence is a bladder capacity large enough to enable storage of urine for a certain time. A longitudinal study of children between 3 and 36 months of age revealed that bladder capacity remains at a similar size from 3 to 18 months, but nearly doubles from 18 to 36 months (Jansson, Hanson, Hanson, Hellström, \& Sillén, 2000), precisely at that age, when most children start toilet training. There is also a decrease in voiding frequency (from once per hour after birth to 3-7 times/day in school children (Hellström, Hanson, Hansson, Hjälmås, \& Jodal, 1990) and in interrupted voiding, which is frequent in neonates, but rare in in children after toilet training (Jansson et al., 2000). These changes reflect the bladder maturation processes that finally enable the child becoming dry (Ogunyemi \& Wu, 2015; Sillén, Sölsnes, Hellström, \& Sandberg, 2000).

Some study results implicate a smaller bladder capacity and a more frequent interrupted voiding in genetic syndromes. Bladder capacity itself was only examined in one study on Williams syndrome (WS) (Sammour, Gomes, Duarte, Trigo-Rocha, \& Srougi, 2006). In 28 persons aged 3-19 years (mean 9.7) with WS, measured bladder capacity was $28 \%$ lower than expected for age $(180 \mathrm{ml}$ vs. $254 \mathrm{ml})$. Other symptoms, such as urge incontinence, urgency or increased frequency that can be indicators for a smaller bladder capacity, were found in persons with WS, as well (Sammour et al., 2006; Schulman, Zderic, \& Kaplan, 1996). Urgency is the most common LUTS reported in children with WS (von Gontard et al., 2016) and was also found in Down syndrome (DS) and Angelman syndrome (AS) (Chapter 2.1; 2.3). In DS, urgency symptoms were reduced significantly with increasing age, whereas in AS the rates stayed high in all age groups, similar as the 
overall incontinence rates in those two syndromes. In FXS, the maximum voided volume (MVV) was measured, which is an indicator of bladder capacity, recommended by the ICCS (Chapter 3). The MVV was not lower in the FXS group compared to healthy controls, but, though not significant, it was lower in the incontinent compared to the continent FXS boys $(219 \mathrm{ml}$ vs. $432 \mathrm{ml}$ ). Further, urge incontinence was more common in the FXS sample than other DUI subtypes (e.g. voiding postponement), another indication of a smaller bladder capacity. Interrupted voiding, which is a further indicator of an immature bladder function, was found in persons with DS who were assessed with uroflowmetry (Kitamura et al., 2014). As a smaller bladder capacity is related to incontinence and is a sign of immature development, this could be another explanation for higher incontinence rates in genetic syndromes.

Regarding bowel control, most children develop a coordinated defecation before the age of 4 years (Heron et al., 2008; Weaver \& Lucas, 1993). The defecation process involves the enteric nervous system (ENS), the autonomic nervous system (ANS) and the gut muscles (e.g. internal and external anal sphincter) (Ejerskov \& Siggaard Rittig, 2015). The ENS is a neuronal network that innervates the bowel and controls the gastrointestinal tract autonomously (Lake \& Heuckeroth, 2013). As the ENS develops early in the embryonic stadium, disruptions at that time may lead to somatic conditions, as Hirschsprung's disease (HSCR), which is associated with $\mathrm{Fl}$ and constipation and is discussed further in one of the next sections. In accordance with bladder development, there is a decline of bowel movements in children from $3 x /$ day (with a large variance) at the age of four weeks to $1.3 x$ /day in 3.5-year-olds. Also, the consistency of stools changes from mostly soft/liquid to mostly hard (Steer, Emond, Golding, \& Sandhu, 2009). At that age, it becomes easier to control the defecation reflex and to learn a voluntary relaxation of the external anal sphincter which leads to continence. In a study on children with autism spectrum disorder (ASD), which can be accompanied by ID or a genetic syndrome (e.g. FXS), daily bowel movements were significantly more frequent in children with ASD at the age of 30 months than in typically developing children (Sandhu, Steer, Golding, \& Emond, 2009), which could be a sign of developmental delay of bowel control in these children.

\section{Incontinence associated with delayed development of the central nervous system}

Another requirement for urinary continence is the volitional control of the external urethral sphincter that can only be achieved by involving higher centers of the brain. Bladder emptying leads to awaking and arousal already in neonates and infants and is accompanied by EEG alterations (Jansson et al., 2000; Yeung et al., 1995; Zhang et al., 2016). These findings support the hypothesis that anatomical neural pathways from the bladder to corresponding brain regions are already developed at neonate age, but do not function maturely, yet (Franco, 2015; Sillén, 2001). When regarding the maturation process of 
bladder function, the reduction of detrusor overactivity makes the control over the urethral sphincter easier, and thus, learning to empty the bladder volitionally becomes more likely. At that stage, bladder control is influenced by further personal or social factors, e.g. motivation, social context, emotions, stress, and sensation, which means that other higher brain centers must be involved.

A model of central nervous system (CNS) involvement in bladder filling and emptying based on functional brain imaging data was proposed by Fowler and Griffiths (2010): The periaqueductal gray (PAG) of the brain stem receives afferent signals from the sacral region, and has connections to other brain regions, as the hypothalamus, thalamus, insula, anterior cingulate cortex (ACC) and the prefrontal cortex. During bladder filling, the PAG is inhibited by pathways from the medial prefrontal cortex, where the decision-making of 'voiding or not' is located. The PAG inhibits the pontine micturition center (PMC), from which efferent signals are sent to the sacral region. During bladder emptying, signals from the prefrontal cortex "activate" the PAG, which reduces the inhibition of the PMC (Fowler \& Griffiths, 2010). The volitional control of bladder and bowel function is mainly attributed to the prefrontal cortex, a region for e.g. decision-making, or cognition (Franco, 2015). This is supported by the findings of Andrew and Nathan (1964), who reported incontinence, frequency, urgency and a total loss of bladder sensation in patients with prefrontal cortex lesions (Andrew \& Nathan, 1964). In recent functional imaging studies on bladder function, an activation of the ACC is typical (Franco, 2015). The ACC is associated with motivation or response to cognitive or emotional stimuli.

As neuroimaging studies on incontinence are scarce for typically developing persons, studies on individuals with genetic syndromes and incontinence do not exist at all. However, when regarding other brain imaging studies in genetic syndromes, some conclusions about the impact of brain development on bladder and bowel function can be drawn.

In structural MRI studies on Down syndrome (DS), volumes of the total brain, the frontal and temporal lobes, hippocampus and amygdala were significantly reduced compared to controls (Pinter et al., 2001; Śmigielska-Kuzia et al., 2011). Volume of the right hippocampus was negatively correlated with ID (Śmigielska-Kuzia et al., 2011). There is also a reduction of the total, parietal and occipital brain, thalamus, the basal ganglia and midbrain volumes, and a significant correlation to IQ in Williams syndrome (Chiang et al., 2007). In Angelman syndrome (AS), reduced gray matter volume in striatum, limbic structures, insular and orbitofrontal regions was found (Aghakhanyan et al., 2016). In children with AS, myelination delay and a white matter deficit were present, which were interpreted as signs of delayed brain maturation (Harting et al., 2009). Two DTI studies revealed decreased axonal density, aberrant axonal organization, white matter alterations associated with language, cognitive and social functioning, and alterations in many different brain regions, among others in the left brainstem and left cingulum. It is hypothesized that the loss of the UBE3A gene expression in AS leads to this aberrant brain connectivity (Peters et al., 2011; Tiwari et al., 2012). 
In contrast to other genetic syndromes, in which volumes of brain regions and axonal density were reduced, MRI studies on infants with FXS (age 1-3 years) showed increased and altered gray matter volumes in orbital gyri, basal forebrain and thalamus (Hoeft et al., 2010). In a DTI study on young males with FXS, an increased axonal density compared to typically developing and to developmentally delayed controls was found, which was associated with lower IQ (Haas et al., 2009). Further, white matter structure was altered in the frontostriatal pathways, prefrontal, temporal and central regions, amygdala and insula (Haas et al., 2009; Hoeft et al., 2010). It is hypothesized that the decreased or absent expression of the FMR-1 protein leads to white matter alterations and thus to cognitive dysfunctions and an abnormal brain development in persons with a full mutation (Haas et al., 2009).

To date, there are no brain imaging studies on Noonan syndrome. In Mowat-Wilson syndrome (MWS), only one research group examined brain anomalies via MRI (Garavelli et al., 2016) and found anomalies of the corpus callosum, hippocampus, ventricles, white matter reductions, enlargements of basal ganglia, and cortical and cerebellar malformations.

There is evidence that alterations in brain development in genetic syndromes could be associated with incontinence and delayed bladder/bowel control, as they are associated with $I Q$, neurodevelopmental, and social functions. Further, many of the brain regions that are relevant for bladder function, as the prefrontal cortex, brainstem or insula, are altered in individuals with genetic syndromes. Also, white or gray matter anomalies are reported for nearly all genetic syndromes that are examined in this thesis. White and gray matter alterations are associated with incontinence. White matter anomalies were associated with incontinence and symptom severity in older people (Kuchel et al., 2009) and gray matter was reduced in schizophrenic patients with a history of enuresis compared to those without (Hyde et al., 2008).

In summary, brain development is delayed in persons with genetic syndromes, which can lead to developmental delays in cerebral centers that are involved in bladder control. Unfortunately, there is no study so far, that has examined incontinence or bladder/bowel dysfunction and cerebral alterations in genetic syndromes. The possible associations can therefore only be speculated.

\section{Incontinence associated with somatic conditions}

Another important aspect of incontinence in different genetic syndromes is the comorbidity with somatic conditions. According to the ICCS guidelines, functional or non-organic incontinence has to be distinguished from organic incontinence, which can occur due to neurological conditions (e.g. spina bifida, tethered-cord-syndrome), structural anomalies (e.g. hypospadias, malformations of the LUT) or other medical causes (e.g. diabetes insipidus, diabetes mellitus) (von Gontard, 2012b). 
Somatic causes of chronic constipation are Hirschsprung's disease (HSCR), anorectal malformations (stenosis, anal fissures etc.), metabolic diseases (cystic fibrosis, celiac disease, diabetes mellitus) and neurological conditions (cerebral palsy, spina bifida etc.) which are present in $5 \%$ of children. Side effects of diverse medication must also be considered in constipation. In non-retentive $\mathrm{Fl}$, somatic causes are found in $<1 \%$, including neurological conditions (spina bifida) or diarrhea due to infections (von Gontard \& Nevéus, 2006).

In typically developing children, the majority of incontinence is functional, so that organic incontinence is rare (von Gontard \& Nevéus, 2006). In contrast, genetic syndromes are accompanied by a variety of medical conditions that can be associated with bladder and bowel dysfunction and therefore lead to higher incontinence rates. Also, functional and organic forms of incontinence can co-exist.

In four syndromes (DS, NS, AS, MWS) of this thesis, parental information on medical conditions is available and in FXS, a full neurological and somatic was conducted. Possible associations with the most relevant conditions are discussed in the following.

\section{Hirschsprung's disease (HSCR)}

HSCR is the most important somatic differential diagnosis in children with constipation. HSCR is characterized by an aganglionosis of the rectum, the rectosigmoid or further parts of the colon and leads to symptoms of vomiting, food refusal and constipation already in neonates (Langer, 2013). The prevalence of HSCR is 1:5000 live births with a male preponderance and a higher incidence in certain genetic syndromes, as DS or MWS (Sergi, Caluseriu, McColl, \& Eisenstat, 2016).

DS is significantly associated with HSCR with a prevalence of about $2.5 \%$ of HSCR in DS (Friedmacher \& Puri, 2013), which is a 40-fold higher risk than in the general population (Arnold et al., 2009). Individuals with DS and HSCR have a higher risk for FI (Friedmacher \& Puri, 2013), which could contribute to the higher rates of FI in DS. In the sample of DS individuals in this thesis, four had HSCR ( $=1.3 \%$ of the sample), one with concomitant $\mathrm{Fl}$ and two with constipation (Chapter 2.1). The ret proto-oncogene (RET) is discussed as a possible gene involved in the pathogenesis of HSCR in DS, as specific gene variations were found more often in individuals with DS and HSCR than in HSCR without DS (Moore, 2008). The RET gene is expressed in the embryonic stadium during the development of the enteric nervous system (ENS) and supports proliferation, migration, differentiation and neurite growth (Lake \& Heuckeroth, 2013).

In MWS, rates of HSCR are even higher than in DS. (Coyle \& Puri, 2015) found rates of $45 \%$, and in our sample, $38.3 \%$ had a history of HSCR (Chapter 2.4). The majority of affected persons continue having constipation or Fl even after surgery (Coyle \& Puri, 2015). In contrast to DS, the zinc finger homeobox 1B (ZFHX1B) gene is discussed as a cause of HSCR in MWS, representing a syndromic type of HSCR. A mutation or deletion of the ZFHX1B gene causes MWS and affects prenatal development, especially the development 
of the enteric nervous system (ENS) (Sergi et al., 2016). In mouse models, knockout of the ZFHX1B gene prevents nerve cell migration beyond the distal half of the stomach (van de Putte, Francis, Nelles, van Grunsven, \& Huylebroeck, 2007), which leads to aganglionosis of further parts of the gastrointestinal tract, as e.g. the colon.

As HSCR leads to a variety of symptoms already in the early neonatal period, up to $80 \%$ of cases are diagnosed and operated by the age of four years (Felt et al., 1999), that means before the diagnosis onset age of FI. Nevertheless, even operated HSCR is associated with higher rates of $\mathrm{FI}$ and constipation. As HSCR is associated with several genetic syndromes, such as DS or MWS, it could contribute to higher rates of FI and constipation in these groups. For example, the rate of FI in the MWS population (Chapter 2.4) was much higher than in the Angelman syndrome population (Chapter 2.3) (81.4\% vs. 57.1\%), despite being similar syndromes regarding to their cognitive and physical impairments. HSCR could be an explanation for these different rates of FI and constipation.

\section{Anomalies of the genitourinary and renal tract}

Genitourinary and renal tract anomalies are a further important differential diagnosis in children with incontinence. In the general population, the prevalence of renal and genitourinary tract anomalies lies at $0.3 \%$ (Dastgiri, Stone, Le-Ha, \& Gilmour, 2002). In the examined syndromes of this thesis, genitourinary problems were found in $3.2 \%$ in DS, $10.3 \%$ in NS, $0.7 \%$ in AS, 36.2\% in MWS and 36.4\% in FXS (Chapters $2.1-3$ ). This variance of rates indicates that some genetic syndromes are more at risk to develop anomalies of the genitourinary and renal tract than others. Similar rates of anomalies were previously reported for NS (especially renal anomalies in 10\%; (George, Patton, El Sawi, Sharland, \& Adam, 1993; Noonan, 1994; Sommerschild \& Soerland, 1974)), DS (1.8\% urinary, 7.2\% genital anomalies; (Torfs \& Christianson, 1998) and MWS (52\%, (Garavelli et al., 2009)), whereas in AS, genitourinary and renal anomalies are not a typical clinical sign. In NS, renal anomalies are associated with urinary tract infections (UTI) (Romano et al., 2010) that can induce incontinence. In children with FXS, the rate of genitourinary/renal anomalies was higher than in healthy controls ( $36.4 \%$ vs. $4.5 \%)$, but the reported anomalies (macroorchidism, circumcision) were not associated with incontinence in the examined children (Chapter 3). Therefore, one can conclude that incontinence in the FXS boys of the present thesis is functional and somatic forms can be excluded, as all boys received a complete physical examination. In conclusion, the variety of genitourinary and renal anomalies in genetic syndromes shows that these can be a major cause of urinary incontinence. 
Neurological conditions

\section{Epilepsy}

One neurological condition with a proven association to incontinence is epilepsy. In patients with epilepsy, incontinence can occur as a symptom during the seizure (Brigo et al., 2013). $24.3 \%$ of typically developed adults with epilepsy had an incontinence episode during seizure, but also other symptoms as urgency or urinary retention were described (Motamedi et al., 2011). In children, parasomnias, are associated with epilepsy (Manni \& Terzaghi, 2010). Epilepsy is a common feature of the somatic phenotype in several genetic syndromes with ID. In this thesis, epilepsy was found in $18 \%$ of FXS, $71 \%$ of AS and $85 \%$ of MWS (Chapter $2.3 ; 2.4 ; 3$ ). In the AS sample, rates of NE and DUI were significantly higher in those persons with epilepsy than in those without (NE $85.1 \%$ vs. $70.7 \%$; DUI $67.0 \%$ vs. 47.5\%; Chapter 2.3). A higher risk for NE in patients with AS and epilepsy was also found in another study (Radstaake et al., 2013).

The exact pathogenesis of epilepsy in AS is not clear yet, but changes in the glutamatergic and GABAergic systems are discussed (Fiumara, Pittalà, Cocuzza, \& Sorge, 2010; Leung \& Ring, 2013). The microdeletion on 15q11-q13 leads to the loss of expression of the maternal $U B E 3 A$ gene, which is involved in the regulation of a subunit of $G A B A_{a}$ receptors, and that alterations in this mechanism are linked to ID and epilepsy (Leung \& Ring, 2013). The UBE3A gene also mediates the regulation of postsynaptic glutamatergic receptor function, which is hypothesized to influence brain development (Fiumara et al., 2010).

In individuals with FXS, the prevalence of seizures is lower, the onset age is higher and forms are milder than in AS. However, changes in the inhibitory GABAergic system were described in FXS, as well, supporting the hypothesis that dysregulation of glutamate and GABA receptor activation results in higher risks of epilepsy (Leung \& Ring, 2013). To understand the association between incontinence and epilepsy in genetic syndromes, especially in AS, further research is needed.

Dementia / Alzheimer's disease (AD)

In contrast to other genetic syndromes, the prevalence of Alzheimer's disease (AD) in Down syndrome (DS) increases in adults at the age of 40 years or more (Dykens, 2007). As a cause of the early onset of $A D$ in DS, the accumulation of amyloid- $\beta$-protein is discussed, which occurs due to the overexpression of the APP gene in DS and leads to neurodegeneration (Lott, 2012). A consequence of $A D$ is the loss of acquired abilities, including bladder and bowel control.

In the DS sample of this thesis (Chapter 2.1), incontinence rates increased from young adults (18-30 years) to older adults (>30 years), a phenomenon, which was not found in the other syndromes. In a study of Lin et al., incontinence was identified as one age-onset condition in adults with DS and was associated with daily living skills (Lin et al., 2015). 
Therefore, the increasing rates of incontinence in older DS individuals could be due to beginning AD symptoms, possibly caused by degeneration of common cerebral pathways.

In general, the huge variety of accompanying neurologic conditions in genetic syndromes has influence on different subtypes of incontinence and causes differences in incontinence rates between the syndromes. As the exact mechanisms of several medical disorders in syndromes are not completely revealed yet (e.g. epilepsy in AS), their association with incontinence remains even more unclear. In further research projects, the underlying mechanisms should be examined.

\section{Association with behavioral symptoms}

A main asset of the examinations in this thesis was to assess behavioral and psychological symptoms in individuals with genetic syndromes. In DS, NS, AS and MWS, psychological symptoms were assessed by a parental questionnaire designed especially for individuals with ID (Chapter 2.1 - 2.4). In FXS, psychological symptoms and psychiatric diagnoses were assessed by a parental questionnaire and also by a structured parental interview (Chapter 3).

In general, clinically relevant psychological symptoms are present in approximately 30-40\% of individuals with ID (Dekker, Koot, Ende, \& Verhulst, 2002), but rates and type of symptoms differ between different levels of ID. For example, individuals with mild ID have a similar psychopathology as typically developing persons (e.g. oppositional problems, attention and hyperactivity symptoms, anxiety, depression), but the prevalence rates are 3-4 times higher (Dekker et al., 2002). In contrast, persons with moderate or severe ID have qualitatively different behavioral symptoms than the general population, e.g. stereotyped or self-injuring behavior (Dekker et al., 2002). Further, differences in psychological symptoms in genetic syndromes are reflected in specific 'behavioral phenotypes' of each genetic syndrome, i.e. a pattern of psychiatric disorders, as for example ADHD and autism in FXS (Backes et al., 2000; Tranfaglia, 2011). Because of the variety of these symptoms, it is important to use instruments that are valid to assess behavioral problems adequately in persons with ID.

The Developmental Behavior Checklist (DBC) is an optimal parental questionnaire with separate norms for mild, moderate and severe ID. Thus, the risk of an overestimation of psychological problems in patient groups with ID can be lowered. In the samples of the present thesis, clinically relevant psychological problems were higher in the children and adolescent group (NS 35.3\%, DS 13.6\%, AS 50.6\%, MWS 39.5\%) than in the adult group (NS 10\%, DS 8.4\%, AS 34.1\%, MWS 37.5\%). Although the questionnaires were evaluated according to norms of mild ID in NS and DS and according to severe ID in AS and MWS, psychological problems were more often found in syndromes with severe ID than in those with a milder impairment. 
In the assessment of boys with FXS and a typically developing control group (Chapter 3), psychiatric disorders were assessed by a structured interview and revealed psychiatric diagnoses in $90.9 \%$ of boys with FXS. Behavioral symptoms were measured by the Child Behavior Checklist (CBCL, Achenbach, 1991) and not by the DBC, as it could also be applied to the controls. The main differences in the rates $(90.9 \%$ psychiatric disorders, $68.2 \%$ CBCL clinically relevant scores) probably refer to "diagnostic overshadowing", which means that psychological symptoms are underestimated in ID by parents, because aberrant behavior is seen as a part of their child's ID (Dykens, 2007; Reiss, Levitan, \& Szyszko, 1982). Therefore, diagnostic overshadowing should be always considered in individuals with ID and in the diagnostic process, valid instruments and structured interviews should be used.

\section{Behavioral symptoms and incontinence}

In typically developing children, psychological symptoms and psychiatric comorbidity are strongly associated to incontinence. In a British population-based study on over 8000 children at the age of 7.5 years, psychological symptoms in children with and without NE, DUI and FI were examined (Joinson, Heron, \& von Gontard, 2006; Joinson, Heron, Emond, \& Butler, 2007). Concomitant psychological symptoms were present in about $20 \%$ of children with isolated NE and in $25 \%$ of children with DUI. Children with FI were the most affected (up to $40 \%$ ). In all subtypes of incontinence, externalizing symptoms (e.g. ADHD, ODD, conduct problems), as well as internalizing symptoms (e.g. depression, anxiety) were present. The higher co-existence rates of psychopathology and incontinence is no coincidence, but may be explained by several factors, for example by common neurobiological factors, which are hypothesized in some comorbidities, e.g. in ADHD (von Gontard \& Equit, 2015). In other cases, psychological symptoms can be a consequence of incontinence, which is typical for subclinical symptoms, e.g. low self-esteem and social problems, and which improve with successful incontinence treatment (Longstaffe, Moffatt, \& Whalen, 2000). The assessment of comorbid psychiatric disorders in incontinence is important, as it affects compliance and treatment success negatively (Crimmins, Rathbun, \& Husmann, 2003).

In a systematic review on children and adults with ID, significant associations between challenging behavior (e.g. aggression, self-injury) and urinary incontinence were found (de Winter, Jansen, \& Evenhuis, 2011). In the present thesis, associations between psychological symptoms and incontinence were found for NS, DS and to a lesser extent in FXS. In NS, children with NE had higher mean scores in the DBC subscales „social relating“ and „self-absorbed“ (Chapter 2.2). According to validation assessments, higher values on the "social relating" subscale are linked to autistic behavior (Einfeld \& Tonge, 1995). In typically developing children, incontinence/NE is linked to autism (von Gontard, Pirrung, Niemczyk, \& Equit, 2015). Therefore, autistic symptoms could be a moderator variable for this association between incontinence and NS. Another moderator for the association 
in NS could be the level of ID, because persons with a lower IQ usually score higher on the „self-absorbed“ subscale (Einfeld \& Tonge, 1995). Therefore, children with NS and NE could have also a lower IQ. Unfortunately, IQ or adaptive skills could not be measured due to the questionnaire design.

In DS, rates of incontinence (NE and DUI) were significantly higher in adults with psychological symptoms than in those without (Chapter 2.1). In children and adolescents with DS, the rates were slightly higher, too, but did not reach statistical significance. An explanation for the association in adults could be again the early onset Alzheimer's disease (AD). As AD affects both intellectual capability and incontinence in DS (Lin et al., 2015), impairments in both domains could result in psychological symptoms as a consequence of beginning AD.

In FXS, information on IQ, incontinence and psychiatric comorbidity is available (Chapter 3). Although boys with FXS had significantly more incontinence and psychiatric diagnoses and a lower IQ than the controls, a comparison between continent and incontinent FXS boys revealed only significant differences in externalizing symptoms measured by the $\mathrm{CBCL}$. No differences in IQ, internalizing and autistic symptoms were found. The association with externalizing symptoms is similar to typically developing children with incontinence, who have also high rates of ADHD, ODD and conduct problems (Joinson, Heron \& von Gontard, 2006; Joinson, Heron, Butler, \& von Gontard, 2006; Joinson et al., 2007).

In AS and MWS, no significant associations to behavioral problems were found (Chapter $2.3,2.4)$. This could be due to factors as somatic conditions or developmental delays that affect continence, but also due to a 'ceiling effect': incontinence rates were high in both persons with and without psychological symptoms, so that possible differences could not be detected. In further studies, behavioral problems in genetic syndromes with severe ID should be examined in association with additional aspects of continence and to adaptive skills.

In summary, incontinence and psychopathology are associated in some genetic syndromes, but according to the results to a lesser extent than in typically developing samples. The findings of this thesis indicate that behavioral problems and incontinence are mainly associated in syndromes with mild or moderate ID impairment, which was also found in former studies on similar syndromes (Equit, Piro-Hussong, Niemczyk, Curfs, \& von Gontard, 2013; Mantry et al., 2008; von Gontard et al., 2016).

\section{Clinical implications}

As incontinence is a frequent problem in genetic syndromes associated with ID, a thorough diagnostic process and an adequate treatment approach should be provided for these individuals. The assessment of incontinence in these groups should include a detailed history-taking, 48-hour bladder diary, uroflowmetry, a neurological examination and sonography of the bladder, rectum and kidneys, as recommended by the ICCS and 
ROME-IV criteria (Austin et al., 2016; Hyams et al., 2016). In addition, syndrome-associated somatic conditions that can affect continence, e.g. Hirschsprung's disease (HSCR) in MWS, must be always considered. Further, behavioral symptoms have to be assessed, because they can lead to incapacitation and can have a negative effect on treatment and compliance.

So far, no specific treatment approaches for incontinence in genetic syndromes exist - they are the same as in typically developing individuals. Guidelines for persons with ID or special needs should be followed (von Gontard, 2013). In general, all treatment principles of incontinence in typically developing children can be applied to children with ID, but have to be adapted individually. For example, directive positive reinforcements for motivating the child to change its toileting habits have to be implemented more often, or behavioral therapeutic techniques as shaping or chaining are used to change behavior (von Gontard, 2013). Further, establishing an adequate fluid intake leads to lower incontinence rates in children with developmental disabilities (van Laecke, Raes, Vande Walle, \& Hoebeke, 2009). For persons with ID, who do not reach continence by these first methods, special intensive training programs were developed including many repeats of urinations and toilet visits, reducing diaper wearing, positive reinforcements, and in some cases, also the wearing of an alarm device during the day. These methods reduce incontinence in many patients with ID (Azrin \& Foxx, 1971; Richmond, 1983; Smith, Smith, Lee, \& Kwok, 2000).

In summary, the treatment of incontinence in genetic syndromes associated with ID should be adapted to the individual abilities of the person affected. In persons with combined incontinence, the same treatment order should be followed as in typically developing persons (FI first, DUI second, NE third) because of a lower rate of complications and more pronounced synergistic effects.

The lower incontinence rates in the adult groups of NS and DS, in comparison to children and adolescents (Chapter 2.1,2.2), but also the increase in toileting skills in MWS in the adult group (Chapter 2.4) implicate that changes in toileting behavior can be achieved, even in syndromes with severe ID. But due to "overshadowing" of other somatic, as well as psychiatric disorders, incontinence treatment is neglected in many cases or it is seen as a part of the disability or syndrome. The achievement of bladder and bowel control is an important milestone in life, which is relevant for independence and social acceptance. It increases self-confidence and quality of life in patients, as well as in parents and caregivers. Therefore, the assessment of incontinence and implementation of treatment is worthwhile and recommended in every individual patient. 


\section{Methodological considerations}

In Noonan (NS) and Mowat-Wilson syndrome (MWS) (Chapter 2.1, 2.4), the present studies were the first systematic descriptions of incontinence and the association to behavioral problems in those genetic syndromes. In Down (DS) and Angelman syndrome (AS) (Chapter 2.2, 2.3), the present examinations were the first that linked psychopathology to incontinence in large samples including different age groups. The incontinence questionnaires (PQ-EnU, Encopresis Questionnaire - Screening Version and ICIQ-CLUTS (De Gennaro et al., 2010; von Gontard, 2012a; von Gontard, 2012b) are clinically tested and widespread questionnaires, which were used in the assessment of incontinence in several genetic syndromes before (Equit et al., 2013; Giesbers et al., 2012; Radstaake et al., 2013; von Gontard, Didden, Sinnema, \& Curfs, 2010; von Gontard et al., 2016) and which, though not validated in patients with syndromes or ID yet, provide a variety of clinicallyrelevant information on toileting behavior and incontinence symptoms. Although larger samples could have been assessed with this methodology, possible biases can occur. The derived information is only based on parental reporting and not confirmed by medical examinations, which may have led to an over- or underestimation of incontinence rates.

The study on boys with FXS (Chapter 3), in contrast, provides more valid results, as the boys were examined clinically according to current guidelines (Austin et al., 2016; Hyams et al., 2016) and were compared to a typically developing matched control group. Also, in this study, IQ was measured and psychiatric disorders were assessed by a validated, structured interview and not only by a parental questionnaire.

In the other syndromes (NS, DS, AS, MWS), psychological symptoms were assessed by a questionnaire (DBC) that was validated in large samples of children and adults with different levels of ID (Einfeld \& Tonge, 1995), so that valid estimations of symptom severity depending on IQ impairment can be made. Unfortunately, due to the questionnaire design of the studies in Chapter $2.1-2.4$, IQ could not have been measured, which could have also led to possible biases. In future questionnaire studies, the assessment of adaptive skills should be considered, e.g. by the recently published Vineland Adaptive Behavior Scales (Vineland-3; (Sparrow, Cicchetti, \& Saulnier, 2016)), so that the individual level of impairment can be measured.

\section{Future incontinence research in genetic syndromes}

The studies that are part of this thesis confirmed that more individuals with genetic syndromes that are associated with ID suffer from incontinence than typically developing persons. In addition, the results reveal that incontinence subtypes, as well as associated problems differ between different genetic syndromes. That means, that not only impairments in intelligence are the cause for incontinence in the affected persons, but also somatic conditions, genetic factors, brain development and psychological symptoms play a 
role. Future studies should focus on these factors and include a more detailed examination of incontinence (e.g. as in FXS, Chapter 3). Longitudinal studies could contribute to a better understanding of the course incontinence over lifetime in different genetic syndromes. Brain imaging studies could also reveal more information on neurological pathways that are affected in incontinence. 


\section{References}

Achenbach, T. M. (1991). Manual for the Child Behavior Checklist/4-18 and 1991 profile. Burlington, VT: University of Vermont.

Adam, M. P., Schelley, S., Gallagher, R., Brady, A. N., Barr, K., Blumberg, B., .. . Hudgins, L. (2006). Clinical features and management issues in Mowat-Wilson syndrome. American Journal of Medical Genetics, Part A, 140(24), 2730-2741.

Aghakhanyan, G., Bonanni, P., Randazzo, G., Nappi, S., Tessarotto, F., De Martin, L., ... Kuppers, B. (2016). From cortical and subcortical grey matter abnormalities to neurobehavioral phenotype of Angelman syndrome: A voxel-based morphometry study. PloS One, 11(9), e0162817.

American Psychiatric Association (APA) (2013). Diagnostic and statistical manual of mental disorders - Fifth edition (DSM 5). Washington, D.C.: APA.

Andrew, J., \& Nathan, P. W. (1964). Lesions on the anterior frontal lobes and disturbances of micturition and defaecation. Brain : A Journal of Neurology, 87, 233-262.

Arnold, S., Pelet, A., Amiel, J., Borrego, S., Hofstra, R., Tam, P., .. Chakravarti, A. (2009). Interaction between a chromosome 10 RET enhancer and chromosome 21 in the down syndrome-hirschsprung disease association. Human Mutation, 30(5), 771-775.

Austin, P.F., Bauer, S.B., Bower, W., Chase, J., Franco, I., Hoebeke, P., ... , Yang, S. S. (2016). The Standardization of Terminology of Lower Urinary Tract Function in Children and Adolescents: Update Report from the Standardization Committee of the International Children's Continence Society. Neurourology \& Urodynamics, 35(4), 471-481.

Azrin, N., \& Foxx, R. (1971). A rapid method of toilet training the institutionalized retarded. Journal of Applied Behavior Analysis, 4(2), 89-99.

Backes, M., Genç, B., Schreck, J., Doerfler, W., Lehmkuhl, G., \& von Gontard, A. (2000). Cognitive and behavioral profile of fragile X boys: Correlations to molecular data. American Journal of Medical Genetics, 95(2), 150156.

Belva, B., Matson, J. L., Barker, A., Shoemaker, M. E., \& Mahan, S. (2011). The relationship between adaptive behavior and specific toileting problems according to the profile on toileting issues (POTI). Journal of Developmental and Physical Disabilities, 23(6), 535-542.

Berk, L. B., \& Friman, P. C. (1990). Epidemiologic aspects of toilet training. Clinical Pediatrics, 29(5), 278-282.

Bray, N. W., Fletcher, K. L., \& Turner, L. A. (1997). Cognitive Competencies and Strategy Use in Individuals with Mental Retardation. In W. E. MacLean, Jr. (Ed.), Ellis' Handbook of Mental Deficiency, Psychological Theory and Research (3 $3^{\text {rd }}$ ed.) (pp. 197-218). Mahwah, NJ: Lawrence Erlbaum Associates.

Brigo, F., Nardone, R., Ausserer, H., Storti, M., Tezzon, F., Manganotti, P., \& Bongiovanni, L. G. (2013). The diagnostic value of urinary incontinence in the differential diagnosis of seizures. Seizure, 22(2), 85-90.

Brown III, F. R., Greer, M. K., Aylward, E. H., \& Hunt, H. H. (1990). Intellectual and adaptive functioning in individuals with Down syndrome in relation to age and environmental placement. Pediatrics, 85(3 SUPPL.), 450-452.

Chiang, M., Reiss, A. L., Lee, A. D., Bellugi, U., Galaburda, A. M., Korenberg, J. R., .. Thompson, P. M. (2007). 3D pattern of brain abnormalities in Williams syndrome visualized using tensor-based morphometry. Neurolmage, 36(4), 1096-1109.

Coyle, D., \& Puri, P. (2015). Hirschsprung's disease in children with Mowat-Wilson syndrome. Pediatric Surgery International, 31(8), 711-717.

Crimmins, C. R., Rathbun, S. R., \& Husmann, D. A. (2003). Management of urinary incontinence and nocturnal enuresis in attention-deficit hyperactivity disorder. The Journal of Urology, 170(4, Part 1), 1347-1350.

Dastgiri, S., Stone, D. H., Le-Ha, C., \& Gilmour, W. H. (2002). Prevalence and secular trend of congenital anomalies in glasgow, UK. Archives of Disease in Childhood, 86(4), 257-263.

De Gennaro, M., Niero, M., Capitanucci, M. L., von Gontard, A., Woodward, M., Tubaro, A., \& Abrams, P. (2010). Validity of the international consultation on incontinence questionnaire-pediatric lower urinary tract symptoms: A screening questionnaire for children. Journal of Urology, 184(4 SUPPL.), 1662-1667. 
de Waal, K. H., Tinselboer, B. M., Evenhuis, H. M., \& Penning, C. (2009). Unnoticed post-void residual urine volume in people with moderate to severe intellectual disabilities: Prevalence and risk factors. Journal of Intellectual Disability Research, 53(9), 772-779.

de Winter, C., Jansen, A., \& Evenhuis, H. (2011). Physical conditions and challenging behavior in people with intellectual disability: A systematic review. Journal of Intellectual Disability Research, 55(7), 675-698.

Dekker, M. C., Koot, H. M., Ende, J. v. d., \& Verhulst, F. C. (2002). Emotional and behavioral problems in children and adolescents with and without intellectual disability. Journal of Child Psychology and Psychiatry, 43(8), 1087-1098.

Dykens, E. M. (2007). Psychiatric and behavioral disorders in persons with Down syndrome. Mental Retardation and Developmental Disabilities Research Reviews, 13(3), 272-278.

Einfeld, S., \& Tonge, B. (1995). Manual for the Developmental behavior checklist - primary carer version (DBC- $P$ ) \& teacher version $(D B C-T)(2 n d$ ed.). Clayton, Melbourne: Monash University Centre for Developmental Psychiatry and Psychology.

Ejerskov, C., \& Siggaard Rittig, C. (2015). Neurophysiology of defecation. In I. Franco, P. Austin, S. Bauer, A. von Gontard \& Y. Homsy (Eds.), Pediatric incontinence: Evaluation and clinical management (pp. 15-20). Oxford, UK: Wiley Blackwell.

Equit, M., Piro-Hussong, A., Niemczyk, J., Curfs, L., \& von Gontard, A. (2013). Elimination disorders in persons with Prader-Willi and Fragile-X syndromes. Neurourology and Urodynamics, 32(7), 986-992.

Felt, B., Wise, C. G., Olson, A., Kochhar, P., Marcus, S., \& Coran, A. (1999). Guideline for the management of pediatric idiopathic constipation and soiling. Archives of Pediatrics \& Adolescent Medicine, 153(4), 380-385.

Fiumara, A., Pittalà, A., Cocuzza, M., \& Sorge, G. (2010). Epilepsy in patients with Angelman syndrome. Italian Journal of Pediatrics, 36(1), 31.

Fowler, C. J., \& Griffiths, D. J. (2010). A decade of functional brain imaging applied to bladder control. Neurourology and Urodynamics, 29(1), 49-55.

Franco, I. (2015). Functional brain imaging in bowel and bladder control. In I. Franco, P. Austin, S. Bauer, A. von Gontard \& Y. Homsy (Eds.), Pediatric incontinence: Evaluation and clinical management (pp. 21-34). Oxford, UK: Wiley Blackwell.

Friedmacher, F., \& Puri, P. (2013). Hirschsprung's disease associated with down syndrome: A meta-analysis of incidence, functional outcomes and mortality. Pediatric Surgery International, 29(9), 937-946.

Gallagher, A., \& Hallahan, B. (2012). Fragile X-associated disorders: A clinical overview. Journal of Neurology, 259(3), 401-413.

Garavelli, L., Ivanovski, I., Caraffi, S. G., Santodirocco, D., Pollazzon, M., Cordelli, D. M., . . Baldo, C. (2016). Neuroimaging findings in Mowat-Wilson syndrome: A study of 54 patients. Genetics in Medicine, 19(6), 691

Garavelli, L., Zollino, M., Cerruti Mainardi, P., Gurrieri, F., Rivieri, F., Soli, F., . . Neri, G. (2009). Mowat-Wilson syndrome: Facial phenotype changing with age: Study of 19 italian patients and review of the literature. American Journal of Medical Genetics, Part A, 149(3), 417-426.

George, C. D., Patton, M. A., El Sawi, M., Sharland, M., \& Adam, E. J. (1993). Abdominal ultrasound in Noonan syndrome: A study of 44 patients. Pediatric Radiology, 23(4), 316-318.

Giesbers, S., Didden, R., Radstaake, M., Korzilius, H., von Gontard, A., Lang, R., . . Curfs, L. M. (2012). Incontinence in individuals with Rett syndrome: A comparative study. Journal of Developmental and Physical Disabilities, 24(3), 287-300.

Haas, B. W., Barnea-Goraly, N., Lightbody, A. A., Patnaik, S. S., Hoeft, F., Hazlett, H., . . Reiss, A. L. (2009). Early white-matter abnormalities of the ventral frontostriatal pathway in fragile $\mathrm{X}$ syndrome. Developmental Medicine \& Child Neurology, 51(8), 593-599.

Harting, I., Seitz, A., Rating, D., Sartor, K., Zschocke, J., Janssen, B., . . Wolf, N. I. (2009). Abnormal myelination in Angelman syndrome. European Journal of Paediatric Neurology, 13(3), 271-276.

Hellström, A., Hanson, E., Hansson, S., Hjälmås, K., \& Jodal, U. (1990). Micturition habits and incontinence in 7year-old swedish school entrants. European Journal of Pediatrics, 149(6), 434-437.

Heron, J., Joinson, C., Croudace, T., \& von Gontard, A. (2008). Trajectories of daytime wetting and soiling in a united kingdom 4 to 9-year-old population birth cohort study. Journal of Urology, 179(5), 1970-1975. 
Hoeft, F., Carter, J. C., Lightbody, A. A., Cody Hazlett, H., Piven, J., \& Reiss, A. L. (2010). Region-specific alterations in brain development in one- to three-year-old boys with fragile $X$ syndrome. Proceedings of the National Academy of Sciences of the United States of America, 107(20), 9335-9339.

Hyams, J. S., Di Lorenzo, C., Saps, M., Shulman, R. J., Staiano, A., \& Van Tilburg, M. (2016). Childhood functional gastrointestinal disorders: Child/adolescent. Gastroenterology, 150(6), 1456-1468e2.

Hyde, T. M., Deep-Soboslay, A., Iglesias, B., Callicott, J. H., Gold, J. M., Meyer-Lindenberg, A., ... Weinberger, D. R. (2008). Enuresis as a premorbid developmental marker of schizophrenia. Brain : A Journal of Neurology, 131(Pt 9), 2489-2498.

Jansson, U., Hanson, M., Hanson, E., Hellström, A., \& Sillén, U. (2000). Voiding pattern in healthy children 0 to 3 years old: a longitudinal study. The Journal of Urology, 164(6), 2050-2054.

Joinson, C., Heron, J., Butler, U., \& von Gontard, A. (2006). Psychological differences between children with and without soiling problems. Pediatrics, 117(5), 1575-1584.

Joinson, C., Heron, J., Emond, A., \& Butler, R. (2007). Psychological problems in children with bedwetting and combined (day and night) wetting: A UK population-based study. Journal of Pediatric Psychology, 32(5), 605-616.

Joinson, C., Heron, J., \& von Gontard, A. (2006). Psychological problems in children with daytime wetting. Pediatrics, 118(5), 1985-1993.

Kitamura, A., Kondoh, T., Noguchi, M., Hatada, T., Tohbu, S., Mori, K. -., . . Moriuchi, H. (2014). Assessment of lower urinary tract function in children with Down syndrome. Pediatrics International, 56(6), 902-908.

Kuchel, G. A., Moscufo, N., Guttmann, C. R., Zeevi, N., Wakefield, D., Schmidt, J., . . W Wolfson, L. (2009). Localization of brain white matter hyperintensities and urinary incontinence in community-dwelling older adults. The Journals of Gerontology. Series A, Biological Sciences and Medical Sciences, 64(8), 902-909.

Lake, J. I., \& Heuckeroth, R. O. (2013). Enteric nervous system development: Migration, differentiation, and disease. American Journal of Physiology. Gastrointestinal and Liver Physiology, 305(1), G1-24.

Langer, J. C. (2013). Hirschsprung disease. Current Opinion in Pediatrics, 25(3), 368-374.

Lee, D. A., Portnoy, S., Hill, P., Gillberg, C., \& Patton, M. A. (2005). Psychological profile of children with Noonan syndrome. Developmental Medicine and Child Neurology, 47(1), 35-38.

Leung, H., \& Ring, H. (2013). Epilepsy in four genetically determined syndromes of intellectual disability. Journal of Intellectual Disability Research, 57(1), 3-20.

Lin, J., Lin, L., Hsu, S., Chen, W., Lin, F., Wu, J., \& Chu, C. (2015). Are early onset aging conditions correlated to daily activity functions in youth and adults with down syndrome? Research in Developmental Disabilities, 36, 532-536.

Longstaffe, S., Moffatt, M. E., \& Whalen, J. C. (2000). Behavioral and self-concept changes after six months of enuresis treatment: A randomized, controlled trial. Pediatrics, 105(Supplement 3), 935-940.

Lott, I. T. (2012). Neurological phenotypes for Down syndrome across the life span. Progress in brain research, 197, 101-121.

Manni, R., \& Terzaghi, M. (2010). Comorbidity between epilepsy and sleep disorders. Epilepsy Research, 90(3), 171-177.

Mantry, D., Cooper, S., Smiley, E., Morrison, J., Allan, L., Williamson, A., . . J Jackson, A. (2008). The prevalence and incidence of mental ill-health in adults with Down syndrome. Journal of Intellectual Disability Research, 52(2), 141-155.

Moore, S. W. (2008). Down syndrome and the enteric nervous system. Pediatric Surgery International, 24(8), 873-883.

Motamedi, M., Nikoobakht, M. R., Aloosh, M., Nasrabady, S. E., Afshin, A., Orandi, A., \& Khatibi, F. T. (2011). Periictal urinary dysfunction in patients with epilepsy: A cross-sectional study. Urology Journal, 8(3), 222.

Mowat, D., \& Wilson, M. (2010). Mowat-Wilson syndrome. Management of genetic syndromes: Third edition (pp. 517-527)

Noonan, J. A. (1994). Noonan syndrome: An update and review for the primary pediatrician. Clinical Pediatrics, 33(9), 548-555. 
Ogunyemi, O., \& Wu, H. (2015). Neurophysiology of voiding. In I. Franco, P. Austin, S. Bauer, A. von Gontard \& Y. Homsy (Eds.), Pediatric incontinence: Evaluation and management (pp. 3-14). Oxford, UK: Wiley Blackwell.

Peters, S. U., Kaufmann, W. E., Bacino, C. A., Anderson, A. W., Adapa, P., Chu, Z., . . Wilde, E. A. (2011). Alterations in white matter pathways in Angelman syndrome. Developmental Medicine \& Child Neurology, 53(4), 361-367.

Pinter, J. D., Brown, W. E., Eliez, S., Schmitt, J. E., Capone, G. T., \& Reiss, A. L. (2001). Amygdala and hippocampal volumes in children with Down syndrome: A high-resolution MRI study. Neurology, 56(7), 972-974.

Powers, M. K., Brown, E. T., Hogan, R. M., Martin, A. D., Ortenberg, J., \& Roth, C. C. (2015). Trends in toilet training and voiding habits among children with Down syndrome. Journal of Urology, 194(3), 783-787.

Radstaake, M., Didden, R., Giesbers, S., Korzilius, H., Peters-Scheffer, N., Lang, R., . . Curfs, L. M. G. (2013). Incontinence in individuals with Angelman syndrome: A comparative study. Research in Developmental Disabilities, 34(11), 4184-4193.

Reiss, S., Levitan, G. W., \& Szyszko, J. (1982). Emotional disturbance and mental retardation: Diagnostic overshadowing. American Journal of Mental Deficiency, 86(6):567-574.

Richmond, G. (1983). Shaping bladder and bowel continence in developmentally retarded preschool children. Journal of Autism and Developmental Disorders, 13(2), 197-204.

Romano, A. A., Allanson, J. E., Dahlgren, J., Gelb, B. D., Hall, B., Pierpont, M. E., . . Noonan, J. A. (2010). Noonan syndrome: Clinical features, diagnosis, and management guidelines. Pediatrics, 126(4), 746-759.

Sammour, Z. M., Gomes, C. M., Duarte, R. J., Trigo-Rocha, F. E., \& Srougi, M. (2006). Voiding dysfunction and the Williams-Beuren syndrome: A clinical and urodynamic investigation. Journal of Urology, 175(4), 1472 1476.

Sandhu, B., Steer, C., Golding, J., \& Emond, A. (2009). The early stool patterns of young children with autistic spectrum disorder. Archives of Disease in Childhood, 94(7), 497-500.

Sarimski, K. (2000). Developmental and behavioral phenotype in Noonan syndrome? Genetic Counseling, 11(4), 383-390.

Schulman, S. L., Zderic, S., \& Kaplan, P. (1996). Increased prevalence of urinary symptoms and voiding dysfunction in Williams syndrome. Journal of Pediatrics, 129(3), 466-469.

Sergi, C. M., Caluseriu, O., McColl, H., \& Eisenstat, D. D. (2016). Hirschsprung's disease: Clinical dysmorphology, genes, micro-RNAs, and future perspectives. Pediatric Research, 81(1-2), 177-191.

Sillén, U. (2001). Bladder function in healthy neonates and its development during infancy. The Journal of Urology, 166(6), 2376-2381.

Sillén, U., Sölsnes, E., Hellström, A. L., \& Sandberg, K. (2000). The voiding pattern of healthy preterm neonates. Journal of Urology, 163(1), 278-281.

Śmigielska-Kuzia, J., Boćkowski, L., Sobaniec, W., Sendrowski, K., Olchowik, B., \& Cholewa, M. (2011). A volumetric magnetic resonance imaging study of brain structures in children with Down syndrome. Neurologia i Neurochirurgia Polska, 45(4), 363-369.

Smith, L., Smith, P., Lee, Y., \& Kwok, S. (2000). Behavioral treatment of urinary incontinence and encopresis in children with learning disabilities: Transfer of stimulus control. Developmental Medicine \& Child Neurology, 42(4), 276-279.

Sommerschild, H. C., \& Soerland, S. J. (1974). Urinary tract malformations in Noonan's syndrome (XX, XY turner phenotype). Zeitschrift fuer Kinderchirurgie, 14(4), 422-425.

Sparrow, S., Cicchetti, D., \& Saulnier, C. (2016). Vineland adaptive behavior scales, third edition (Vineland-3). San Antonio, TX: Pearson.

Steer, C. D., Emond, A. M., Golding, J., \& Sandhu, B. (2009). The variation in stool patterns from 1 to 42 months: A population-based observational study. Archives of Disease in Childhood, 94(3), 231-233.

Switzky, H. N. (1997). Individual Differences in Personality and Motivational Systems in Persons with Mental Retardation. In W. E. MacLean, Jr. (Ed.), Ellis' Handbook of Mental Deficiency, Psychological Theory and Research (3rd ed.) (pp. 343-378). Mahwah, NJ: Lawrence Erlbaum Associates.

Thibert, R. L., Larson, A. M., Hsieh, D. T., Raby, A. R., \& Thiele, E. A. (2013). Neurologic manifestations of Angelman syndrome. Pediatric Neurology, 48(4), 271-279. 
Tiwari, V. N., Jeong, J., Wilson, B. J., Behen, M. E., Chugani, H. T., \& Sundaram, S. K. (2012). Relationship between aberrant brain connectivity and clinical features in angelman syndrome: A new method using tract based spatial statistics of DTI color-coded orientation maps. Neurolmage, 59(1), 349-355.

Tomporowski, P. D. \& Tinsley, V. (1997). In W. E. MacLean, Jr. (Ed.), Ellis' Handbook of Mental Deficiency, Psychological Theory and Research (3rd ed.) (pp. 219-244). Mahwah, NJ: Lawrence Erlbaum Associates.

Torfs, C. P., \& Christianson, R. E. (1998). Anomalies in Down syndrome individuals in a large population-based registry. American Journal of Medical Genetics Part A, 77(5), 431-438.

Tranfaglia, M. R. (2011). The psychiatric presentation of fragile X: Evolution of the diagnosis and treatment of the psychiatric comorbidities of fragile X syndrome. Developmental Neuroscience, 33(5), 337-348.

van de Putte, T., Francis, A., Nelles, L., van Grunsven, L. A., \& Huylebroeck, D. (2007). Neural crest-specific removal of Zfhx1b in mouse leads to a wide range of neurocristopathies reminiscent of Mowat-Wilson syndrome. Human Molecular Genetics, 16(12), 1423-1436.

Van Laecke, E., Raes, A., Vande Walle, J., \& Hoebeke, P. (2009). Adequate fluid intake, urinary incontinence, and physical and/or intellectual disability. Journal of Urology, 182(4 SUPPL.), 2079-2084.

von Gontard, A., \& Nevéus, T. (2006). Management of bladder and bowel control in children. London: MacKeith Press.

von Gontard, A. (2012a). Encopresis. In J. M. Rey (Ed.), IACAPAP e-textbook of child and adolescent mental health. Geneva: International Association for Child and Adolescent Psychiatry and Allied Professions. http://iacapap.org/wp-content/uploads/C.5-ENCOPRESIS-0072012.pdf. Accessed 11.03.16.

von Gontard, A. (2012b). Enuresis. In J. M. Rey (Ed.), IACAPAP e-textbook of child and adolescent mental health. Geneva: International Association for Child and Adolescent Psychiatry and Allied Professions. http://iacapap.org/wp-content/uploads/C.4-ENURESIS-072012.pdf. Accessed 11.03.16.

von Gontard, A. (2013). Urinary incontinence in children with special needs. Nature Reviews Urology, 10(11), 667-674.

von Gontard, A., Didden, R., Sinnema, M., \& Curfs, L. (2010). Urinary incontinence in persons with Prader-Willi syndrome. BJU International, 106(11), 1758-1762.

von Gontard, A., \& Equit, M. (2015). Comorbidity of ADHD and incontinence in children. European Child \& Adolescent Psychiatry, 24(2), 127-140.

von Gontard, A., Niemczyk, J., Borggrefe-Moussavian, S., Wagner, C., Curfs, L., \& Equit, M. (2016). Incontinence in children, adolescents and adults with Williams syndrome. Neurourology and Urodynamics, 35(8), $1000-$ 1005.

von Gontard, A., Pirrung, M., Niemczyk, J., \& Equit, M. (2015). Incontinence in children with autism spectrum disorder. Journal of Pediatric Urology, 11(5), 264-e1.

von Wendt, L., Simila, S., Niskanen, P., \& Jarvelin, M. (1990). Development of bowel and bladder control in the mentally retarded. Developmental Medicine and Child Neurology, 32(6), 515-518.

Warren, S. F. \& Yoder, P. J. (1997). In W. E. MacLean, Jr. (Ed.), Ellis' Handbook of Mental Deficiency, Psychological Theory and Research (3 ${ }^{\text {rd }}$ ed.) (pp. 379-404). Mahwah, NJ: Lawrence Erlbaum Associates.

Weaver, L. T., \& Lucas, A. (1993). Development of bowel habit in preterm infants. Archives of Disease in Childhood, 68(3 Spec No), 317-320.

Yang, P. Y., Meng, N. H., \& Chou, E. C. L. (2010). Voiding dysfunctions in children with mental retardation. Neurourology and Urodynamics, 29(7), 1272-1275.

Yeung, C., Godley, M., Ho, C., Ransley, P., Duffy, P., Chen, C., \& Li, A. (1995). Some new insights into bladder function in infancy. BJU International, 76(2), 235-240.

Zhang, Y. S., Huang, C. X., Wen, J. G., Sheng, G. Y., Cheng, X. Y., \& Zhang, Q. (2016). Relationship between brain activity and voiding patterns in healthy preterm neonates. Journal of Pediatric Urology, 12(2), 113.e1113.e6. 
Summary 

Functional incontinence includes nocturnal enuresis (NE; nighttime wetting), daytime urinary incontinence (DUI) and fecal incontinence (FI) and is a common disorder in childhood. In typically developing 7-year-old children, about $10 \%$ are affected by NE, 6-8\% by DUI and $1-7 \%$ by FI. In individuals with intellectual disability (ID), prevalence of incontinence is 2 to 4 times higher than in typically developing persons. The rates of incontinence are higher in persons with severe and profound ID and persist more often into adulthood than in typically developing persons.

In persons with genetic syndromes that are associated with ID, incontinence has not been examined systematically, yet. First studies show higher incontinence rates than in general population, but the studies differ in methodology, sample sizes and sample populations. Also, the behavioral phenotype has not been considered in all studies, although in typically developing persons, incontinence is highly associated with psychological symptoms, which can reduce treatment compliance and outcome.

Therefore, the aim of this thesis was to assess incontinence and psychopathology in a standardized way in five different genetic syndromes that are associated with ID.

In Chapter 2, rates of incontinence and associated psychological problems were assessed by parental questionnaires in children, adolescents and adults with Down syndrome, Noonan syndrome, Angelman syndrome and Mowat-Wilson syndrome.

Chapter 2.1 shows the results of persons with Down syndrome, a genetic syndrome caused by trisomy of chromosome 21 . Incontinence rates were high in children (64\%), lower in adolescents and young adults (10-13\%) and increased in older adults (22\%). Behavioral symptoms are associated with NE and DUI in adults with Down syndrome.

In Chapter 2.2, incontinence in persons with Noonan syndrome, a neurodevelopmental disorder due to mutations in several genes of the RasMAPK signaling pathways was examined. $44 \%$ of children and $14-17 \%$ of adolescents and adults had any subtype of incontinence. Children and adolescents with NE had more psychological symptoms than those without.

In Angelman syndrome (Chapter 2.3), caused by a microdeletion or uniparental disomy (UPD) of chromosome 15q11-13, rates of incontinence were high in all age groups (74-100\%). Incontinence was not associated with behavioral problems, but NE and DUI were associated with genotype and epilepsy.

Chapter 2.4 describes the findings in Mowat-Wilson syndrome, caused by deletion/mutation of the ZEB2 gene on chromosome 2 q22 and associated with severe ID. Incontinence was high over all age groups (96-100\%) with $\mathrm{Fl}$ being the most common subtype. $25-46 \%$ had clinically relevant psychological symptoms. The ability to use the toilet for micturition improved with age.

In Chapter 3, boys with Fragile-X syndrome (FXS), which is caused by a mutation on the $X$-chromosome, were examined and compared to typically developing boys. The children and adolescents were examined in their home setting not just by questionnaires, but also by a full medical, urological and psychiatric assessment. Boys with FXS had higher rates 
of incontinence (59\% vs. 5\%) and psychological comorbidity (91\% vs. 4.5\%) than controls. Incontinence and behavioral symptoms were not associated. Constipation is not a major problem in FXS, but in general, boys with FXS have a higher risk for physical disabilities, psychological disorders and incontinence than healthy boys.

In Chapter 4, the results are discussed in a broader perspective including methodological considerations. Several aspects of incontinence, as the delayed achievement of bladder and bowel control, neurological and genetic factors are addressed. Persons with ID have deficits in language skills, memory, attention processes, which can reduce learning of practical skills e.g. going to the bathroom. Further, maturational and developmental delays of the urinary or gastrointestinal tract can lead to a delayed achievement of bladder and bowel control and thus increase rates of incontinence. There is also evidence that alterations in brain development in genetic syndromes are associated with incontinence and delayed bladder/bowel control, as they are associated with $1 Q$, neurodevelopmental, and social functions. In addition, functional and organic forms of incontinence can coexist, as genetic syndromes are accompanied by a variety of medical conditions (e.g. Hirschsprung's disease, genitourinary and renal tract anomalies) that can be associated with bladder and bowel dysfunction. And as a last factor, incontinence and psychopathology are mainly associated in syndromes with mild or moderate ID impairment, but to a lesser extent than in typically developing samples.

In summary, incontinence is a frequent problem in genetic syndromes associated with ID. The achievement of bladder and bowel control is an important milestone in life, which increases self-confidence and quality of life in patients, as well as in parents and caregivers. Therefore, the assessment of incontinence and implementation of treatment is worthwhile and recommended in every individual patient. 
Samenvatting 

Functionele incontinentie bestaat uit niet zindelijk zijn voor urine gedurende de nacht (NE), niet zindelijk zijn voor urine overdag (DUI) en fecale incontinentie (FI) en is een veel voorkomende aandoening in de kindertijd. Bij 7-jarige kinderen zonder beperking heeft ongeveer 10\% NE, 6-8\% DUI en 1-7\% FI. Bij personen met een verstandelijke beperking (ID) is de prevalentie van incontinentie 2 tot 4 keer hoger dan bij personen zonder verstandelijke beperking. De incontinentiepercentages zijn hoger bij personen met een ernstige en zeer ernstige ID en de zindelijkheidsproblemen komen meer voor op latere leeftijd in vergelijking met personen zonder ID.

Bij personen met genetische syndromen die geassocieerd zijn met ID, is incontinentie nog niet systematisch onderzocht. Eerste studies laten hogere incontinentiecijfers zien in vergelijking met de algemene populatie, maar de studies verschillen qua methodologie, steekproefomvang en steekproefpopulaties. Ook komt het gedragsfenotype niet in alle onderzoeken aan de orde, hoewel bij normaal ontwikkelende personen incontinentie sterk geassocieerd is met psychologische symptomen, die therapietrouw en -uitkomst negatief kunnen beïnvloeden.

Daarom was het doel van dit proefschrift om incontinentie en psychopathologie op een gestandaardiseerde manier te onderzoeken bij vijf verschillende genetische syndromen, die geassocieerd zijn met ID.

In hoofdstuk 2 werden de incontinentiepercentages en de bijbehorende psychologische problemen bestudeerd aan de hand van door ouders ingevulde vragenlijsten voor kinderen, adolescenten en volwassenen met het Down-syndroom, het Noonan-syndroom, het Angelman-syndroom en het Mowat-Wilson-syndroom.

Hoofdstuk 2.1 laat de resultaten zien van personen met het Down-syndroom, een genetisch syndroom veroorzaakt door trisomie van chromosoom 21. Het incontinentiepercentage was hoog bij kinderen (64\%), lager bij adolescenten en jonge volwassenen (10$13 \%$ ) en verhoogd bij oudere volwassenen ( $22 \%$ ). Gedragssymptomen zijn bij volwassenen met het syndroom van Down geassocieerd met NE en DUI.

In Hoofdstuk 2.2 werd incontinentie onderzocht bij personen met het Noonan syndroom, een neurologische aandoening als gevolg van mutaties in verschillende genen van de RasMAPK-signaalroutes. $44 \%$ van de kinderen en $14-17 \%$ van de adolescenten en volwassenen had een subtype van incontinentie. Kinderen en adolescenten met NE hadden meer psychische klachten dan degenen zonder NE.

Bij het Angelman-syndroom (hoofdstuk 2.3), veroorzaakt door een microdeletie of uniparentale disomie (UPD) van chromosoom 15q11-13, waren de incontinentiepercentages hoog in alle leeftijdsgroepen (74-100\%). Incontinentie werd niet geassocieerd met gedragsproblemen, maar NE en DUI werden geassocieerd met genotype en epilepsie.

Hoofdstuk 2.4 beschrijft de bevindingen in het Mowat-Wilson-syndroom, veroorzaakt door deletie / mutatie van het ZEB2-gen op chromosoom 2q22 en geassocieerd met ernstige ID. Incontinentie was hoog in alle leeftijdsgroepen (96-100\%), waarbij FI het meest voorkomende subtype was. $25-46 \%$ had klinisch relevante psychologische symptomen. 
Het vermogen om het toilet te gebruiken voor mictie verbeterde met toenemende leeftijd.

In Hoofdstuk 3 werden jongens met Fragile-X syndroom (FXS), veroorzaakt door een mutatie op het X-chromosoom, onderzocht en vergeleken met normaal ontwikkelende jongens. De kinderen en adolescenten werden in hun thuissituatie onderzocht, niet alleen met behulp van vragenlijsten, maar ook aan de hand van een volledige medische, urologische en psychiatrische onderzoek. Jongens met FXS hadden hogere incontinentiepercentages (59\% versus 5\%) en psychologische comorbiditeit ( $91 \%$ vs. $4,5 \%$ ) dan de kontrole groep. Incontinentie en gedragssymptomen waren niet geassocieerd. Obstipatie is geen groot probleem bij FXS. Over het algemeen hebben jongens met FXS een hoger risico voor lichamelijke beperkingen, psychische stoornissen en incontinentie dan gezonde jongens.

In hoofdstuk 4 worden de resultaten in een breder perspectief besproken, inclusief methodologische overwegingen. Aandacht wordt besteed aan verschillende aspecten van incontinentie, zoals het vertraagde bereiken van blaas- en darmbeheersing, neurologische en genetische factoren. Personen met een ID hebben tekortkomingen in taalvaardigheid, geheugen en aandachtsprocessen, wat het leren van praktische vaardigheden moeilijker maakt, bijvoorbeeld naar het toilet gaan. Verder kunnen maturatie- en ontwikkelingsvertragingen van het urinaire of maagdarmkanaal leiden tot een vertraagde voltooiing van de controle van de blaas en de darm en dus de mate van incontinentie verhogen. Er zijn ook aanwijzingen dat veranderingen in de ontwikkeling van de hersenen bij genetische syndromen gepaard gaan met incontinentie en vertraagde controle van de blaas / darm, daar deze geassocieerd zijn met IQ, neurologische en sociale functies. Bovendien kunnen functionele en anatomische vormen van incontinentie naast elkaar bestaan, aangezien genetische syndromen gepaard gaan met een verscheidenheid aan medische aandoeningen (bijvoorbeeld de ziekte van Hirschsprung, aandoeningen van het urogenitaal en het nierkanaal) die geassocieerd kunnen zijn met blaas- en darmstoornis. En als een laatste factor zijn incontinentie en psychopathologie vooral geassocieerd bij syndromen met een lichte of matige ID-, maar in mindere mate dan bij personen zonder ID.

Kortom, incontinentie is een veel voorkomend probleem bij genetische syndromen die geassocieerd zijn met ID. Het bereiken van controle over de blaas- en darmbeheersing is een belangrijke mijlpaal in de ontwikkeling. Het vergroot het zelfvertrouwen en de kwaliteit van leven bij patiënten, evenals bij ouders en verzorgers. Daarom is bestudering van incontinentie en implementatie van behandeling de moeite waard en wordt aanbevolen voor iedere individuele patiënt. 
Valorization 
This thesis has two main socially relevant aims. First, it shall raise awareness to the topic of incontinence as a problem, which is not only common in small children, but occurs in all age groups, social classes and populations. Although effective treatment methods are available, many people still do not benefit from them.

Becoming continent, or gaining control of one's bladder and bowel functions, is a crucial milestone in the life of every individual. As the majority of us takes this step at an early age, mostly between 2 and 4 years, we are expected from then on to act socially acceptable and answer the call of nature using provided facilities. But for the $10-15 \%$ of children with problems of gaining continence, this becomes an increasing problem, the older he or she becomes. Whilst wetting during sleep or some, spots' every now and then in children are not seen to be dramatic, frequent wetting or even soiling, which occurs in up to $1 \%$ of adults, can be socially stigmatizing. One can imagine that many children, adolescents and adults develop psychological problems, like depression or a low self-esteem due to feelings of guilt or shame.

The second aim of the thesis is to identify incontinence in persons with intellectual disability as a possibly solvable problem. Still, some might expect that individuals with intellectual disability will not be able to learn going to the toilet or to stay continent. Many professionals in the healthcare system do not diagnose and treat incontinence adequately, because it is seen as a part of the disability or it is seen as a minor problem compared to other medical conditions. However, this thesis' results show that incontinence is a major problem in the examined groups and that rates vary between different age groups and also between different genetic syndromes. The results also show that medical examination and also improvements in toileting skills are possible.

The results of this thesis are interesting to various groups, including scientific researchers, clinical practitioners and persons that are directly involved with individuals with genetic syndromes (e.g. parents, caregivers, nurses).

Researchers with interest in the topics incontinence, intellectual disability or genetic syndromes may develop further studies based on the results of this thesis. Many populations, e.g. the Noonan syndrome group or the Mowat-Wilson syndrome group were assessed for the first time regarding incontinence. Further investigations could include the associations with further somatic conditions or the assessment of intellectual skills.

Clinical practitioners, who work clinically with the affected persons, (e.g. general practitioners, pediatricians, psychologists, psychotherapists, nurses, urotherapists, physiotherapists) shall be encouraged by the results of the thesis to actively ask about incontinence problems and start first interventions. Also, assessment methods, e.g. the ultrasound, can be used reliably, as the results in chapter 3 in Fragile-X syndrome show.

The results may also address the social system of a child or adult with a genetic syndrome, as it raises awareness in parents, caregivers or the individual him/herself that improvements in getting continent are possible. After a thorough examination, intervention 
methods as used in typically developing persons, can be adapted. This can lead to an increasing mobility, independence and higher quality of life in the affected persons and their caregivers.

The results of this thesis will be published as a book, which will be available at the Maastricht University library. Further, a systematic review on incontinence in different genetic syndromes is planned. The results of this thesis will be a crucial part of it.

The studies of this thesis (chapters $2.1-3$ ) have been presented at many international conferences and have been published in peer-reviewed academic journals. These journals address clinical experts and the scientific community in the fields of urology, pediatrics, developmental disability and psychology and aim to encourage further research and also the implementation of effective assessment and treatment programs.

The results of this thesis have also been presented at many family meetings of the support groups of different genetic syndromes. These presentations addressed primarily parents and carepersons of children with a specific genetic syndrome. The main topics were education on incontinence, the subtypes, how assessment looks like and first intervention steps. The talks were always accompanied by a fruitful discussion with many questions and comments from the interested parents. Based on the results in boys with Fragile-X syndrome (chapter 3 ), counselling interviews were offered for families with a child with incontinence, which were requested by many families.

Results of the study on Down syndrome were also published in an article in the German Down syndrome magazine "Leben mit Down Syndrom" which is read by a lot of families and professionals. The article included information on incontinence in children and adolescents and raised awareness in the target groups.

Although gaining continence is such a crucial milestone in life, incontinence is often neglected in pediatric practice. And even less is known about incontinence in intellectual disability or genetic syndromes. These results are innovative, as in those genetic syndromes addressed in this thesis, incontinence and comorbid psychological problems are examined in a systematic way for the first time. For instance, in Noonan syndrome, these results (chapter 2.2) were the first estimation of incontinence prevalence in this syndrome. Also, the boys with Fragile-X syndrome (chapter 3) were clinically assessed for the first time including all relevant measurements (ultrasound, uroflowmetry, clinical examination). The results revealed first information on urological data in this population. Further, this study shows that an clinical assessment is feasible in patients with a genetic syndrome and intellectual disability and should therefore be implemented in clinical practice.

The author does not only plan similar studies on other genetic syndromes to gain a solid information base on incontinence subtypes and associated medical issues, psychological problems and adaptive skills, but also wants to develop further treatment approaches for incontinence in individuals with intellectual disability, genetic syndromes and other special needs. 

Acknowledgements 

I take this opportunity to express my gratitude to all persons, without whom this thesis could not have been accomplished.

Firstly, I would like to express my sincere gratitude to my promotor Prof. Leopold Curfs, for making this thesis possible, for his continuous support, patience, insightful comments and encouragement. His advice helped me in the time of research and writing of this thesis.

My sincere thanks and special appreciation go to my co-promotor Prof. Alexander von Gontard, who has been a tremendous mentor for me. I would like to thank him for encouraging my research, for sharing his expertise with me and for allowing me to grow as a research scientist.

I thank my former colleague PD Dr. Monika Equit. She assisted in study design and data analysis, supported me with her comments and suggestions, and has done so much more.

Special thanks go to my colleague and friend Catharina Wagner for her help and advice regarding the studies and for all the fun we have had in the last years.

I am grateful to my former colleagues and students Dr. Sorina Borggrefe-Moussavian, Dr. Teresa Holländer and Katharina Bauer for helping to recruit and examine the participants in our studies.

I would also like to express my thanks to Dr. Sylvia Roozen for being so patient and helpful through the whole PhD process, for helping with the summary translation into Dutch, and for always answering my questions in no time.

My thanks go to my current research team, Dr. Alisha Rosenthal and Hannah Mattheus, also to Diana El Khatib and the whole team of the "Pipi-Ambulanz" in Homburg. They were always prepared to help, either with good advice, coffee or chocolate.

Special thanks go to the chairpersons and teams of all support groups and foundations, who promoted our project among their member families and gave us the opportunity to cooperate: Rita Lawrenz (Arbeitskreis Down-Syndrom e.V.), the team of the magazine "Leben mit Down-Syndrom", Manuela Schnabel (Noonan-Kinder e.V. Deutschland), the support group „Angelman e.V. Deutschland“, the support group „Mowat-Wilson Deutschland“, Deby Curry, Al and Susan Triunfo (International Mowat-Wilson Foundation) and Dr. Jörg Richstein (Interessengemeinschaft Fragiles-X e. V.).

Many thanks to all families, who participated in the studies. Without them this work would have been impossible.

Special mention to Prof. Stewart Einfeld and Dr. Dawid Mowat, who introduced me to a very interesting genetic syndrome.

Last but not least, I thank the most important persons in my life, my parents and my husband Andreas. They always believe in me, support me and are there when times are rough. Thank you! 

Curriculum vitae 

Justine Niemczyk was born February 6, 1985, in Cieszyn, Poland and moved to Homburg, Germany in 1989. In 2004, she finished the Christian von Mannlich-Gymnasium in Homburg and graduated with the "Abitur" (A-levels). From 2004 on, she studied psychology at the Saarland University in Saarbrücken and graduated with the diploma in 2009.

She started working as psychologist at the general outpatient clinic at the Child and Adolescent Psychiatry, Saarland University Hospital in Homburg in 2009. In 2010, she focused her work on treatment of children and adolescents with incontinence and worked clinically at the special outpatient clinic for incontinence located at the Child and Adolescent Psychiatry in Homburg.

In 2009, she commenced an additional training to become a Child and Adolescent Psychotherapist at the "Institut für Fort- und Weiterbildung in klinischer Verhaltenstherapie e.V." (IFKV) in Bad Dürkheim. She received the licence to practise child and adolescent psychotherapy (Approbation) in 2016.

Being part of the clinical team in the incontinence clinic, she was soon introduced to the research projects related to incontinence in children and adolescents and supported the studies including operationalization, methodological suggestions, data analysis and writing publications.

From 2014 on, she works as a research psychologist at the Department of Child and Adolescent Psychiatry in Homburg with focus on incontinence, intellectual disability, psychological symptoms, attention-deficit/hyperactivity disorder (ADHD), autism spectrum disorders and genetic syndromes.

In 2015, she started her PhD at Governor Kremers Centre, Maastricht University. 

Publications 


\section{Peer-reviewed journals:}

Equit, M., Paulus, F., Fuhrmann, P., Niemczyk, J. \& von Gontard, A. (2011). Comparison of ICD-10 and DC: 0-3R diagnoses in infants, toddlers and preschoolers. Child Psychiatry and Human Development, 42, 623-633.

Equit, M., Piro-Hussong, A., Niemczyk, J., Curfs, L., von Gontard, A. (2012). Elimination disorders in persons with Prader-Willi and Fragile-X syndromes. Neurourology and Urodynamics , 32(7), 986-992.

Equit, M., Sambach, H., Niemczyk, J., von Gontard, A. (2013). Children's concepts of the urinary tract. Journal of Pediatric Urology, 9(5), 648-652.

Niemczyk, J., Equit, M., Braun-Bither, K., Klein, A., \& von Gontard, A. (2014). Prevalence of incontinence, attention deficit/hyperactivity disorder and oppositional defiant disorder in preschool children. European Child and Adolescent Psychiatry, 24(7), 837-843.

Niemczyk, J., Equit, M., El Khatib, D., \& von Gontard, A. (2014). Toilet refusal syndrome in preschool children: Do different subtypes exist? Journal of Pediatric Gastroenterology and Nutrition, 58(3), 303-306.

von Gontard, A., Pirrung, M., Niemczyk, J., \& Equit, M. (2014). Incontinence in children with autism spectrum disorder. Journal of Pediatric Urology, 11(5), 264-e1.

Niemczyk, J., Equit, M., Borggrefe-Moussavian, S., Curfs, L., \& von Gontard, A. (2015). Incontinence in persons with Noonan syndrome. Journal of Pediatric Urology, 11(4), 201.e1201.e5.

Niemczyk, J., Equit, M., Hoffmann, L., \& von Gontard, A. (2015). Incontinence in children with treated attention-deficit/hyperactivity disorder. Journal of Pediatric Urology, 11(3), 141.e1-141.e6.

von Gontard, A., Niemczyk, J., Weber, M. \& Equit, M. (2015). Specific behavioural comorbidity in a large sample of children with functional incontinence - report of 1001 cases. Neurourology and Urodynamics, 34(8), 763-768.

Wagner, C., Equit, M., Niemczyk, J., \& von Gontard, A. (2015). Obesity, overweight, and eating problems in children with incontinence. Journal of Pediatric Urology, 11(4), 202207.

Niemczyk, J., von Gontard, A., Equit, M., Bauer, K., Naumann, T., Wagner, C., \& Curfs, L. (2016). Detailed assessment of incontinence in boys with Fragile-X-syndrome in a home setting. European Journal of Pediatrics, 175(10), 1325-1334.

von Gontard, A., Niemczyk, J., Borggrefe-Moussavian, S., Wagner, C., Curfs, L., \& Equit, M. (2016). Incontinence in children, adolescents and adults with Williams syndrome. Neurourology and Urodynamics, 35(8), 1000-1005. 
von Gontard, A., Niemczyk, J., Thome-Granz, S., Nowack, J., Moritz, A. M., \& Equit, M. (2016). Incontinence and oppositional defiant disorder in young children - a populationbased study. Journal of Pediatric Nephrology, Pediatric Nephrology, 30(7), 1147-1155.

von Gontard, A., Niemczyk, J., Wagner, C., \& Equit, M. (2016). Voiding postponement in children-a systematic review. European Child and Adolescent Psychiatry, 25(8), 809-820.

Niemczyk, J., Einfeld, S., Mowat, D., Equit, M., Wagner, C., Curfs, L. \& von Gontard, A. (2017). Incontinence and psychological symptoms in individuals with Mowat-Wilson Syndrome. Research in Developmental Disabilities, 62, 230-237.

Niemczyk, J., Equit, M., Rieck, K., Rubly, M., Wagner, C., \& von Gontard, A. (2017). EEG Measurement of Emotion Processing in Children with Daytime Urinary Incontinence. Zeitschrift für Kinder-und Jugendpsychiatrie und Psychotherapie, in press.

Niemczyk, J., von Gontard, A., Equit, M., Medoff, D., Wagner, C., Curfs, L. (2017). Incontinence in persons with Down Syndrome. Neurourology \& Urodynamics, 36(6), 1550-1556.

Niemczyk, J., Wagner, C., \& von Gontard, A. (2017). Incontinence in Autism spectrum disorder: a systematic review. European Child \& Adolescent Psychiatry, (Epub ahead of print).

Roozen, S., Olivier, L., Niemczyk, J., von Gontard, A., Peters, G. J. Y., Kok, G., Viljoen, D. \& Curfs, L. (2017). Nocturnal incontinence in children with fetal alcohol spectrum disorders (FASD) in a South African cohort. Journal of Pediatric Urology, 13(5), 496.e1-496.e7.

Schäfer, S. K., Niemczyk, J., von Gontard, A., Pospeschill, M., Becker, N., \& Equit, M. (2017). Standard urotherapy as first-line intervention for daytime incontinence: a metaanalysis. European Child \& Adolescent Psychiatry, (Epub ahead of print).

Wagner, C., Niemczyk, J., Equit, M., Curfs, L. \& von Gontard, A. (2017). Incontinence in persons with Angelman syndrome. European Journal of Pediatrics. 176(2), 225-232.

Wagner, C., Niemczyk, J., \& von Gontard, A. (2017). Toilet Phobia and Toilet Refusal In Children. Klinische Pädiatrie, 229(01), 27-31.

Niemczyk, J., Schäfer, S., Becker, N., Equit, M., \& von Gontard, A. (2018). Psychometric properties of the "parental questionnaire: Enuresis/urinary incontinence"(PQ-EnU). Neurourology and urodynamics, 1-11. doi:10.1002/nau.23564

\section{Book contributions:}

Equit, M. Sambach, H., Niemczyk, J., \& von Gontard, A. (2013). Ausscheidungsstörungen bei Kindern und Jugendlichen. Ein Therapieprogramm zur Blasen- und Darmschulung. Göttingen: Hogrefe. 
Equit, M. Sambach, H., Niemczyk, J., \& von Gontard, A. (2014). Urinary and Fecal Incontinence. A Training program for Children and Adolescents. Göttingen, New York: Hogrefe Publishing.

\section{Conference proceedings:}

Schwab, F., Grunow, J., Niemczyk, J. \& Unz, D. (2011). Zeitverschwendung? Oder machen uns die Medien mit der Zeit immer schlauer? In Suckfüll, M. Schramm, H. \& Wünsch, C. (Hrsg.), Rezeption und Wirkung in zeitlicher Perspektive. Tagungsband, (Reihe Rezeptionsforschung, Band 22). Nomos, Baden-Baden.

Note:

Publications printed in bold are part of this thesis. 
